\title{
DANIELE CANALE
}

\section{Mecanismos de lesão renal em ratos com deficiência de vitamina D submetidos ao tratamento com Tenofovir}

Tese apresentada à Faculdade de Medicina da Universidade de São Paulo para obtenção do título de Doutor em Ciências

Programa de Nefrologia

Orientador: Prof. Dr. Antonio Carlos Seguro

\section{SÃO PAULO}

2014 


\section{Dados Internacionais de Catalogação na Publicação (CIP)}

Preparada pela Biblioteca da

Faculdade de Medicina da Universidade de São Paulo

Creprodução autorizada pelo autor

\section{Canale, Daniele}

Mecanismos de lesão renal em ratos com deficiência de vitamina $\mathrm{D}$ submetidos ao tratamento com Tenofovir / Daniele Canale. -- São Paulo, 2014.

Tese(doutorado)--Faculdade de Medicina da Universidade de São Paulo.

Programa de Nefrologia.

Orientador: Antonio Carlos Seguro.

Descritores: 1.Nefropatias/induzido quimicamente 2.Tenofovir 3.Reações adversas e efeitos colaterais relacionados a drogas 4.Inibidores de transcriptase reversa/efeitos adversos 5.Taxa de filtração glomerular/efeitos de drogas 6.Deficiência de vitamina D 7.HIV 8.Hepatite B 9.Ratos Wistar

USP/FM/DBD-029/14 
Trabalho realizado no Laboratório de Pesquisa Básica em Doenças Renais (LIM12), Departamento de Nefrologia, da Faculdade de Medicina da Universidade de São Paulo, com apoio financeiro do CNPq (Conselho Nacional de Desenvolvimento Científico e Tecnológico), através do auxílio à pesquisa (Proc. $\mathrm{n}^{\circ}$ 309947/2009-0) e da FAPESP (Fundação de Amparo à Pesquisa do Estado de São Paulo), através dos auxílios à pesquisa (Proc. $n^{\circ}$ 2010/52294-0, 2011/50409-7 e 2012/50227-9) e concessão da bolsa. 


\section{Dedicatória}

Se eu tivesse que escolher para vir ainda ao mundo, pediria a Deus, como desejo profundo, para que vocês fossem meus pais mais uma vez. Dedico essa tese a vocês, Marcia e Luiz, pessoas mais importantes da minha vida. 


\section{AGRADECIMENTOS}

A vida é feita de etapas. É como um ciclo, onde tudo acontece... emoções, sentimentos, sensações e desejos. Cada fase por qual passamos nos traz novas descobertas, novas alegrias e novos desafios. Iniciar o doutorado foi uma decisão difícil e um pouco inesperada. Nós nunca sabemos de fato qual é o momento certo de nos aventurarmos novamente. Para mim, o anseio de aprender coisas novas somado com a minha paixão por fazer ciência e a motivação e apoio absolutamente incontestável dos meus pais e namorado foram decisivos na minha escolha. A partir daí, a minha única certeza era que queria voltar para o mesmo lugar onde já tinha concluído com muito sucesso a minha iniciação científica e o meu mestrado. Nesse momento, lembrei de um convite feito pelo Prof. Dr. Antonio Carlos Seguro e de algumas pessoas maravilhosas e super receptivas do LIM12 que me acolheram e me proporcionaram momentos incríveis nos congressos quando eu ainda estava no mestrado.

Eu não conhecia direito o Prof. Seguro, só sabia o que as pessoas falavam nos corredores... que ele era um professor querido, um médico excelente e uma pessoa simplesmente adorável. Ele me abriu as portas do LIM12 e me ofereceu muito mais do que eu esperava. Além de me aceitar como orientanda de doutorado e me presentear com um projeto de pesquisa, os seus ensinamentos foram (e ainda são) essenciais para a minha formação como profissional e como ser humano. Hoje, eu concordo com tudo que ouvi nos corredores e, em alguns momentos, eu tenho a sensação de estar conversando com o meu pai... acho que o jeito, os pensamentos e o comportamento são um pouco semelhantes. Não tenho palavras para agradecer, foi uma grande satisfação ter sido sua aluna!

Uma das pessoas maravilhosas que eu conheci ainda no mestrado foi o Dr. Rildo Volpini, o meu co-orientador. Além de me auxiliar com todas as etapas do desenvolvimento desse projeto, ele também me dá suporte e atenção sempre que tenho problemas, sejam eles "laboratoriais" ou pessoais... Eu acho que não teria 
coragem de falar com o Prof. Seguro sobre a possibilidade de iniciar o doutorado se não tivesse conversado com o Rildo antes. Ele não só me recebeu com os braços abertos, como dividiu tudo o que era dele comigo para que o meu trabalho fosse realizado do início ao fim. Tive muita sorte de ter tido uma pessoa tão competente e participativa como co-orientador e me considero privilegiada de tê-lo como amigo!

A essa altura eu já tinha um orientador, um co-orientador e um projeto, mas faltavam pessoas que me ajudassem e colocassem a mão na massa para a realização desse trabalho. Três pessoas foram essenciais nessa etapa. A Dra. Maria Heloisa Massola Shimizu, sempre estilosa e com seu bom-humor, fez com que os dias árduos e intermináveis de experimentos parecessem agradáveis. Acho que só ela consegue fazer isso! Além de todo o comprometimento com o nosso trabalho, ela é como uma mãe, me ensina tudo. Eu não sobreviveria ao meu primeiro ano de emprego público se não fosse as preciosas dicas que ela me deu e ainda me dá. Outra pessoa que trabalhou tanto quanto eu para a conclusão desse trabalho foi a Ms. Ana Carolina de Bragança Viciana. Eu considero a Carolzinha a minha alma-gêmea, acho que somos parecidas em muitos aspectos, começando pelo nível de organização e terminando pelo tamanho do frio e da fome. Nós passamos juntas por momentos intensos que me trouxeram muita felicidade, mas que também me fizeram chorar... o que confirmou ainda mais a sua verdadeira amizade. A Carol é a pessoa mais ética e correta que eu conheço. Por último, eu também preciso agradecer a amiga e companheira de pósgraduação Janaína Garcia Gonçalves que me ajudou nos experimentos e me acalmou nas horas mais difíceis e estressantes. Com seu jeito tranquilo e sereno, ela sempre enxerga o lado positivo das coisas. Conversar com a Jana definitivamente aumenta a sua autoestima!

Além de todo o envolvimento com o projeto, eu tive a oportunidade de conhecer a Dra. Talita Rojas Sanches. É impressionante como a vida é inesperada... Quem ia imaginar que seríamos amigas? Nós fizemos a mesma faculdade, nos encontrávamos no corredor diversas vezes, tínhamos até alguns amigos em comum e não nos conhecíamos! A única coisa que eu tenho a dizer agora é que a Tali tem um 
coração de ouro: está sempre disposta a ajudar, é super alegre e agradável. No quesito formatação, essa tese tem muito a agradecer a ela! Agradeço também a amiga Leticia Urbano, vulgo serva da Talita. Brincadeirinhas a parte, a Leti é uma pessoa muito amável e sempre me ajuda com a minha apresentação fashion em todos os eventos. Não saio de casa sem antes ligar para ela e fazer uma consultoria.

Em todo esse tempo acho que, profissionalmente, cresci muito e se alguém perguntasse hoje quem eu gostaria de ser quando crescer provavelmente eu responderia Prof. Dra. Lúcia Andrade. Eu a considero extremamente inteligente e prestativa. Como pessoa, pesquisadora e médica, ela sempre pensa em ajudar os outros. Isso sem falar na elegância... simplesmente indiscutível! Além disso, agradeço a Dra. Lúcia, a Prof. Dra. Rosa Affonso Moysés e ao Dr. Jessé Reis Alves por dividirem comigo muitos dos conhecimentos deles e por fazerem parte da minha banca de qualificação. Suas ideias e sugestões preciosas foram essenciais para que essa tese fosse concluída.

Nada disso aconteceria se não fossem os nossos queridos ratinhos, que sacrificam suas vidas pelo bem da ciência. Acho que todos nós somos muito gratos a eles por nos proporcionarem sempre mais e mais anos de vida. Nesse sentido, eu tenho que agradecer a nossa bioterista e futura bióloga Denise Ariane de Jesus que é responsável pela parte básica de todos os projetos, mas que é essencial para o bom andamento e conclusão de qualquer trabalho científico.

Algumas pessoas não tiveram a oportunidade de acompanhar esse trabalho, mas me proporcionaram momentos de descontração e alegria. Muito obrigada Monique Silva Martines por me escutar sempre e me dar apoio, Pedro Gois por me salvar nos momentos difíceis e de desespero, Weverton Luchi e Daniela Ferreira pela companhia e pelo bom-humor que me renderam muitas risadas. Obrigada pelo carinho e pela amizade! 
Por fim, não posso deixar de agradecer os nossos secretários, Eloá Neves e Nivaldo Francisco da Silva, os outros professores do LIM 12, Dra. Cláudia Helou e Dr. Antonio José de Barros Magaldi, os responsáveis pela pós-graduação da Nefrologia, Dr. Rui Toledo e Dr. Emmanuel de Almeida Burdmann, a FAPESP pelo apoio financeiro, aos amigos do LIM16 que estão sempre dispostos a me ajudar e aos outros alunos que também fazem parte dessa grande família - Lectícia Jorge, Fernanda Coelho, Camila Eleutério, Roberto Moreira e José Manuel Cóndor.

Durante os 3 anos de pós-graduação obtive muitas conquistas, realizei sonhos, conheci pessoas maravilhosas, fiz amigos muito especiais, ganhei conhecimento e descobri que tenho ainda muito mais para aprender. Fiz muitas escolhas, algumas certas e outras nem tanto, mas não me arrependo de nenhuma delas, porque tudo isso permitiu que eu ganhasse um pouquinho mais de experiência e contribuiu na construção da pessoa que sou hoje. Tudo isso foi possível porque fui abençoada com uma família linda... Meus pais, Marcia e Luiz, me deram a melhor educação do mundo e sempre me apoiam em todas as minhas decisões. Minha irmã, Isabele, que embora me encha a paciência de vez em quando sempre está ao meu lado. Meu namorado, Neto, meu companheiro para todas as horas, que me escuta e me apoia sempre. Minha madrinha, Maria, que é praticamente minha segunda mãe, participa de tudo o que acontece na minha vida. Amo muito todos vocês! Obrigada por fazerem parte da minha vida!

Estou muito feliz, pessoalmente e profissionalmente, por chegar até aqui e estou ainda mais feliz por dividir esse momento com todos vocês. Muito obrigada a todos pelo carinho! 
"Por vezes sentimos que aquilo que fazemos não é senão uma gota de água no mar. Mas o mar seria menor se lhe faltasse uma gota".

Madre Teresa de Calcutá 


\section{SUMÁRIO}

Lista de Abreviaturas e Siglas

Lista de Figuras

Lista de Tabelas

Resumo

Summary

1. INTRODUÇÃO

1

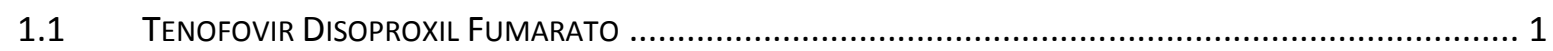

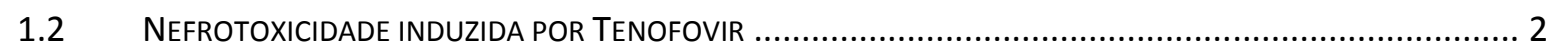

1.3 HIPOVITAMINOSE D E A PROGRESSÃo DA LESÃo RENAL................................................................. 3

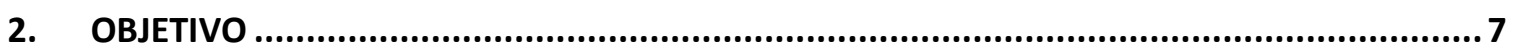

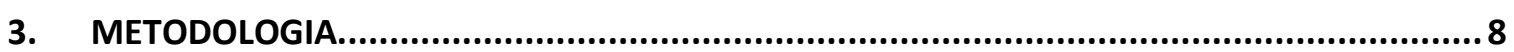

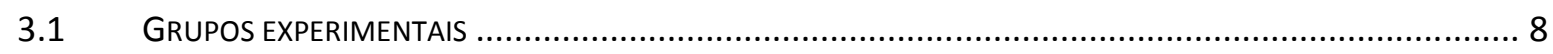

3.2 REPRESENTAÇÃo ESQUEMÁtICA do Protocolo EXPERIMENTAL ...................................................... 9

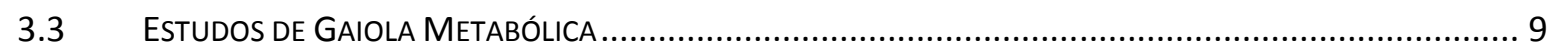

3.4 DETERMINAÇÃO DA TAXA DE FILTRAÇÃO GLOMERULAR: CLEARANCE DE INULINA .................................. 9

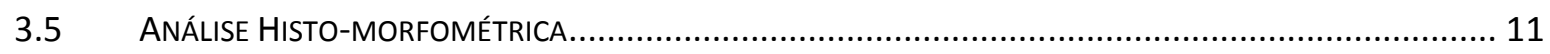

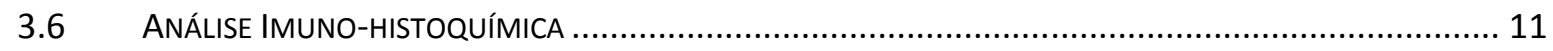

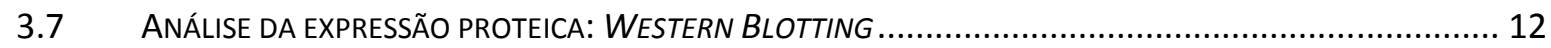

3.8 ANÁLISE DA EXPRESSÃO GÊNICA: REAÇÃO EM CADEIA DA POLIMERASE QUANTITATIVO.......................... 13

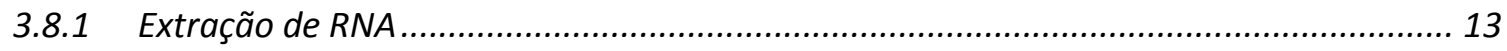

3.8.2 Reação em cadeia da polimerase quantitativo - qPCR................................................ 13

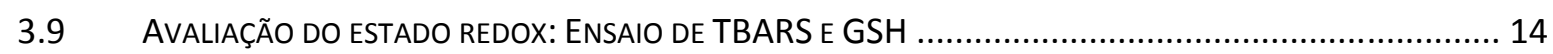

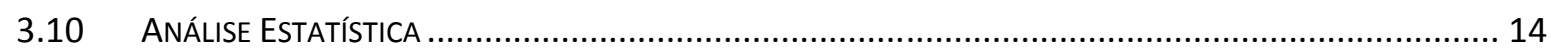




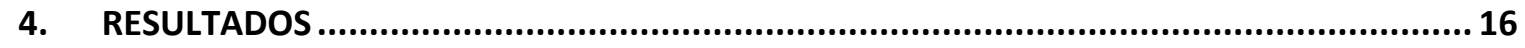

5. DISCUSSÃO

5.1 O AGRAVAMENTO DA INJÚRIA RENAL INDUZIDA PELO TDF ESTÁ ASSOCIADO COM A DEFICIÊNCIA DE

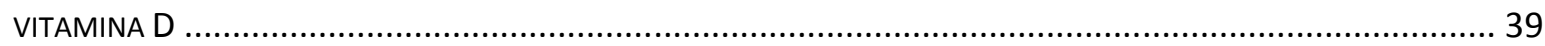

5.2 HIPERTENSÃO, PARTICIPAÇÃO DO SISTEMA RENINA-ANGIOTENSINA-ALDOSTERONA E ENVOLVIMENTO DA CASCATA DO ÓXIDO NÍTRICO NA NEFROTOXICIDADE INDUZIDA PELO TDF ASSOCIADA À DEFICIÊNCIA EM VITAMINA D

5.3 O PAPEL DO PARATORMÔNIO E DA DEFICIÊNCIA DE VITAMINA D NO METABOLISMO DE CÁLCIO E FÓSFORO ASSOCIADO À ADMINISTRAÇÃO DE TDF

5.3.1 Fosfatúria e expressão do cotransportador sódio/fosfato.

5.3.2 Paratormônio na deficiência de vitamina D e tratamento com TDF.

5.4 SínDROME METABÓlICA ASSOCIADA AO TRATAMENTO COM TDF E A DEFICIÊNCIA EM VITAMINA D. 44

5.5 AUMENTO DO ESTRESSE OXIDATIVO ESTÁ ASSOCIADO À INJÚRIA RENAL E Às ALTERAÇÕES RENOVASCULARES.

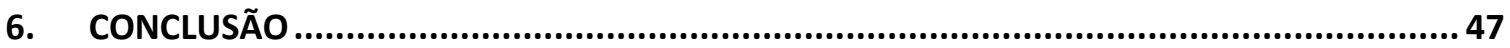

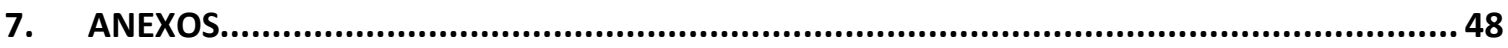

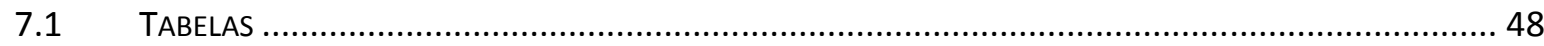

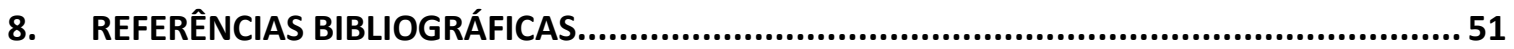




\section{LISTA DE ABREVIATURAS E SIGLAS}

\begin{tabular}{|c|c|}
\hline $25(\mathrm{OH}) \mathrm{D}$ & Calcidiol \\
\hline $1,25(\mathrm{OH})_{2} \mathrm{D}$ & Calcitriol \\
\hline AIDS & Síndrome da Imunodeficiência Adquirida \\
\hline AGT & Angiotensinogênio \\
\hline AT1a & Receptor AT1 da angiotensina II tipo a \\
\hline AT1r & Receptor AT1 da angiotensina II \\
\hline cDNA & DNA complementar \\
\hline$C_{\ln }$ & Clearance de Inulina \\
\hline $\mathrm{Ct}$ & Ciclo limiar \\
\hline DBP & Vitamin D binding protein \\
\hline DNA & Ácido Desoxirribonucleico \\
\hline ECA & Enzima conversora de angiotensina \\
\hline $\mathrm{ENaC}$ & Canal epitelial de sódio \\
\hline eNOS & Oxido nítrico sintase endotelial \\
\hline EPM & Erro Padrão Médio \\
\hline FDA & Food and Drug Administration \\
\hline FGF-23 & Fator de crescimento de fibroblastos 23 \\
\hline FSR & Fluxo sanguíneo renal \\
\hline GSH & Glutationa \\
\hline GSSG & Glutationa oxidada \\
\hline $\mathrm{HE}$ & Hematoxilina-Eosina \\
\hline HIV & Vírus da Imunodeficiência Humana \\
\hline h-OAT1 & Transportador aniônico orgânico humano tipo 1 \\
\hline h-OAT-3 & Transportador aniônico orgânico humano tipo 3 \\
\hline IRA & Injúria Renal Aguda \\
\hline LDL & Lipoproteína de baixa densidade \\
\hline MRP-1 & Multidrug Resistence-Associated Protein tipo 1 \\
\hline
\end{tabular}


MRP-4

$\mathrm{NAD}(\mathrm{P}) \mathrm{H}$

NaPi-Ila

NHE3

NO

PAM

PC

$\mathrm{P}_{\text {Ca }}$

$\mathrm{P}_{\mathrm{K}}$

$\mathrm{P}_{\mathrm{Na}}$

$\mathrm{P}_{\mathrm{P}}$

PTH

qPCR

RAAS

REN

RNA

ROS

RVR

RXR

SOD-1

SOD-2

TBARS

TBARS $_{p}$

TBARS $_{\mathrm{t}}$

TBARS $_{\mathrm{u}}$

TCA

TDF

TP

$\mathrm{U}_{\mathrm{Ca}} \mathrm{V}$

$\mathrm{U}_{\mathrm{K}} \mathrm{V}$

$\mathrm{U}_{\mathrm{K}} / \mathrm{U}_{\mathrm{Na}}$
Multidrug Resistence-Associated Protein tipo 4

Nicotinamide adenine dinucleotide phosphate-oxidase

Cotransportador sódio/fosfato subtipo II-a

Trocador sódio/hidrogênio tipo 3

Óxido Nítrico

Pressão arterial média

Peso Corpóreo

Concentração plasmática de cálcio

Concentração plasmática de potássio

Concentração plasmática de sódio

Concentração plasmática de fósforo

Paratormônio

Reação em cadeia da polimerase quantitativo

Sistema Renina-Angiotensina-Aldosterona

Renina

Ácido ribonucleico

Espécies reativas de oxigênio

Resistência vascular renal

Receptor retinóide $\mathrm{X}$

Superóxido dismutase tipo 1

Superóxido dismutase tipo 2

Substâncias Reativas ao Ácido Tiobarbitúrico

Substâncias Reativas ao Ácido Tiobarbitúrico no plasma

Substâncias Reativas ao Ácido Tiobarbitúrico no tecido renal

Substâncias Reativas ao Ácido Tiobarbitúrico na urina

Ácido Tricloroacético

Tenofovir Disoproxil Fumarato

Túbulo Proximal

Excreção urinária de cálcio

Excreção urinária de potássio

Relação da excreção urinária de potássio e sódio 
$\mathrm{UPV}_{\mathrm{p}}$

$U_{\text {Prot }} \mathrm{V}$

VDR

VDRE

Vitamina $D_{2}$

Vitamina $D_{3}$
Excreção urinária de fósforo

Excreção urinária de proteínas

Receptor de vitamina D

Vitamin D Responsive Elements

Ergocalciferol

Colecalciferol 


\section{LISTA DE FIGURAS}

Figura 1. Avaliação do tempo de estudo sobre a concentração plasmática de 25(OH)D.

Figura 2. Taxa de filtração glomerular

Figura 3. Avaliação do tempo de estudo sobre a taxa de filtração glomerular

Figura 4. Excreção urinária de proteína............................................................. 19

Figura 5. Score de lesão tubular renal .......................................................... 20

Figura 6. Fotomicrografia do córtex renal ................................................... 21

Figura 7. Pressão arterial média ................................................................... 22

Figura 8. Avaliação semiquantitativa da expressão proteica de angiotensinogênio/angiotensina I e II no tecido renal ....................... 23

Figura 9. Imunolocalização de angiotensina II no córtex renal ........................ 24

Figura 10. Avaliação semiquantitativa da expressão proteica de AT1r no tecido renal

Figura 11. Concentração plasmática de aldosterona ........................................ 26

Figura 12. Relação da excreção urinária de potássio e sódio ............................ 27

Figura 13. Expressão gênica dos componentes do SRAA .................................. 28

Figura 14. Resistência vascular renal ........................................................... 29

Figura 15. Avaliação semiquantitativa da expressão proteica de e-NOS no tecido renal ............................................................................ 30

Figura 16. Concentrações plasmáticas de fósforo e cálcio iônico ....................... 31

Figura 17. Excreção urinária de fósforo ......................................................... 32

Figura 18. Avaliação semiquantitativa da expressão proteica de NaPi-Ila no tecido renal ............................................................................. 33

Figura 19. Níveis plasmáticos de PTH .......................................................... 34

Figura 20. Níveis plasmáticos de colesterol total e triglicérides ....................... 35

Figura 21. Concentração plasmática e excreção urinária de TBARS ................. 36

Figura 22. Concentração de TBARS no tecido renal .......................................... 37 
Figura 23. Níveis de glutationa . 


\section{LISTA DE TABELAS}

Tabela 1. Peso corporal, parâmetros funcionais e hemodinâmicos.................. 48

Tabela 2. Parâmetros bioquímicos .................................................................... 49

Tabela 3. Avaliação do estado redox ............................................................. 50

Tabela 4. Avaliação da expressão proteica no tecido renal ............................ 50

Tabela 5. Avaliação da expressão gênica .......................................................... 50 


\section{RESUMO}

CANALE, D. Mecanismos de lesão renal em ratos com deficiência em vitamina D submetidos ao tratamento com Tenofovir. [tese]. São Paulo: Faculdade de Medicina da Universidade de São Paulo; 2014.

A Síndrome da Imunodeficiência Adquirida (AIDS) é um problema de saúde pública. O Tenofovir Disoproxil Fumarato (TDF) foi o primeiro inibidor do nucleotídeo da transcriptase reversa e é a droga mais recomendada para o tratamento da AIDS. Entretanto, o uso prolongado de TDF está associado com a nefrotoxicidade. A deficiência de vitamina $D$ tem alta prevalência em indivíduos infectados com o Vírus da Imunodeficiência Humana (HIV). A vitamina D participa da regulação de atividades fisiológicas de diversos órgãos, incluindo o rim, oferecendo proteção contra as lesões ocasionadas por diferentes causas. Portanto, pacientes com níveis baixos de vitamina D infectados com o HIV podem apresentar complicações renais e cardiovasculares durante a terapia antirretroviral. Sendo assim, a carência desta vitamina pode acelerar a progressão da doença renal. Tendo em vista o aumento da incidência de hipovitaminose D na população mundial, esse trabalho tem o objetivo de verificar os mecanismos que levam ao desenvolvimento da lesão renal em ratos depletados de vitamina D submetidos ao tratamento com TDF. Ratos Wistar foram divididos em quatro grupos: controle, animais que receberam dieta padrão por 60 dias; dVD, animais que receberam dieta depletada em vitamina D por 60 dias; TDF, animais que receberam dieta padrão por 60 dias com a adição de TDF (50 mg/kg de dieta) nos últimos 30 dias; e dVD+TDF, animais que receberam dieta depletada em vitamina $D$ por 60 dias com a adição de TDF nos últimos 30 dias. Ao final dos 60 dias, os animais foram submetidos à eutanásia, amostras de sangue, urina e o tecido renal foram coletados para a análise dos mecanismos de lesão renal. O tratamento com TDF levou a insuficiência renal observada pela queda da filtração glomerular e lesão tubular proximal com aparecimento de fosfatúria ocasionada pela diminuição do cotransportador sódio/fosfato subtipo Ila. Essas alterações foram acompanhadas de 
hipertensão e modificações no perfil lipídico. A deficiência em vitamina D associada à administração de TDF agravou os efeitos renovasculares e a nefrotoxicidade induzida pelo TDF, pelo menos em parte, devido ao aumento nos marcadores de estresse oxidativo e a participação do sistema renina-angiotensina-aldosterona. Portanto, é essencial monitorar os níveis de vitamina D em pacientes infectados com o HIV tratados com TDF.

Descritores: nefropatias/induzido quimicamente, Tenofovir, reações adversas e efeitos colaterais relacionados a drogas, inibidores de transcriptase reversa/efeitos adversos, taxa de filtração glomerular/efeitos de drogas, deficiência de vitamina D, HIV, hepatite B, ratos Wistar. 


\section{SUMMARY}

CANALE, D. Mechanisms of renal injury in vitamin D deficient rats treated with Tenofovir. [thesis]. São Paulo: "Faculdade de Medicina, Universidade de São Paulo"; 2014.

Acquired Immunodeficiency Syndrome (AIDS) has become one of the world's most serious health problem. Tenofovir Disoproxil Fumarate (TDF) was the first available nucleotidic reverse transcription inhibitor and is a widely prescribed antiretroviral medication for treatment of Human Immunodeficiency Virus (HIV). However, the long-term use of TDF has been associated with a number of toxicities, including those affecting the kidney. Vitamin D deficiency is prevalent among HIVinfected individuals. Vitamin D not only regulates numerous physiological activities of multiple organ systems, but also protects the kidney from injury from different causes. Thus, HIV-infected subjects with low levels of vitamin D could experience increased complications during antiretroviral therapy, such as cardiovascular disease and renal impairment. In view of the high worldwide incidence of hypovitaminosis $D$, the aim of this study was to investigate the effects of vitamin D deficiency on TDF-induced nephrotoxicity. Wistar rats were divided into four groups: control, receiving a standard diet for 60 days; dVD, receiving a vitamin D-free diet for 60 days; TDF, receiving a standard diet for 60 days with the addition of TDF (50 mg/kg food) for the last 30 days; and dVD+TDF receiving a vitamin D-free diet for 60 days with the addition of TDF for the last 30 days. At the end of the protocol, animals were euthanized and blood, urine and tissue samples were collected in order to evaluate the mechanisms responsible for renal injury. TDF led to impaired renal function, hyperphosphaturia, hypophosphatemia, hypertension and increased renal vascular resistance due to downregulation of the sodium-phosphorus cotransporter and upregulation of reninangiotensin-aldosterone system (RAAS). TDF also increased oxidative stress, as evidenced by higher TBARS and lower GSH levels, and induced dyslipidemia. Association of TDF and vitamin D deficiency aggravated renovascular effects and TDF- 
induced nephrotoxicity at least in part by the increase of oxidative stress and the involvement of RAAS. Hence, it is important to monitor vitamin D levels in HIV-infected patients treated with TDF.

Descriptors: kidney diseases/chemically induced, Tenofovir, drug-related side effects and adverse reactions, reverse transcriptase inhibitors/adverse effects, glomerular filtration rate/drug effects, vitamin D deficiency, HIV, hepatitis B, Wistar rats. 


\section{INTRODUÇÃO}

A Síndrome da Imunodeficiência Adquirida, popularmente conhecida como AIDS, é um problema de saúde pública que afeta aproximadamente 33,3 milhões de pessoas ao redor do mundo, sendo os países subdesenvolvidos responsáveis por mais de $97 \%$ dessa estimativa [1].

O aumento da expectativa de vida das pessoas infectadas com o vírus da imunodeficiência humana (HIV) acarretou no aparecimento de inúmeras comorbidades, como doenças cardiovasculares [2], osteoporose [3], distúrbios metabólicos [4], doenças hepáticas e renais [5]. A injúria renal aguda (IRA) é uma complicação que acomete cerca de 10 a $30 \%$ dos pacientes com AIDS. Uma das causas mais comuns para o desenvolvimento de IRA está relacionada com a terapia antirretroviral $[4,6]$.

Atualmente, uma das drogas frequentemente recomendada para o tratamento da AIDS é o Tenofovir disoproxil fumarato (TDF). O TDF foi o primeiro inibidor do nucleotídeo da transcriptase reversa aprovado pela Food and Drug Administration (FDA) e pela European Medicine Agency para o tratamento do HIV em adultos e tem sido utilizado como medicamento antirretroviral desde 2001 [7]. Além do tratamento da AIDS [8,9], o TDF também foi aprovado para o tratamento da hepatite B em adultos em 2008 e é largamente empregado desde então com base na sua eficácia comprovada por estudos clínicos [10-12].

\subsection{Tenofovir Disoproxil Fumarato}

O TDF é uma pró-droga rapidamente convertida em tenofovir após sua absorção através da hidrólise enzimática de dois grupos ésteres. A adição de dois radicais ésteres alcalinos proporciona o aumento da sua lipossolubilidade e absorção intestinal, permitindo sua administração oral [13]. 
O tenofovir é um análogo nucleotídeo da adenosina monofosfato, que após sofrer duas reações de fosforilação intracelular, se transforma em seu metabólito ativo, o tenofovir difosfato. Em sua forma ativa, o tenofovir compete com o substrato natural deoxiadenosina 5'-trifosfato pela incorporação no DNA durante a transcrição reversa induzida pelo HIV. Essa incorporação do tenofovir no DNA viral resulta em uma cadeia terminal, uma vez que o tenofovir difosfato não possui o grupamento hidroxila na posição $3^{\prime}$, que atua como ponto de ligação para o próximo deoxirribonucleosídeo trifosfato, responsável pelo alongamento do DNA viral. Dessa forma, a transcriptase reversa, evento chave para a proliferação do HIV, é inibida [14,15].

O TDF não é degradado pelo organismo, é filtrado livremente pelo glomérulo e eliminado via secreção tubular. Contudo, altas concentrações intracelulares de TDF em células tubulares podem interferir na função celular e acarretar efeitos colaterais danosos, especialmente com o seu uso prolongado [16].

\subsection{Nefrotoxicidade induzida por Tenofovir}

Estudos pré-clínicos demonstraram que animais submetidos ao tratamento com tenofovir apresentam glicosúria, proteinúria, fosfatúria, calciúria, aumento na creatinina sérica e hipofosfatemia. Além disso, a exposição ao tenofovir acarretou em uma diminuição da taxa de filtração glomerular $[17,18]$ e toxicidade tubular $[13,16]$. A toxicidade tubular induzida pelo TDF é caracterizada por acidose tubular [19], síndrome de Fanconi e diabetes insipidus nefrogênico [20].

O túbulo proximal (TP) é o principal responsável pela excreção do TDF e a sua disfunção leva a perda de substâncias pela urina que normalmente são filtradas no glomérulo e reabsorvidas por essa porção tubular [18]. O mecanismo pelo qual o tenofovir leva a lesão renal ainda é pouco conhecido, porém sabe-se que a secreção tubular do tenofovir acontece via transporte de ânions orgânicos no TP por meio de transportadores específicos localizados nas membranas basal e apical das células tubulares [13]. 
De forma geral, os análogos nucleotídeos são captados da corrente sanguínea pelas células tubulares proximais através do transportador aniônico orgânico humano tipos 1 e 3 (hOAT-1 e hOAT-3) localizados na porção basolateral da célula e são secretados para a luz tubular através das Multidrug Resistence-Associated Proteins tipos 1 e 4 (MRP-1 e MRP-4) localizadas na porção apical da célula. Alguns mecanismos explicam a indução da lesão renal por drogas antivirais: a superexpressão ou inibição competitiva dos transportadores tubulares renais, como os da família hOAT ou MRP, ou o comprometimento da mitocôndria, alterando a oxidação de ácidos graxos e a produção de energia. A diminuição da replicação do DNA mitocondrial resulta em estresse oxidativo, promovendo o metabolismo anaeróbico, a acidose lática e o acúmulo de triglicérides, que afeta diretamente a função celular [21-23].

Apesar dos dados em literatura sugerirem que a nefrotoxicidade induzida por tenofovir ocorre em baixa frequência, sua etiologia é confirmada por estudos experimentais [22] e clínicos [24].

\subsection{Hipovitaminose D e a Progressão da Lesão Renal}

Além dos comprometimentos renais ocasionados pelo uso do tenofovir, recentemente foi demonstrado que níveis baixos de vitamina $D$ estão associados com a progressão da lesão renal em pacientes infectados pelo HIV $[25,26]$.

A vitamina $D$ é um nutriente essencial para a homeostase mineral e para o metabolismo ósseo e pode ser obtida na dieta, principalmente em peixes gordurosos, ou, em maiores proporções, sintetizada através da pele. Esse nutriente possui duas formas distintas: o ergocalciferol (vitamina $D_{2}$ ) e o colecalciferol (vitamina $D_{3}$ ). Com a exposição a luz solar, a 7-dehidrocolesterol da pele sofre uma clivagem fotolítica e origina a pró-vitamina $D$, que é convertida, posteriormente, em vitamina $D$ pelo processo de isomerização termal espontânea. Em seguida, a vitamina D é ligada a molécula carreadora Vitamin D Biding Protein (DBP). Para se tornar bioativa, a vitamina D sofre dois processos de hidroxilação: (1) A primeira hidroxilação é catalizada pela enzima 25-hidroxilase e acontece no fígado, resultando na formação da 25-hidroxivitamina $\mathrm{D}$ ou calcidiol - 25(OH)D - , que é a forma 
circulante e sua concentração é utilizada como indicador dos níveis de vitamina $D$ no organismo; (2) A segunda hidroxilação é mediada pela 1 $\alpha$-hidroxilase e ocorre nas células tubulares proximais do rim, levando a produção do metabólito biologicamente ativo 1,25 hidroxivitamina $\mathrm{D}$ ou calcitriol - $1,25(\mathrm{OH})_{2} \mathrm{D}$ - , que está envolvida na manutenção dos níveis séricos de cálcio e fosfato [27-32].

A atividade da $1 \alpha$-hidroxilase é regulada por inúmeros fatores, entre eles os níveis séricos de cálcio, fosfato, de paratormônio $(\mathrm{PTH})$ e pela própria $1,25(\mathrm{OH})_{2} \mathrm{D}$. Uma diminuição nos níveis de cálcio sérico resulta na liberação de PTH pelas glândulas paratireoides. 0 aumento desse hormônio leva a uma maior atividade renal da $1 \alpha$-hidroxilase e, consequentemente, um aumento na produção de $1,25(\mathrm{OH})_{2} \mathrm{D}$. Na tentativa de corrigir o nível sérico de cálcio, a $1,25(\mathrm{OH})_{2} \mathrm{D}$ diminui a excreção renal de cálcio e estimula sua absorção pelo intestino. Além disso, ela estimula a maturação dos osteoclastos para que estes liberem cálcio dos ossos [27].

Outros importantes reguladores da atividade da $1 \alpha$-hidroxilase são o fator de crescimento de fibroblastos (FGF-23) e a proteína Klotho. Níveis elevados de fosfato levam ao aumento da produção de FGF-23, resultando na diminuição da atividade da $1 \alpha$ hidroxilase e, consequentemente, na redução da absorção de cálcio e fósforo [33,34]. A $1,25(\mathrm{OH})_{2} \mathrm{D}$ diminue sua própria produção através da supressão da produção do mRNA da $1 \alpha$-hidroxilase possivelmente via geração do gene klotho [35]. Além disso, a $1,25(\mathrm{OH})_{2} \mathrm{D}$ estimula a 24-hidroxilase, enzima responsável pelo seu catabolismo, que, através do mecanismo de feedback negativo, faz a manutenção dos níveis de vitamina D no organismo [27].

A maioria dos efeitos biológicos da $1,25(\mathrm{OH})_{2}$ D é mediada pela ligação da vitamina $D$ com o seu receptor, VDR (vitamin $D$ receptor). O VDR atua como um heterodímero geralmente através da ligação com o receptor retinóide $X$ (VDR-RXR). Esse complexo heterodimérico interage com sequências específicas de DNA, denominadas Vitamin $D$ Responsive Elements (VDRE), no promotor do gene alvo, levando a ativação ou repressão da transcrição gênica e a ação biológica dos metabólitos da vitamina $D[31,36]$. 
O rim possui um papel importante no metabolismo da vitamina D e esta, por sua vez, é responsável pela sua proteção e pela regulação de inúmeras atividades fisiológicas. Sendo assim, a deficiência $(<10 \mathrm{ng} / \mathrm{mL})$ ou insuficiência $(10-30 \mathrm{ng} / \mathrm{mL})$ de vitamina $D$ pode acelerar a progressão da doença renal [37-40].

As doenças renais, mesmo nas fases iniciais, são acompanhadas pela diminuição dos níveis de $25(\mathrm{OH}) \mathrm{D}$ e de $1,25(\mathrm{OH})_{2} \mathrm{D}$. A 1,25(OH $)_{2} \mathrm{D}$ diminui devido a redução da atividade da $1 \alpha$-hidroxilase e coincide com o aumento da concentração de PTH. A progressão da doença acarreta no acúmulo de fosfato e na elevação do FGF-23, levando a um declínio ainda maior nos níveis séricos de $1,25(\mathrm{OH})_{2}$ D. O FGF-23, produzido pelos osteócitos, promove excreção renal de fosfato, suprimindo a produção de $1,25(\mathrm{OH})_{2} \mathrm{D}$ via inibição da $1 \alpha$-hidroxilase e estimulação da 24-hidroxilase [39,41,42].

Estudos clínicos demonstram que pacientes que sofrem de insuficiência renal apresentam níveis de FGF-23 circulante elevados, taxa de filtração glomerular diminuída e níveis de fosfato e creatinina sérica aumentados [43-45]. Aparentemente, nos estágios iniciais da doença, o FGF-23 sérico está aumentado devido a um mecanismo compensatório, a fim de manter o nível de fosfato adequado. Com o avanço da nefropatia, o FGF-23 está ainda mais elevado, provavelmente devido ao comprometimento da função renal e da retenção de fosfato persistente. Isso contribui para a diminuição do nível de $1,25(\mathrm{OH})_{2} \mathrm{D}$ e, possivelmente, para o desenvolvimento de hiperparatireoidismo [39].

Outro fator que contribui para a redução da $25(\mathrm{OH}) \mathrm{D}$ e de $1,25(\mathrm{OH})_{2} \mathrm{D}$ é a proteinúria, especialmente em pacientes com nefropatia diabética, devido a perda de DBP25(OH)D pela urina, que reduz a sua captura e impede a sua transformação em 25(OH)D e $1,25(\mathrm{OH})_{2} \mathrm{D}[39]$.

Concentrações altas de fosfato e FGF-23, a deficiência de $1,25(\mathrm{OH})_{2} \mathrm{D}$ e a concentração baixa de cálcio acarretam no desenvolvimento de hiperparatireoidismo secundário, caracterizado por hiperplasia na paratireoide, aumento da síntese de PTH e um aumento considerável no nível de PTH sérico. A elevação crônica do PTH em pacientes renais leva ao comprometimento do metabolismo ósseo [39]. 
É importante ressaltar que, além dos mecanismos renais que contribuem para a hipovitaminose $D$, a deficiência desta vitamina também pode estar relacionada à diminuição da exposição à luz solar, ao uso de protetores solares e à dieta pobre em vitamina D. Unger e cols demonstraram que, mesmo em regiões de clima tropical, $80 \%$ dos indivíduos saudáveis apresentam insuficiência de vitamina D após o inverno e $40 \%$ após o verão, indicando que a presença de sol não garante níveis adequados dessa vitamina [46].

Tendo em vista o aumento da incidência de hipovitaminose D na população mundial, esse trabalho visa analisar a nefrotoxicidade induzida pelo TDF associada à deficiência de vitamina D na progressão da doença renal. 


\section{OBJETIVO}

Verificar os mecanismos que levam ao desenvolvimento da lesão renal em ratos depletados de vitamina $D$ submetidos ao tratamento com tenofovir. 


\section{METODOLOGIA}

Foram utilizados ratos Wistar (Rattus novergicus) com peso corpóreo em torno de 180200 g, obtidos do biotério central da Faculdade de Medicina da Universidade de São Paulo. Os animais foram mantidos no biotério do laboratório em temperatura ambiente $\left(23 \pm 1^{\circ} \mathrm{C}\right)$ com ciclo claro/escuro de 12/12 horas. Os procedimentos experimentais utilizados neste estudo foram aprovados pela Comissão de Ética do Hospital das Clínicas da Faculdade de Medicina da Universidade de São Paulo (CAPPesq, processo no 086/11).

Foram utilizados ratos machos que receberam dieta padrão ou depletada em vitamina $D$ $(0,4 \%$ Ca e $0,4 \%$ P, MP Biomedicals, Irvine, CA, EUA) durante 60 dias. Para avaliarmos se a quantidade de dieta consumida foi equivalente, os grupos de animais foram colocados em gaiolas individuais onde receberam dieta, com livre acesso à água. Foi efetuado, diariamente, o balanço da ingestão de dieta e água. O peso dos animais foi verificado semanalmente. Após 30 dias do início do tratamento com ração padrão ou depletada em vitamina $D$, os animais receberam o TDF na dose de $50 \mathrm{mg} / \mathrm{kg}$ de dieta. Essa dose foi baseada em estudos prévios realizados neste laboratório [13].

\subsection{Grupos experimentais}

Foram estudados quatro grupos de animais:

1) Controle (C): ratos que receberam dieta padrão por 60 dias

2) Tenofovir (TDF): ratos que receberam dieta padrão por 60 dias e o tenofovir na dose de $50 \mathrm{mg} / \mathrm{kg}$ de dieta por 30 dias.

3) Deficiência de vitamina $D$ (dVD): ratos que receberam dieta depletada em vitamina $D$ por 60 dias.

4) Deficiência de vitamina $\mathrm{D}$ e tenofovir (dVD+TDF): ratos que receberam dieta depletada em vitamina D por 60 dias e o tenofovir na dose de $50 \mathrm{mg} / \mathrm{kg}$ de dieta por 30 dias. 


\subsection{Representação Esquemática do Protocolo Experimental}

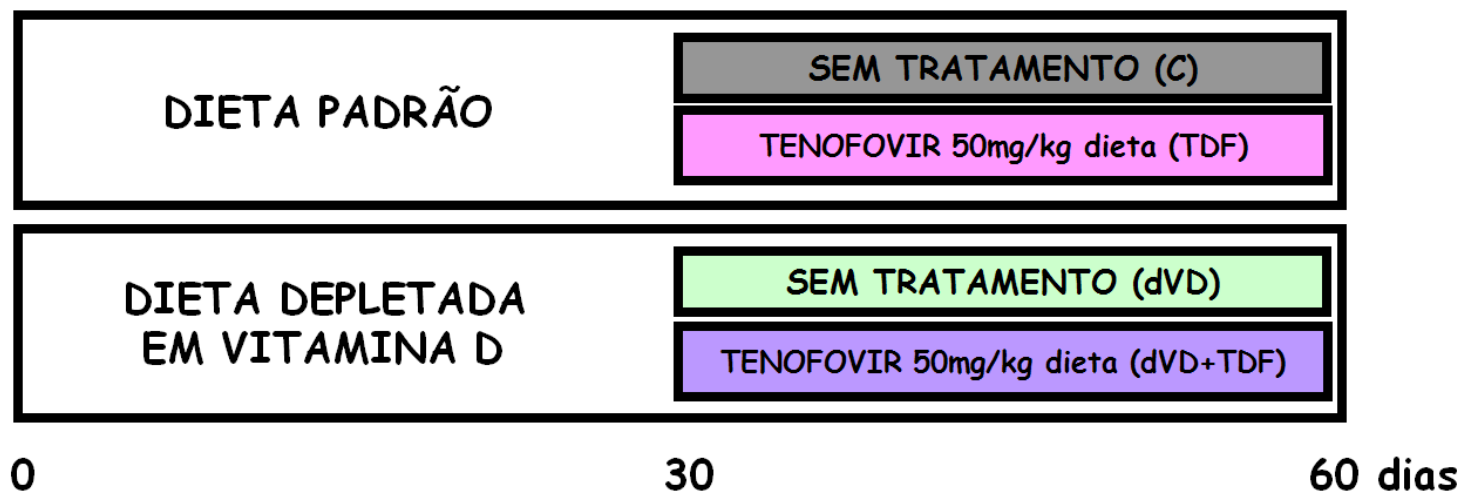

\subsection{Estudos de Gaiola Metabólica}

Após 60 dias de acompanhamento experimental, os animais foram colocados em gaiola metabólica para a coleta de urina de 24 horas. As concentrações urinárias de sódio e potássio foram realizadas por eletrodo específico (ABL800 Flex Analyzer - Radiometer, Brønshøj, Denmark) e a relação $U_{K} / U_{N a}$ foi calculada. As concentrações urinárias de cálcio, fósforo e proteína foram mensuradas por sistema colorimétrico usando kit comercial (LabTest, MG, Brasil). As excreções urinárias de cálcio $\left(U_{C a} V\right)$, fósforo $\left(U_{P} V\right)$ e proteína $\left(\mathrm{U}_{\text {Prot }} \mathrm{V}\right)$ foram determinadas.

\subsection{Determinação da taxa de filtração glomerular: Clearance de Inulina}

Os animais foram anestesiados com tiopental sódico $50 \mathrm{mg} / \mathrm{Kg}$ (Cristália, São Paulo, Brasil). A traqueia foi canulada com cateter PE-240, e a respiração foi mantida espontaneamente. A veia jugular foi canulada com cateter PE-60 para a infusão de inulina e de fluidos. Para o controle da pressão arterial média (PAM) e para a coleta de amostras de sangue, a artéria carótida foi cateterizada com cateter PE-50. Para a coleta de amostras de urina, foi feita uma incisão abdominal e a bexiga do animal foi canulada com cateter PE-240. 
Após o procedimento cirúrgico, uma dose única de inulina $(100 \mathrm{mg} / \mathrm{kg}$ diluída em $1 \mathrm{~mL}$ de solução salina $0,9 \%)$ foi administrada pela veia jugular. Em seguida, uma infusão constante de inulina foi mantida (10 mg/ $\mathrm{kg}$ em solução salina $0,9 \%$ ) a $0,04 \mathrm{~mL} / \mathrm{min}$ do início ao fim do experimento. Foram coletadas três amostras de urinas a cada 30 minutos e amostras de sangue no início e no fim do experimento. Os valores do clearance de inulina representam a média de três períodos de experimento. As concentrações de inulina no sangue e na urina foram determinadas pelo método colorimétrico da Antrona. O clearance de inulina foi expresso corrigindo-se por $100 \mathrm{~g}$ de peso corpóreo.

Para a avaliação do fluxo sanguíneo renal (FSR) foi feita uma incisão mediana abdominal, o pedículo renal esquerdo foi dissecado e a artéria renal isolada. Cuidadosamente, uma sonda de fluxo ultrassônico foi acoplada na artéria renal e obteve-se a mensuração do fluxo sanguíneo renal em mL/min (T110; Transonic Systems, Bethesda, $M D, E U A)$. A resistência vascular renal (RVR) foi calculada dividindo-se a PAM pelo FSR e o resultado foi expresso em $\mathrm{mmHg} / \mathrm{mL} / \mathrm{min}$.

Ao final do experimento de clearance, o sangue total dos animais foi colhido para as seguintes análises no plasma: sódio $\left(\mathrm{P}_{\mathrm{Na}}\right)$, potássio $\left(\mathrm{P}_{\mathrm{K}}\right)$ e cálcio iônico $\left(\mathrm{P}_{\mathrm{Ca}}\right)$ por eletrodo sensível (ABL800 Flex Analyzer - Radiometer, Brønshøj, Denmark), fósforo $\left(\mathrm{P}_{\mathrm{P}}\right)$, colesterol total e triglicérides por sistema colorimétrico (COBAS C111 Analyzer - Roche ${ }^{\circledR}$, USA). A concentração plasmática de 25-hidroxivitamina D (25(OH)D) foi avaliada aos 30 e 60 dias pelo método de radioimunoensaio usando kit comercial 25-Hydroxyvitamin $D^{125} / R I A$ (DiaSorin ${ }^{\circledR}$, Vercelli, Itália). Os níveis de PTH e aldosterona plasmáticos foram determinados usando kit comercial Rat Bioactive Intact PTH (Immunotopics ${ }^{\circledR}$, Califórnia, EUA) pelo método de Elisa e RIA Aldosterone (Immunotech ${ }^{\circledR}$, Marseille, FR) pelo método de radioimunoensaio, respectivamente, aos 60 dias.

Após a coleta do sangue, os rins foram perfundidos com solução de tampão fosfato salino ( $\mathrm{PBS}, \mathrm{NaCl} 0,15 \mathrm{M}$, tampão fosfato $0,01 \mathrm{M}, \mathrm{pH} 7,4$ ). Em seguida, o rim direito foi removido, congelado em nitrogênio líquido e estocado a $-80^{\circ} \mathrm{C}$ para análise da expressão gênica e de proteínas pelas técnicas de reação em cadeia da polimerase quantitativo (qPCR) e Western blotting, respectivamente. O rim esquerdo foi pesado e em seguida fixado em 
formalina tamponada $10 \%$ ou solução de methacarn e mantido nestes mesmos fixadores por um período de 24 horas. Após esse período, os fixadores foram substituídos por álcool $70 \%$ e o tecido foi embebido em parafina e cortado em secções de $4 \mu \mathrm{m}$ para estudos de histomorfometria e imuno-histoquímica.

\subsection{Análise Histo-morfométrica}

As amostras de tecidos renais foram desidratadas, diafanizadas e incluídas em parafina. Após inclusão em parafina, obtiveram-se cortes de $4 \mu \mathrm{m}$, que foram corados pela reação de hematoxilina-eosina $(\mathrm{HE})$ para avaliação das lesões renais.

Para avaliação da extensão das áreas acometidas por lesões renais, entre 40 a 60 campos medindo $0,245 \mathrm{~mm}^{2}$ foram sequencialmente analisados. Cada campo foi avaliado através de scores que variavam de 0 a 4 , de acordo com o seguinte critério: 0 , menos do que 5\% da área apresentando edema celular, degeneração vacuolar, necrose e descamação; I, entre 5-25\% da área com comprometimento; II, 25-50\% da área apresentando lesões renais; III, alterações envolvendo entre 50-75\% do campo analisado; IV, mais do que $75 \%$ da área analisada apresentando lesões renais. Em seguida, um score médio para cada rato foi calculado [47].

\subsection{Análise Imuno-histoquímica}

Os cortes de tecido renal foram incubados com anticorpo anti-angiotensina II (Santa Cruz, Biotechnology Inc., CA, EUA) na diluição 1:1000 por um período de 1 hora à temperatura ambiente. O produto dessa reação foi detectado pelo complexo avidinabiotina-peroxidase (Vector Laboratories Burlingame, CA, EUA) e a cor desenvolvida com 3,3'diaminobenzidina na presença de água oxigenada. A contracoloração foi feita com hematoxilina de Harris. As ligações inespecíficas foram bloqueadas pelas diluições dos anticorpos primário e secundário em solução de PBS contendo albumina bovina $1 \%$. Os cortes foram examinados sob microscopia de luz. 


\subsection{Análise da expressão proteica: Western Blotting}

Para a realização da técnica de Western blotting foram utilizadas as amostras de tecido renal dos animais tratados com dieta padrão e dos animais tratados com dieta depletada em vitamina $D$, previamente congeladas em nitrogênio líquido e estocadas a $80^{\circ} \mathrm{C}$.

A extração da proteína seguiu o protocolo descrito por Burnette [48], com pequenas modificações. As amostras dos tecidos renais foram homogeneizadas (Polytron PT 10-35, Power Control Unit) em solução K-Hepes (20 mM Mannitol; 80 mM Hepes; 41 KOH, pH 7,5) com coquetel de inibidores de protease (Cocktail Protease Inhibitor, Sigma Chemical Company, St. Louis, MO). Em seguida, foram centrifugadas a 4.000 g por 15 minutos a $4^{\circ} \mathrm{C}$ para remover núcleo, mitocôndrias e debris celulares. As proteínas totais foram quantificadas pelo método de Bradford (Bioagency). As amostras foram separadas de acordo com o peso molecular em minigéis SDS-PAGE (SDS-polyacrylamide gel electrophoresis) em tampão de corrida (Tris/Glicina/SDS 10\%, pH 8,3) e a transferência para membrana de nitrocelulose foi feita com tampão de transferência (Tris/Glicina/metanol 20\%). A membrana foi bloqueada com 5\% de leite em pó desnatado (Molico) em TBS-T (24,2 g Tris base, 29,2 g $\mathrm{NaCl}$, 3,36 g EDTA para $1 \mathrm{~L}$ de água destilada) por 1 hora. A incubação primária foi feita com anticorpo anti-eNOS, anti-Angiotensinogênio/Angiotensina, anti-AT1r (Santa Cruz, Biotechnology Inc., CA, EUA) e anti-NaPi-Ila $(0,54 \mu \mathrm{g} / \mathrm{mL}$ - gentilmente cedido pelo Dr. Mark Knepper - NHLBI/NIH, Bethesda, MD, EUA) em solução de TBS-T, overnight a $4^{\circ} \mathrm{C} . \mathrm{A}$ incubação secundária foi realizada com anticorpo anti-mouse, anti-rabbit ou anti-goat (Sigma Chemical, St. Louis, MO, EUA) também em solução de TBS-T com 0,1\% de leite desnatado. O procedimento de detecção foi baseado em quimioluminescência (ECL, Amersham). A normatização foi feita com uma nova hibridização das membranas com anticorpo anti-actina (Santa Cruz, Biotechnology Inc., CA, EUA). A semi-quantificação das proteínas foi feita pelo software Image J for Windows (Image J - NIH Image). 


\subsection{Análise da expressão gênica: reação em cadeia da polimerase quantitativo}

\subsubsection{Extração de RNA}

O rim direito de cada animal foi removido, congelado em nitrogênio líquido e estocado a $-80^{\circ} \mathrm{C}$ para extração de RNA. Em tubos plásticos de $50 \mathrm{ml}$, foram adicionados 50 mg de tecido renal para $1 \mathrm{ml}$ de reagente TRIzol (Life Technologies, Carlsbad, CA, EUA) que foram homegeneizados com auxílio de um Polytron. Em seguida, foi adicionado $200 \mu \mathrm{l}$ de clorofórmio ao homogenato. Após centrifugação e separação das fases, o RNA foi transferido para tubos plásticos de $2 \mathrm{ml}$ para precipitação, lavagem e ressuspensão. As concentrações de RNA de cada amostra foram determinadas por Nanodrop.

\subsubsection{Reação em cadeia da polimerase quantitativo - qPCR}

Fitas únicas de cDNA foram sintetizadas a partir das amostras de RNA isolado utilizando-se o reagente SuperScript ${ }^{\oplus}$ VILO $^{\text {TM }}$ MasterMix (Invitrogen by Life Technologies, Carlsbad, CA, EUA), na proporção de $4 \mu \mathrm{l}$ do reagente para até 2,5 $\mu \mathrm{g}$ de RNA. A reação em cadeia da polimerase (qPCR) foi feita por TaqMan (Applied Biosystem, EUA) para as seguintes moléculas: renina sonda Rn00561847_m1, angiotensinogênio (AGT) sonda Rn00593114_m1, enzima conversora de angiotensina (ECA) sonda Rn00561094_m1, receptor de angiotensina tipo 1a (AT1a) sonda Rn02758772_s1. A sonda para GAPDH Rn01775763_g1 foi utilizada como controle. Todas as reações de qPCR foram conduzidas em duplicata, utilizando-se o equipamento Step One Plus (Applied Biosystems, CA, EUA). Controles negativos sem amostras de cDNA foram feitos para cada sonda. As condições de ciclagem foram as seguintes: $2 \mathrm{~min}$ a $50^{\circ} \mathrm{C}$ seguidos de $10 \mathrm{~min}$ a $95^{\circ} \mathrm{C}$; posteriormente, as amostras foram submetidas a 40 ciclos de 15 segundos a $95^{\circ} \mathrm{C}$ seguido de 1 minuto a $60^{\circ} \mathrm{C}$. Os valores de Ct (ciclo limiar) do gene alvo foram normalizados pelos valores de $\mathrm{Ct}$ do gene de referência $\left(\Delta \mathrm{Ct}=\mathrm{Ct}_{\text {alvo }}-\mathrm{Ct}_{\text {referência }}\right)$. Pelo fato do $\mathrm{Ct}$ do gene de referência permanecer constante, a alteração no valor de $\Delta C$ t corresponde a uma variação na expressão do gene alvo. Pela comparação do valor de $\Delta \mathrm{Ct}$ de amostras desconhecidas com o $\Delta \mathrm{Ct}$ de uma amostra controle, o valor de $\Delta \Delta \mathrm{Ct}$ é obtido. Assim, a expressão gênica relativa é calculada aplicando-se a equação $2^{-\Delta \Delta C t}$ para quantificar a expressão de genes [49]. 


\subsection{Avaliação do estado redox: Ensaio de TBARS e GSH}

Os níveis plasmáticos e urinários de Substâncias Reativas ao Ácido Tiobarbitúrico (TBARS), que são marcadores de peroxidação lipídica, foram determinados utilizando o ensaio do ácido tiobarbitúrico. Foram utilizadas amostras de plasma e urina previamente coletadas durante os experimentos de clearance e perfusão, diluídas na proporção 1:20 (0,2 $\mathrm{mL}$ de amostra diluída em 0,8 $\mathrm{mL}$ de água destilada). Em seguida, foi adicionado $1 \mathrm{~mL}$ de ácido tricloroacético (TCA) a 17,5\% e $1 \mathrm{~mL}$ de ácido tiobarbitúrico (0,6\% pH 2). A solução foi levada ao banho-maria por 20 minutos. Após o resfriamento em gelo, a mistura foi incubada por 20 minutos com $1 \mathrm{~mL}$ de TCA a 70\% e centrifugada por 15 minutos a $3000 \mathrm{rpm}$. A densidade óptica do sobrenadante foi avaliada através da leitura em espectrofotômetro no comprimento de onda de $534 \mathrm{~nm}$. A quantidade de TBARS foi calculada utilizando um coeficiente de extinção molar de $1,56 \times 10^{5} \mathrm{M}^{-1} \mathrm{~cm}^{-1}$ [50]. Os níveis plasmáticos e urinários de TBARS foram expressos em $\mathrm{nmol} / \mathrm{mL}$ e $\mathrm{nmol} / 24$ horas, respectivamente. A concentração de TBARS no tecido renal também foi avaliada. Inicialmente, foi realizada a extração e a quantificação das proteínas do tecido renal pelos métodos de Burnette modificado e Bradford, respectivamente. Em seguida, a avaliação do estresse oxidativo no tecido renal foi realizada de acordo com a técnica descrita acima e expresso em nmol/ $\mathrm{\mu g} / \mu \mathrm{L}$.

A glutationa (GSH) foi determinada no sangue total pelo método descrito por Sedlak e Lindsay (1968) [51]. O sangue total foi processado através da adição de ácido metafosfórico $5 \%$ e centrifugado a 14000 g por 10 minutos. O ensaio consiste na reação do sobrenadante do sangue total com o reagente de Ellman's, formando um pigmento amarelo que é mensurado no espectrofotômetro em $412 \mathrm{~nm}$. O GSH foi quantificado pela média da curva padrão e expresso em $\mu \mathrm{mol} / \mathrm{mL}$ [52].

\subsection{Análise Estatística}

A análise estatística dos dados dos grupos estudados foi o One-Way ANOVA, seguido pelo teste de Newman-Keuls. Para avaliação do tempo de estudo sobre os parâmetros 
analisados foi utilizado o Two-Way ANOVA, seguido pelo teste de Bonferroni. Todas as análises foram realizadas através do programa de estatística GraphPad Prism 5 e foram expressos em média \pm erro padrão da média (EPM). Os valores foram considerados significantes de $p<0,05$. 


\section{RESULTADOS}

Os animais que receberam a dieta depletada em vitamina $D$ apresentaram níveis plasmáticos indetectáveis de $25(\mathrm{OH}) \mathrm{D}$, demonstrando que o modelo experimental de deficiência de vitamina $D$ foi implementado com eficácia (Tabela 2). É importante ressaltar que aos 30 dias de acompanhamento experimental, os animais que receberam dieta depletada em vitamina $D$ já apresentavam níveis plasmáticos baixos dessa vitamina $(4,1 \pm 0,8$ $\mathrm{ng} / \mathrm{mL}$ ) quando comparados com os animais que receberam dieta padrão durante esse mesmo período $(14,8 \pm 0,9 \mathrm{ng} / \mathrm{mL})$, demonstrando que antes de iniciar o tratamento com TDF, os animais já estavam deficientes (Figura 1).

\section{5(OH)D \\ Análise do Tempo de Estudo}

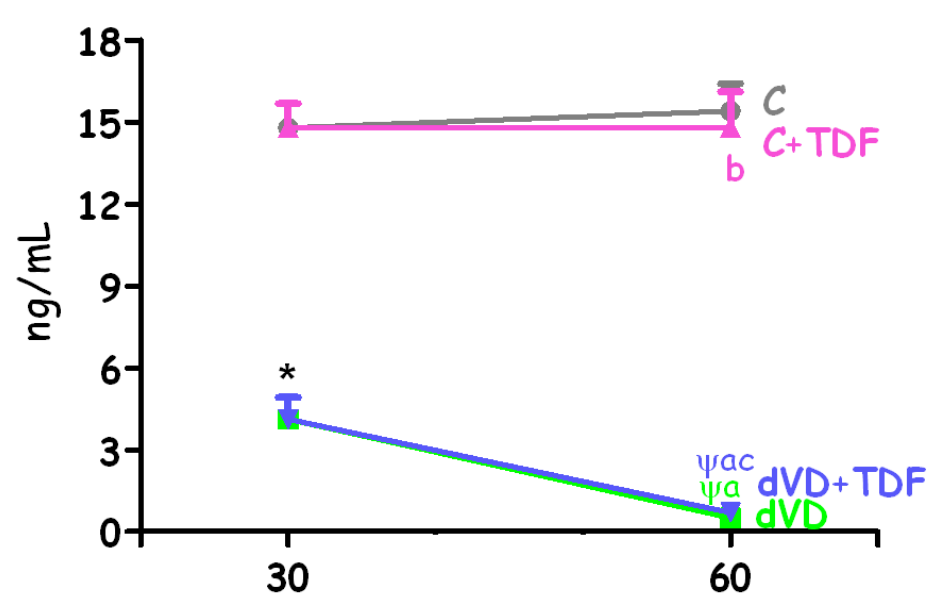

Dias

Figura 1 - Avaliação do tempo de estudo sobre a concentração plasmática de 25(OH)D de ratos controles (C, $n=10)$, deficientes em vitamina $D(d V D, n=6)$, controles que receberam Tenofovir (TDF, $n=10)$ e deficientes em vitamina $D$ que receberam Tenofovir (dVD+TDF, $n=6$ ) com 30 e 60 dias de acompanhamento (antes e depois do tratamento). Valores expressos em média \pm EPM. ${ }^{*} p<0,01$ vs. respectivo $C ;{ }^{a} p<0,05$ vs. respectivo $C ;{ }^{b} p<0,05$ vs. respectivo dVD; ${ }^{c} p<0,05$ vs. respectivo TDF; ${ }^{4} p<0,05$ vs. respectivo 30 dias. 
Os animais de todos os grupos estudados não apresentaram diferenças significativas no peso corpóreo, uma vez que a ingestão de dieta foi similar entre os grupos (aproximadamente $25 \mathrm{~g} / \mathrm{rato} / \mathrm{dia}$ ). O tratamento com TDF levou ao comprometimento da função renal, evidenciado pela menor taxa de filtração glomerular comparado com o grupo C $(0,63 \pm 0,04$ vs. $0,88 \pm 0,04 \mathrm{~mL} / \mathrm{min} / 100 \mathrm{~g})$. Os animais do grupo dVD+TDF apresentaram uma perda ainda mais acentuada da função renal, indicando que a deficiência de vitamina $D$ é um fator agravante na progressão da lesão renal induzida pelo TDF $(0,45 \pm 0,04 \mathrm{~mL} / \mathrm{min} / 100 \mathrm{~g})$. Os dados de peso corpóreo e da taxa de filtração glomerular estão representados na tabela 1 e na figura 2.

\section{Clearance de Inulina}

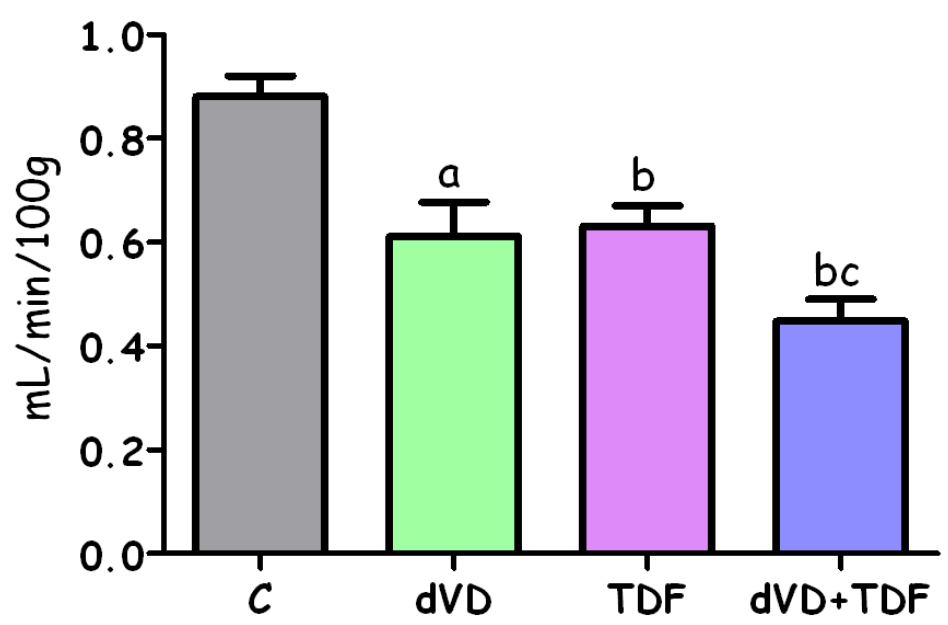

Figura 2 - Taxa de filtração glomerular (TFG) avaliada pelo clearance de inulina de ratos controles (C, $n=13)$, deficientes em vitamina $D(d V D, n=7)$, controle que receberam Tenofovir (TDF, $n=12)$ e deficientes em vitamina $D$ que receberam Tenofovir (dVD+TDF, $n=7$ ). Valores expressos em média \pm EPM. ${ }^{a} p<0,01 ;{ }^{b} p<0,001$ vs. $C ;{ }^{c} p<0,05$ vs. TDF. 
A figura 3 representa a evolução dos animais antes e depois do tratamento com TDF com relação à taxa de filtração glomerular. Aos 30 dias, antes do início da administração do TDF, os animais que receberam dieta padrão $\left(C_{\mathrm{In}}=0,93 \pm 0,05 \mathrm{~mL} / \mathrm{min} / 100 \mathrm{~g}\right)$ apresentaram função renal normal. Entretanto, os animais que receberam a dieta depletada em vitamina D $\left(C_{\text {In }}=0,76 \pm 0,03 \mathrm{~mL} / \mathrm{min} / 100 \mathrm{~g}\right)$ já apresentaram queda na TFG quando comparados ao grupo Controle. Aos 60 dias, os animais do grupo C mantiveram a taxa de filtração glomerular $(0,88 \pm 0,04 \mathrm{~mL} / \mathrm{min} / 100 \mathrm{~g})$, diferentemente dos grupos que receberam o TDF. Interessantemente, os animais que receberam dieta depletada em vitamina D por 60 dias apresentaram uma queda na taxa de filtração glomerular quando comparado com o mesmo grupo aos 30 dias $(0,61 \pm 0,06$ vs. $0,76 \pm 0,03 \mathrm{~mL} / \mathrm{min} / 100 \mathrm{~g})$, sugerindo que a vitamina $D$ tem um papel importante na manutenção da função renal.

\section{Clearance de Inulina Análise do Tempo de Estudo}

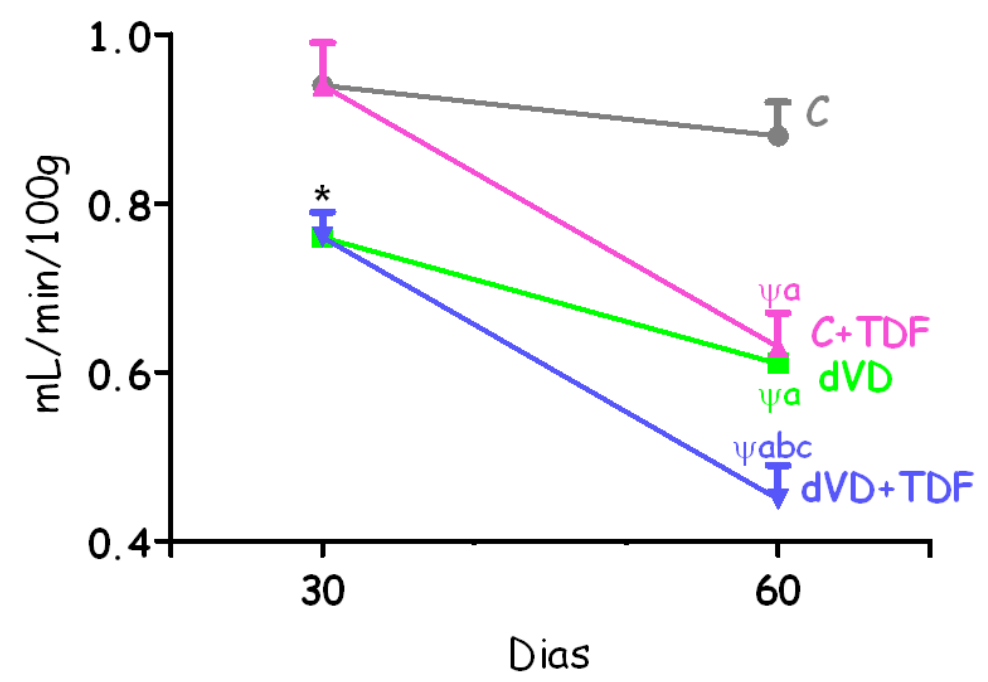

Figura 3 - Avaliação do tempo de estudo sobre a taxa de filtração glomerular avaliada pelo clearance de inulina de ratos controles $(C, n=13)$, deficientes em vitamina $D(d V D, n=7)$, controles que receberam Tenofovir (TDF, $n=12$ ) e deficientes em vitamina $D$ que receberam Tenofovir (dVD+TDF, $n=7$ ) com 30 e 60 dias de acompanhamento (antes e depois do tratamento). Valores expressos em média \pm EPM. $* p<0,01$ vs. respectivo $C ;{ }^{a} p<0.05$ vs. respectivo $C ;{ }^{b} p<0,05$ vs. respectivo dVD; ${ }^{c} p<0,05$ vs. respectivo TDF; ${ }^{4} p<0,05$ vs. respectivo 30 dias. 
Outro marcador de disfunção renal é a proteinúria. Os animais que receberam TDF, junto à dieta depletada $(11,8 \pm 0,5 \mathrm{mg} / 24 \mathrm{~h})$ ou não em vitamina $D(10,8 \pm 0,3 \mathrm{mg} / 24 \mathrm{~h})$, apresentaram uma elevação na excreção urinária de proteínas quando comparado com o grupo $C(5,3 \pm 0,3 \mathrm{mg} / 24 \mathrm{~h})$. A proteinúria também foi maior no grupo dVD $(11,3 \pm 0,8 \mathrm{mg} / 24 \mathrm{~h})$ quando comparado com o grupo C. A combinação da deficiência em vitamina $D$ e o tratamento com TDF não agravou esse parâmetro. É importante ressaltar que se avaliássemos a fração de excreção urinária de proteínas nos animais depletados em vitamina D que receberam o TDF, este grupo apresentaria um aumento dessa fração de excreção proteína devido à menor filtração glomerular com consequente menor carga filtrada de proteína. A tabela 2 e a figura 4 demonstram a excreção urinária de proteínas.

\section{Proteinúria}

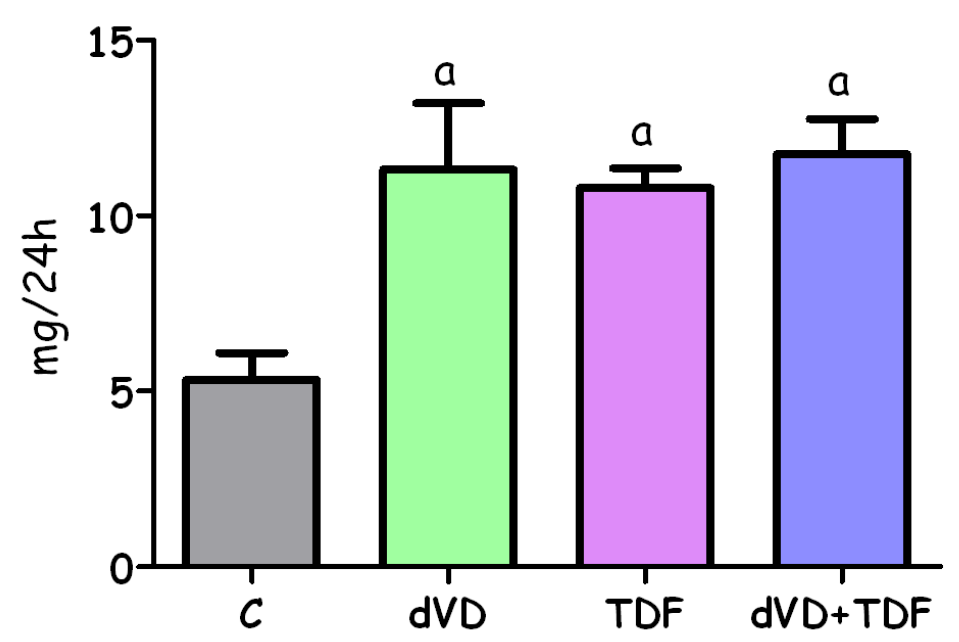

Figura 4 - Excreção urinária de proteína de ratos controles $(C, n=5)$, deficientes em vitamina $D(d V D, n=6)$, controles que receberam Tenofovir (TDF, $n=6)$ e deficientes em vitamina $D$ que receberam Tenofovir (dVD+TDF, $n=6)$. Valores expressos em média \pm EPM. ${ }^{a} p<0,001$ vs. $C$. 
Referente à análise histológica, os animais dos grupos dVD $(0,21 \pm 0,02)$ e TDF $(0,24 \pm 0,02)$ apresentaram um aumento no score de lesão tubular renal quando comparados com os animais do grupo $C(0,07 \pm 0,01)$. Foram observados alterações tais como: necrose tubular, perda da bordura em escova, achatamento das células tubulares e dilatação dos túbulos renais. Os animais deficientes em vitamina $D$ que receberam o TDF exibiram um aumento mais acentuado no score de lesão $(0,36 \pm 0,02)$. Vale ressaltar que essas alterações foram focais e discretas. Entretanto, tais alterações histológicas podem confirmar os efeitos citotóxicos do TDF às células renais, principalmente se associado à deficiência de vitamina D. As figuras 5 e 6 representam o score de lesão observado em todos os grupos experimentais.

\section{Score de Lesão Tubular Renal}

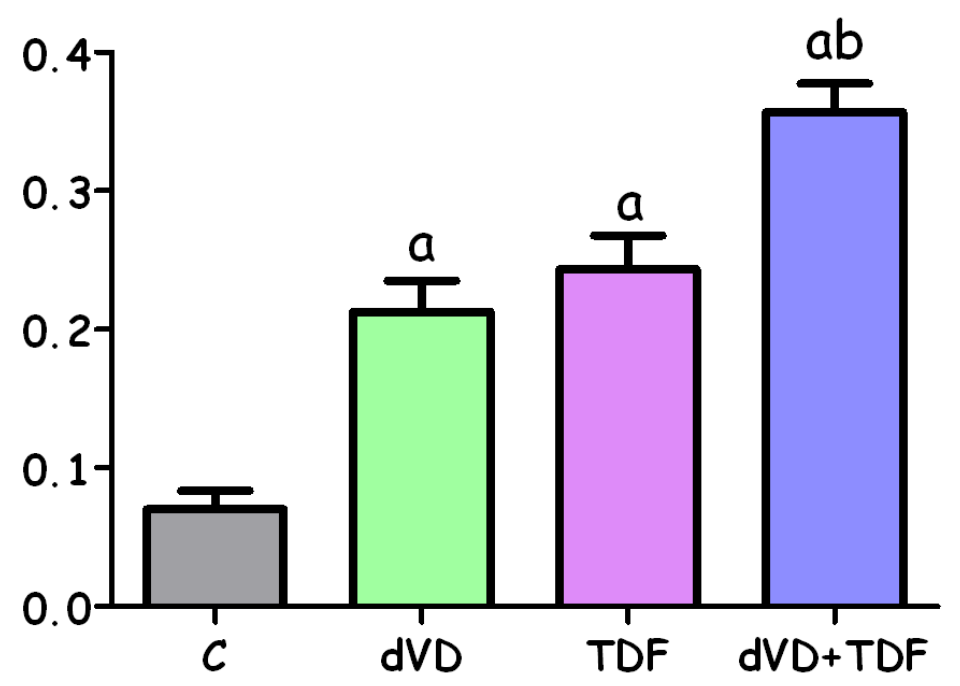

Figura 5 - Score de lesão tubular renal de ratos controles $(C, n=5)$, deficientes em vitamina $D(d V D, n=7)$, controles que receberam Tenofovir (TDF, $n=6)$ e deficientes em vitamina $D$ que receberam Tenofovir (dVD+TDF, n=9). Valores expressos em média \pm EPM. ${ }^{a} p<0,001$ vs. $C,{ }^{b} p<0,001$ vs. TDF. 

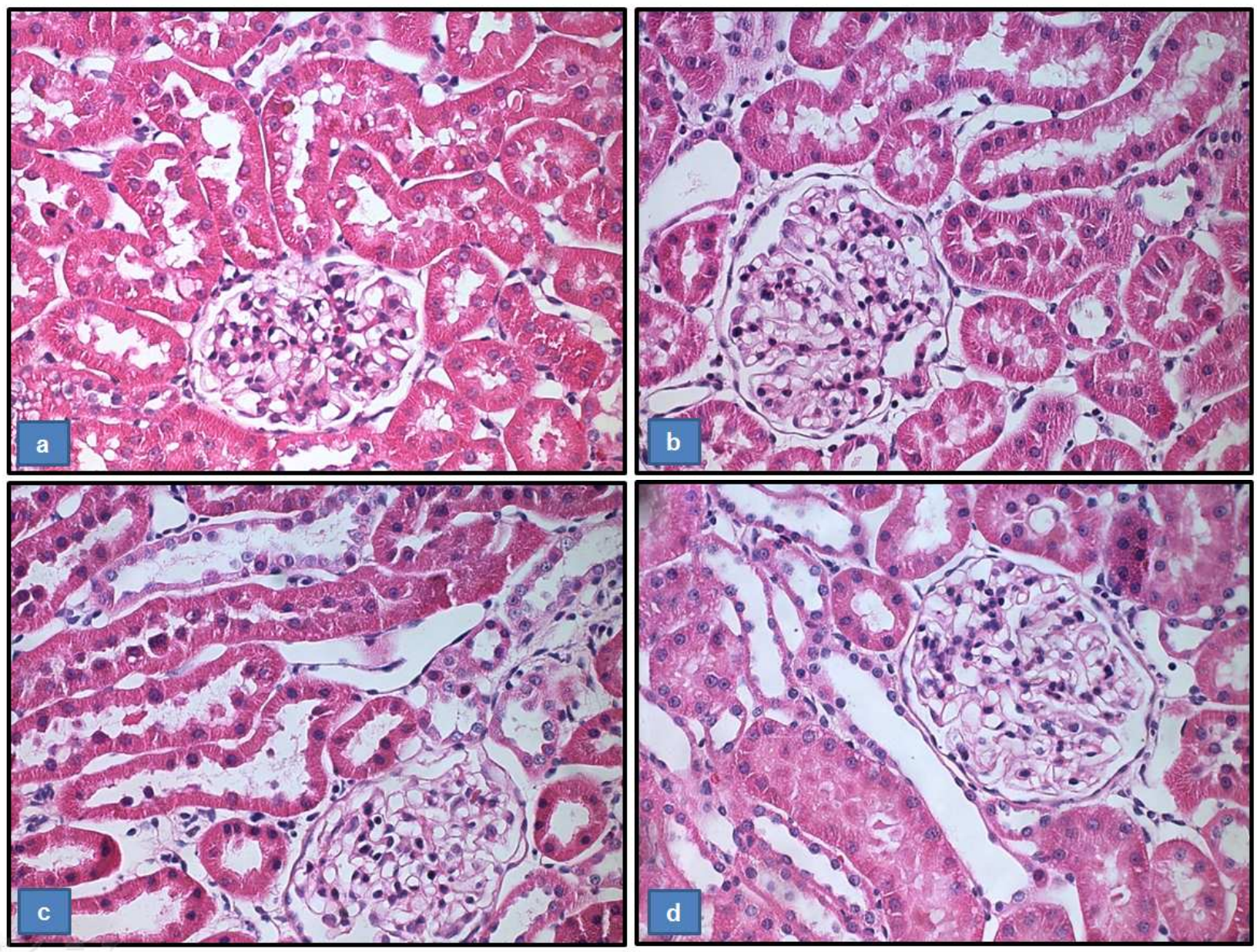

Figura 6 - Fotomicrografia do córtex renal de um rato controle - $C(a)$, de um rato deficiente em vitamina $D-d V D$ (b), de um rato que recebeu TDF - TDF (c) e de um rato deficiente em vitamina D que recebeu TDF - dVD+TDF (d). (400X) 
O grupo TDF mostrou um aumento na PAM comparado com o grupo C $(134 \pm 2$ vs. $117 \pm 3$ $\mathrm{mmHg})$, que foi ainda maior nos animais dVD+TDF $(148 \pm 5 \mathrm{mmHg})$. Os dados da PAM estão representados na tabela 1 e figura 7 .

\section{Pressão Arterial Média}

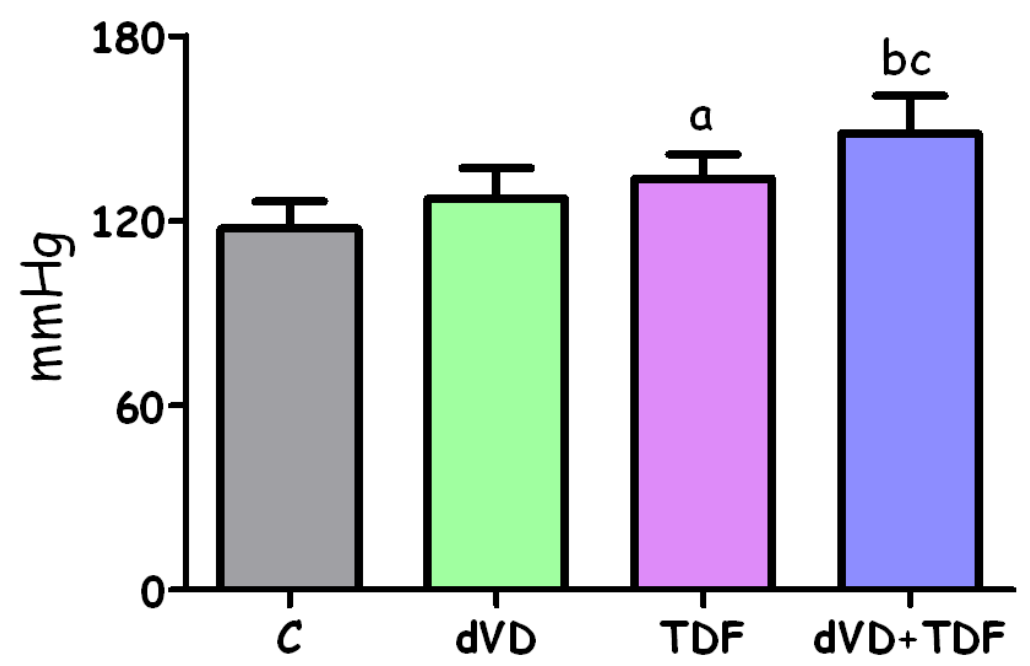

Figura 7 - Pressão arterial média de ratos controles $(C, n=7)$, deficientes em vitamina $D(d V D, n=6)$, controles que receberam Tenofovir (TDF, $n=12$ ) e deficientes em vitamina $D$ que receberam Tenofovir (dVD+TDF, $n=6)$. Valores expressos em média \pm EPM. ${ }^{a} p<0,01 ;{ }^{b} p<0,001$ vs. $C ;{ }^{c} p<0,01$ vs. TDF. 
Além disso, os animais dos grupos dVD (201 $\pm 32 \%)$, TDF $(222 \pm 18 \%)$ e dVD+TDF (244 $\pm 26 \%)$ apresentaram um aumento significativo na expressão proteica de angiotensinogênio/angiotensina I e II quando comparados com os animais do grupo controle (104 $\pm 4 \%)$. Corroborando esses resultados, a análise imuno-histoquímica mostrou aumento da expressão de All nos túbulos renais dos animais dVD, TDF e dVD+TDF. Os dados referentes à expressão proteica de angiotensinogênio/angiotensina I e II e a localização da All no tecido renal estão representados na tabela 4 e nas figuras 8 e 9.

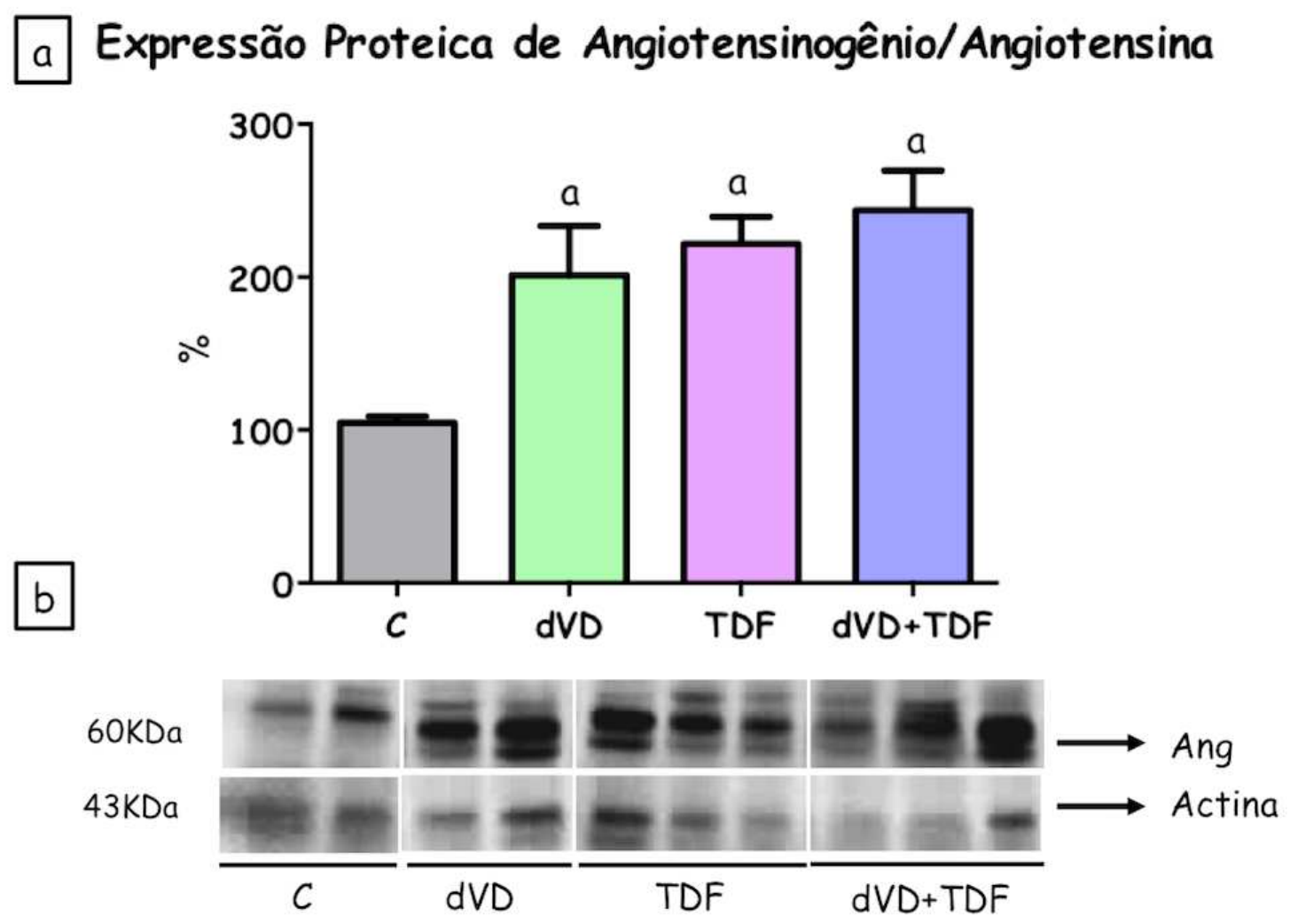

Figura 8 - Avaliação semiquantitativa da expressão proteica de Angiotensinogênio/Angiotensina I e II no tecido renal. (a) Densitometria das amostras de ratos controles $(C, n=4)$, deficientes em vitamina $D(d V D, n=6)$, controles que receberam Tenofovir (TDF, $n=6$ ) e deficientes em vitamina $D$ que receberam Tenofovir (dVD+TDF, $n=6)$. (b) Foto ilustrativa da expressão de All e actina no tecido renal. Valores expressos em média $\pm \mathrm{EPM}$. ${ }^{a} p<0,05$ vs. C. 

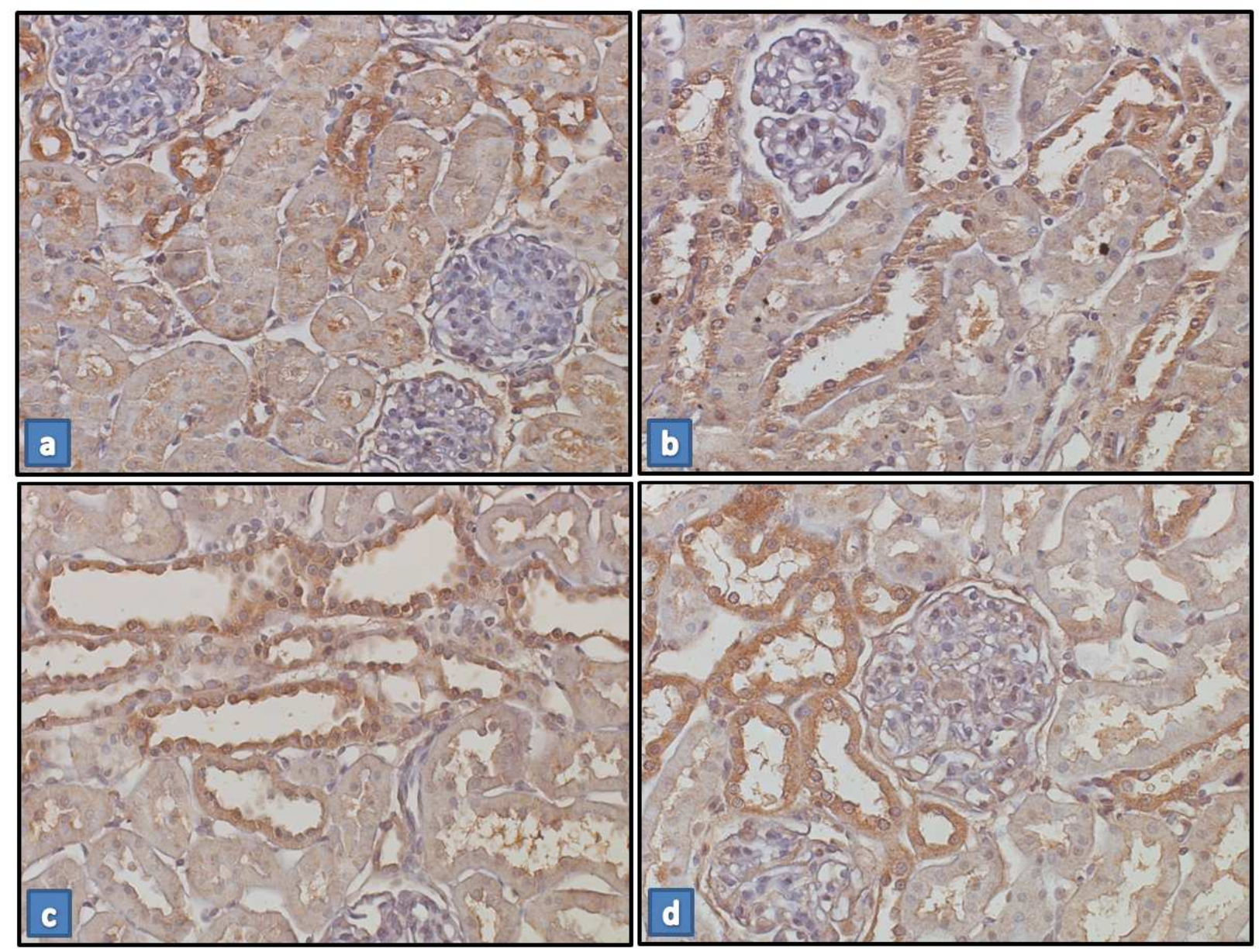

Figura 9 - Imunolocalização de Angiotensina II no córtex renal de um rato controle - C (a), de um rato deficiente em vitamina $D$ - dVD (b), de um rato que recebeu TDF - TDF (c) e de um rato deficiente em vitamina $D$ que recebeu TDF $-d V D+T D F(d)$. Notar que a imunorreação é mais intensa em $B, C$ e D do que em $A(400 X)$. 
Referente à expressão proteica do receptor AT1 da angiotensina II (Tabela 4 e Figura $10)$, os animais dVD (173 $\pm 26 \%)$ e TDF $(247 \pm 34 \%)$ apresentaram um aumento desse receptor

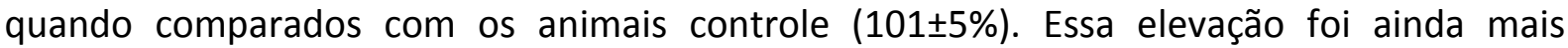

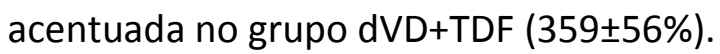
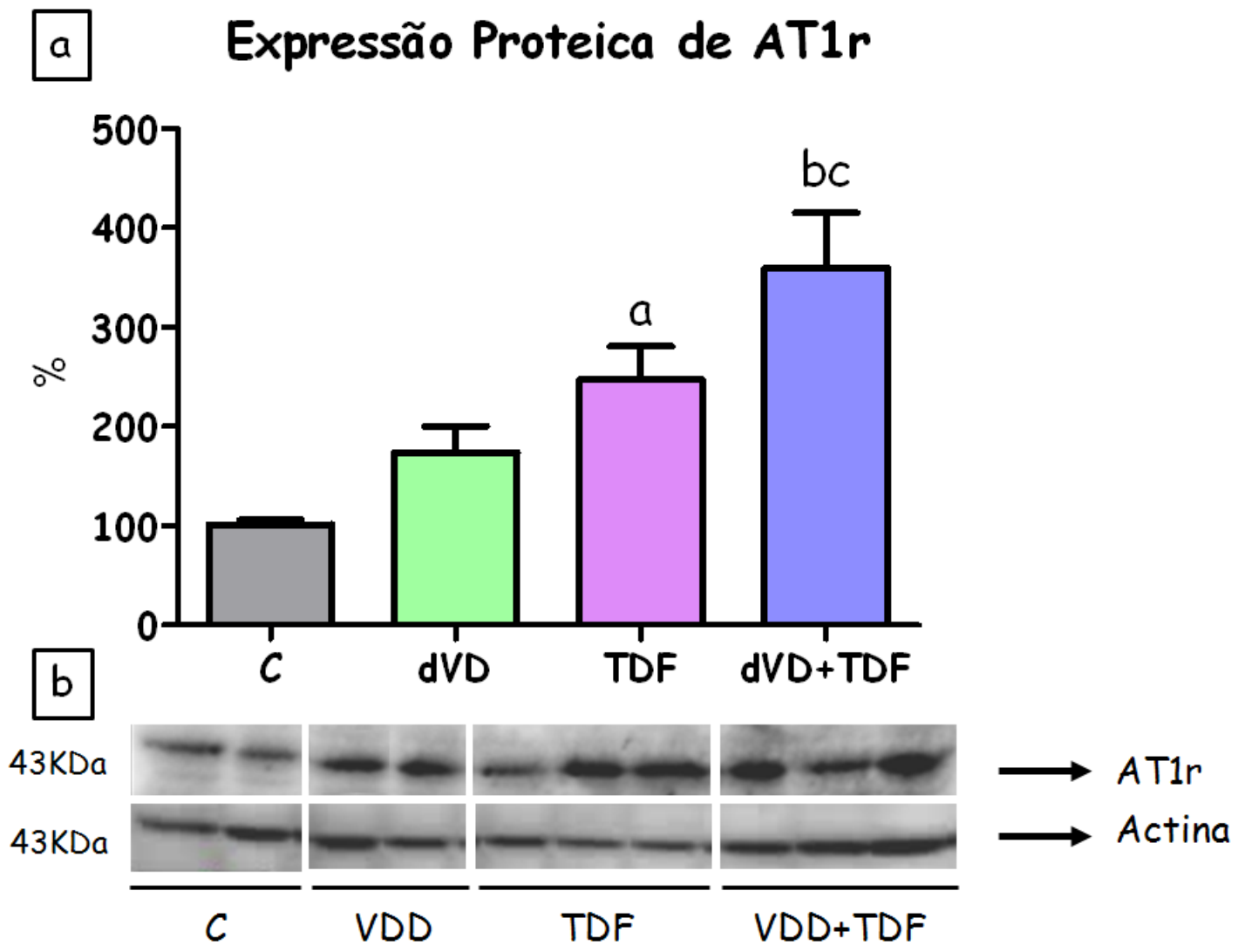

Figura 10 - Avaliação semiquantitativa da expressão proteica de AT1r no tecido renal. (a) Densitometria das amostras de ratos controles $(C, n=4)$, deficientes em vitamina $D(d V D, n=6)$, controles que receberam Tenofovir (TDF, n=6) e deficientes em vitamina D que receberam Tenofovir (dVD+TDF, n=6). (b) Foto ilustrativa da expressão de AT1r e actina no tecido renal. Valores expressos em média \pm EPM. ${ }^{a} p<0,05 ;{ }^{b} p<0,01$ vs. C; ${ }^{c} p<0,05$ vs. TDF. 
Os níveis de aldosterona plasmática mostraram um perfil semelhante ao da expressão proteica de AT1r no tecido renal. Os animais do grupo dVD apresentaram um aumento numérico, porém importante, de aldosterona quando comparados com o grupo C $(234 \pm 46$ $\mathrm{pg} / \mathrm{mL}$ vs. $116 \pm 15 \mathrm{pg} / \mathrm{mL})$. Os animais que receberam o TDF $(316 \pm 57 \mathrm{pg} / \mathrm{mL})$ também exibiram um aumento nos níveis de aldosterona, que foi maior nos animais dVD+TDF $(479 \pm 83 \mathrm{pg} / \mathrm{mL})$. Além disso, a relação entre a excreção renal de potássio e de sódio foi maior e estatisticamente significante nos animais dVD+TDF $(4,45 \pm 0,49)$ quando comparados com os animais $C(3,27 \pm 0,17)$, dVD $(3,39 \pm 0,17)$ e TDF $(3,07 \pm 0,19)$. Esses dados em conjunto demonstram a influência da aldosterona nos túbulos renais. Os níveis de aldosterona plasmática e a relação $U_{K} / U_{N a}$ estão representados na tabela 2 e as figuras 11 e 12 .

\section{Aldosterona Plasmática}

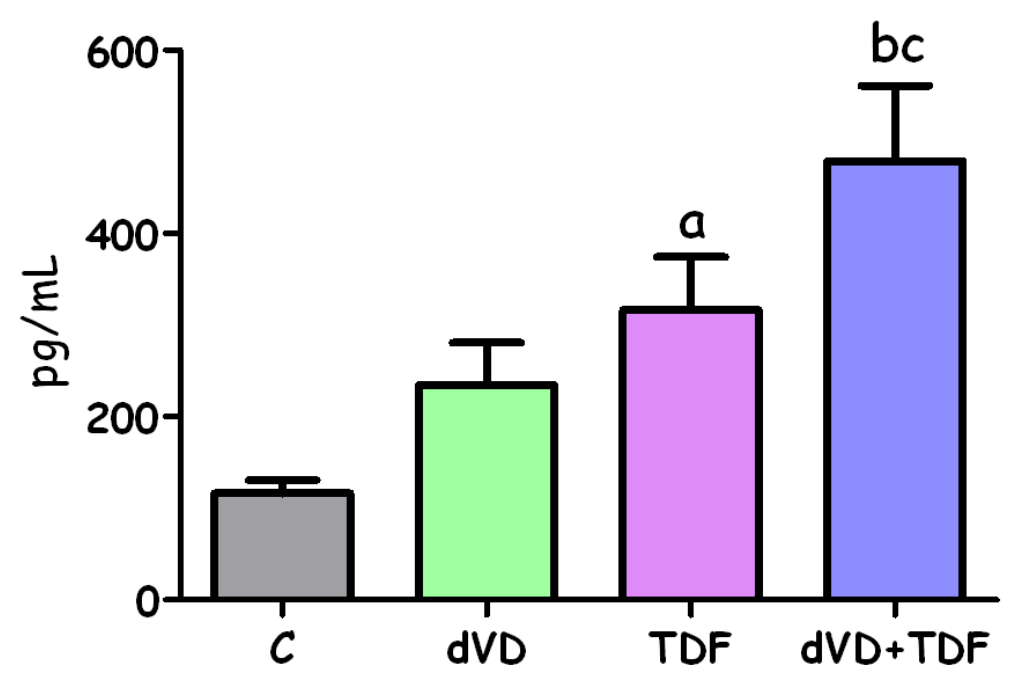

Figura 11 - Concentração plasmática de aldosterona de ratos controles $(C, n=11)$, deficientes em vitamina $D$ (dVD, $n=7)$, controles que receberam Tenofovir (TDF, $n=6)$ e deficientes em vitamina $D$ que receberam Tenofovir (dVD+TDF, $n=7)$. Valores expressos em média \pm EPM. ${ }^{a} p<0,05,{ }^{b} p<0,001$ vs. $C ;{ }^{c} p<0,05$ vs. TDF. 


\section{$U_{K} / U_{N a}$}

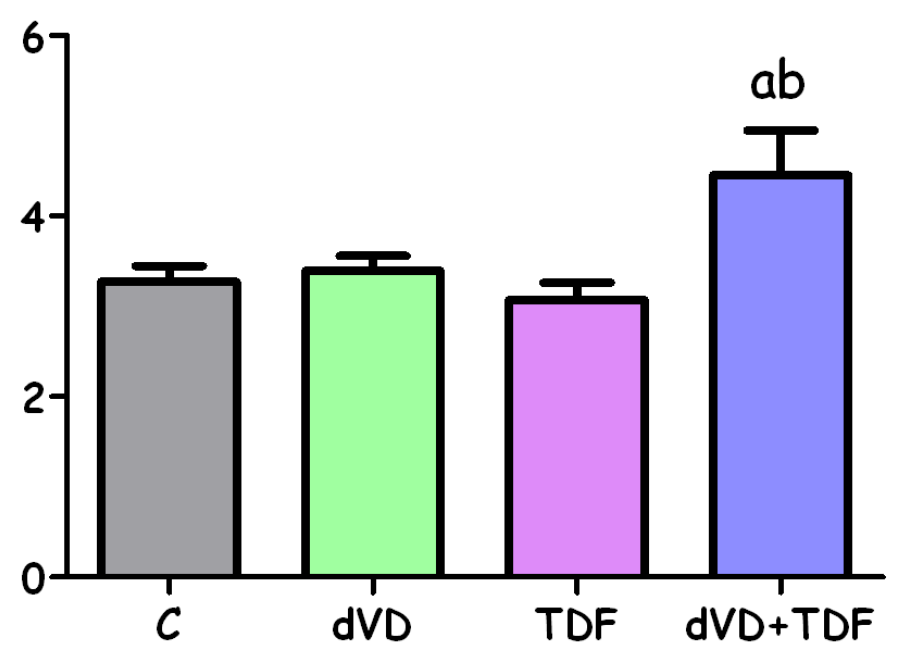

Figura 12 - Relação da excreção urinária de potássio e sódio de ratos controles ( $C, n=11)$, deficientes em vitamina $D(d V D, n=7)$, controles que receberam Tenofovir (TDF, $n=11)$ e deficientes em vitamina $D$ que receberam Tenofovir (dVD+TDF, $n=8$ ). Valores expressos em média \pm EPM. ${ }^{a} p<0,05$ vs. $C ;{ }^{b} p<0,01$ vs. TDF. 
A análise da expressão gênica dos componentes do SRAA revelou uma tendência ao aumento de angiotensinogênio e renina de todos os animais experimentais quando comparados com os animais $\mathrm{C}$ e esse aumento foi ainda mais evidente quando avaliamos a enzima conversora de angiotensina (ECA) e o receptor AT1 subtipo a da angiotensina II. Os dados referentes à expressão gênica dos componentes do sistema renina-angiotensinaaldosterona (SRAA) estão representados na figura 13 e na tabela 5.

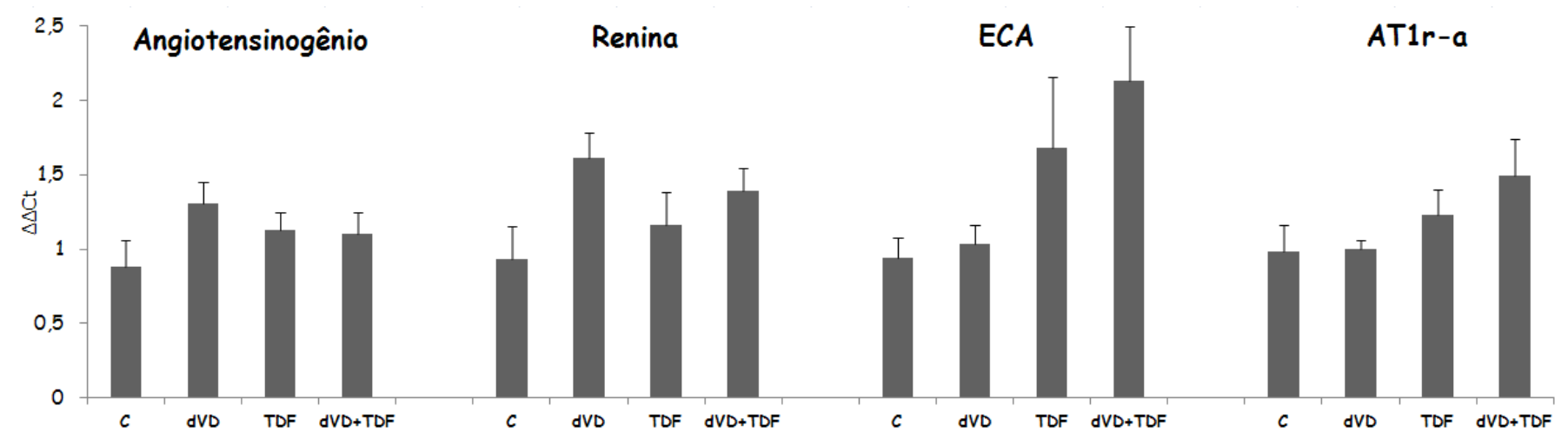

Figura 13 - Expressão gênica dos componentes do SRAA realizada pela técnica de qPCR de ratos controles (C, $n=5)$, deficientes em vitamina $D(d V D, n=6)$, controles que receberam Tenofovir (TDF, $n=5$ ) e deficientes em vitamina $D$ que receberam Tenofovir (dVD+TDF, n=6). Valores expressos em média \pm EPM.

Esses dados em conjunto confirmam a possível participação do SRAA no aumento da PAM dos animais depletados em vitamina $D$ que receberam o TDF.

As alterações no SRAA foram acompanhadas por uma vasoconstrição renal, observada pelo aumento da RVR nos grupos TDF $(24,1 \pm 0,5 \mathrm{mmHg} / \mathrm{mL} / \mathrm{min})$ e dVD+TDF $(26,9 \pm 1,0$ $\mathrm{mmHg} / \mathrm{mL} / \mathrm{min}$ ) quando comparado com o grupo $\mathrm{C}(19,8 \pm 0,4 \mathrm{mmHg} / \mathrm{mL} / \mathrm{min})$. Os animais deficientes em vitamina $D$ que receberam TDF apresentaram um aumento mais acentuado na RVR quando comparados com o grupo TDF $(26,9 \pm 1,0$ vs. $24,1 \pm 0,5 \mathrm{mmHg} / \mathrm{mL} / \mathrm{min})$. Além disso, os animais do grupo dVD+TDF mostraram uma diminuição importante da expressão proteica de eNOS comparado com os grupos C e TDF ( $60 \pm 2$ vs. $99 \pm 1,95 \pm 5 \%)$. O grupo dVD também apresentou uma redução na expressão proteica de eNOS quando comparado com os grupos C e TDF ( $65 \pm 2$ vs. $99 \pm 1,95 \pm 5 \%$ ). Referente ao $F S R$, os grupos não apresentaram 
diferenças significativas. Os resultados de PAM, FSR e RVR estão apresentados na tabela 1 e na figura 14 (RVR). A quantificação da expressão de eNOS está apresentada na tabela 4 e na figura 15.

\section{Resistência Vascular Renal}

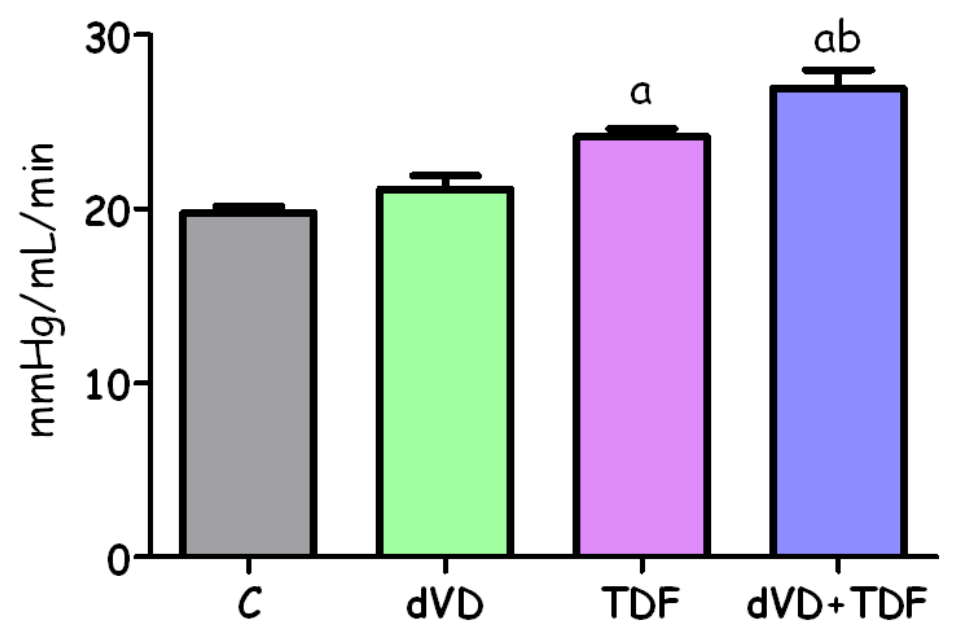

Figura 14 - Resistência vascular renal de ratos controles $(C, n=7)$, deficientes em vitamina $D(d V D, n=7)$, controles que receberam Tenofovir (TDF, $n=12$ ) e deficientes em vitamina $D$ que receberam Tenofovir $(d V D+T D F, n=7)$. Valores expressos em média \pm EPM. ${ }^{a} p<0,001 ;{ }^{b} p<0,01$ vs. TDF. 


\section{a Expressão Proteica de eNOS}

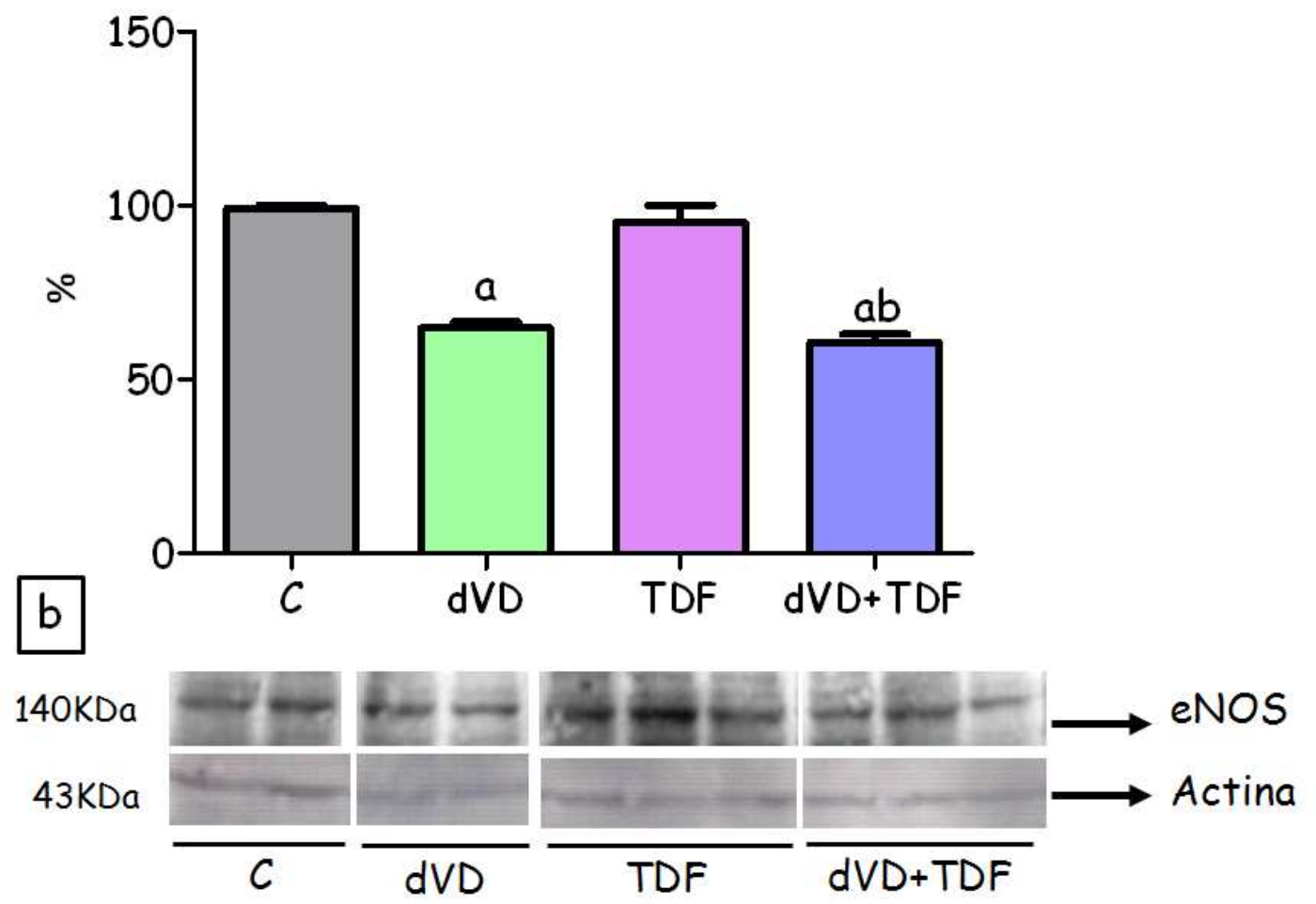

Figura 15 - Avaliação semiquantitativa da expressão proteica de e-NOS no tecido renal. (a) Densitometria das amostras de ratos controles $(C, n=4)$, deficientes em vitamina $D(d V D, n=6)$, controles que receberam Tenofovir (TDF, $n=6$ ) e deficientes em vitamina $D$ que receberam Tenofovir (dVD+TDF, $n=6)$. (b) Foto ilustrativa da expressão de e-NOS e actina no tecido renal. Valores expressos em média \pm EPM. ${ }^{a} p<0,001$ vs. $C ;{ }^{b} p<0,001$ vs. TDF. 
Os níveis plasmáticos de sódio e potássio não apresentaram alterações entre os grupos estudados. Os animais dos grupos dVD (5,03 $\pm 0,11 \mathrm{mg} / \mathrm{dL})$ e dVD+TDF $(6,29 \pm 0,39 \mathrm{mg} / \mathrm{dL})$ apresentaram uma diminuição das concentrações plasmáticas de fósforo quando comparados com o grupo $\mathrm{C}(9,38 \pm 0,40 \mathrm{mg} / \mathrm{dL})$. Entretanto, os animais do grupo TDF apresentaram uma diminuição na concentração plasmática de fósforo $(6,47 \pm 0,34 \mathrm{mg} / \mathrm{dL})$, indicando que o tratamento com TDF por si só leva a hipofosfatemia. A associação da deficiência de vitamina D e o tratamento com TDF não agravou a concentração plasmática de fósforo. Os níveis plasmáticos de cálcio iônico também foram menores nos grupos dVD $(0,94 \pm 0,05 \mathrm{mmol} / \mathrm{L})$ e dVD+TDF $(0,94 \pm 0,03 \mathrm{mmol} / \mathrm{L})$ quando comparado com os grupos $\mathrm{C}$ $(1,13 \pm 0,01 \mathrm{mmol} / \mathrm{L})$ e TDF $(1,14 \pm 0,02 \mathrm{mmol} / \mathrm{L})$. Os resultados das concentrações plasmáticas dos íons sódio, potássio, fósforo e cálcio estão representados na tabela 2 e na figura 16 (a e b).
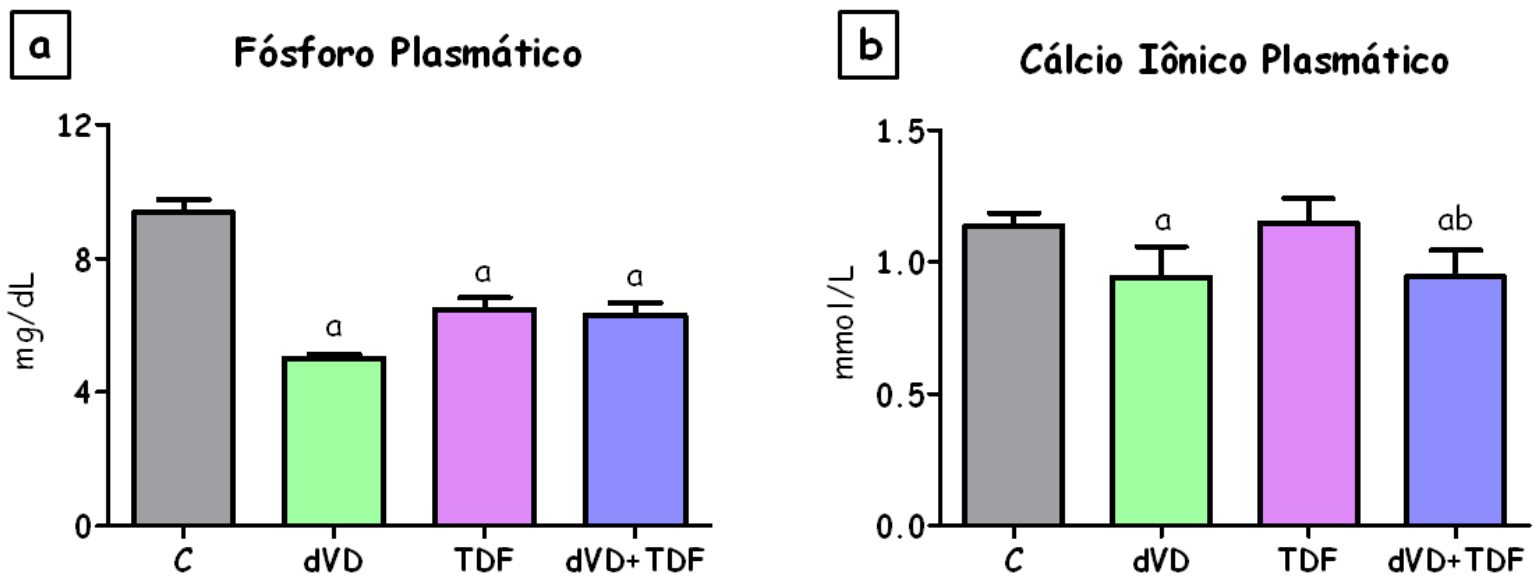

Figura 16 - Concentrações plasmáticas de fósforo (a) e de cálcio iônico (b) de ratos controles ( $C, n=7)$, deficientes em vitamina $D(d V D, n=7)$, controles que receberam Tenofovir (TDF, $n=10)$ e deficientes em vitamina $D$ que receberam Tenofovir (dVD+TDF, $n=10$ ). Valores expressos em média \pm EPM. ${ }^{a} p<0,001$ vs. $C ;{ }^{b} p<0,001$ vs. TDF. 
A excreção urinária dos íons fósforo e cálcio estão descritos na tabela 2. O tratamento com TDF levou ao comprometimento da função tubular proximal, evidenciado pelo aumento da excreção de fósforo nos animais dos grupos TDF $(18,7 \pm 0,8 \mathrm{mg} / 24 \mathrm{~h})$ e dVD+TDF $(21,5 \pm 0,7$

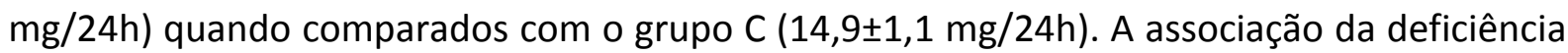
em vitamina $D$ e o tratamento com TDF agravou a função tubular quando comparado com os animais TDF $(21,5 \pm 0,7$ vs. $18,7 \pm 0,8 \mathrm{mg} / 24 \mathrm{~h})$. Corroborando esses achados, a expressão proteica de NaPi-lla no tecido renal está diminuída em aproximadamente $50 \%$ nos grupos dVD e TDF e 78\% no grupo dVD+TDF demonstrando que o aumento discreto na excreção de fósforo dos animais dVD e TDF e a hiperfosfatúria apresentada pelos animais dVD+TDF estão relacionados com o comprometimento do cotransportador sódio/fosfato. Os dados da excreção de fósforo e da expressão proteica do NaPi-lla estão representados nas tabelas 2 e 4 e nas figuras 17 e 18. Não houve diferença entre os grupos em relação à excreção de cálcio.

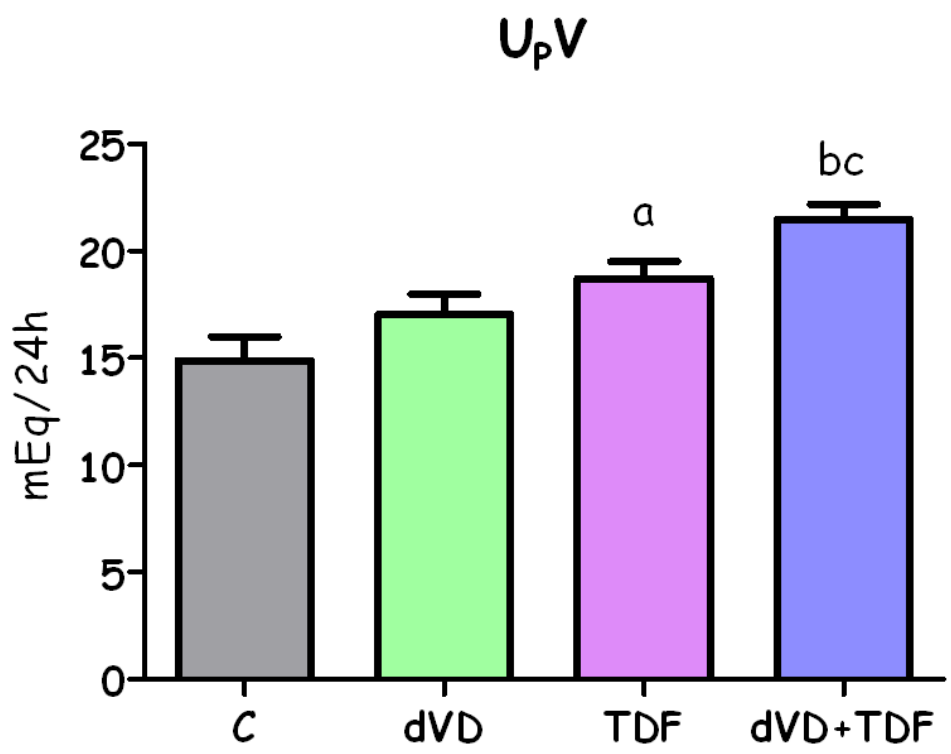

Figura 17 - Excreção urinária de fósforo de ratos controles $(C, n=8)$, deficientes em vitamina $D(d V D, n=6)$, controles que receberam Tenofovir $(T D F, n=7)$ e deficientes em vitamina $D$ que receberam Tenofovir ( $d V D+T D F$, $n=7)$. Valores expressos em média \pm EPM. ${ }^{a} p<0,05 ;{ }^{b} p<0,001$ vs. $C ;{ }^{c} p<0,05$ vs. TDF. 


\section{a Expressão Proteica de NaPi-IIa}

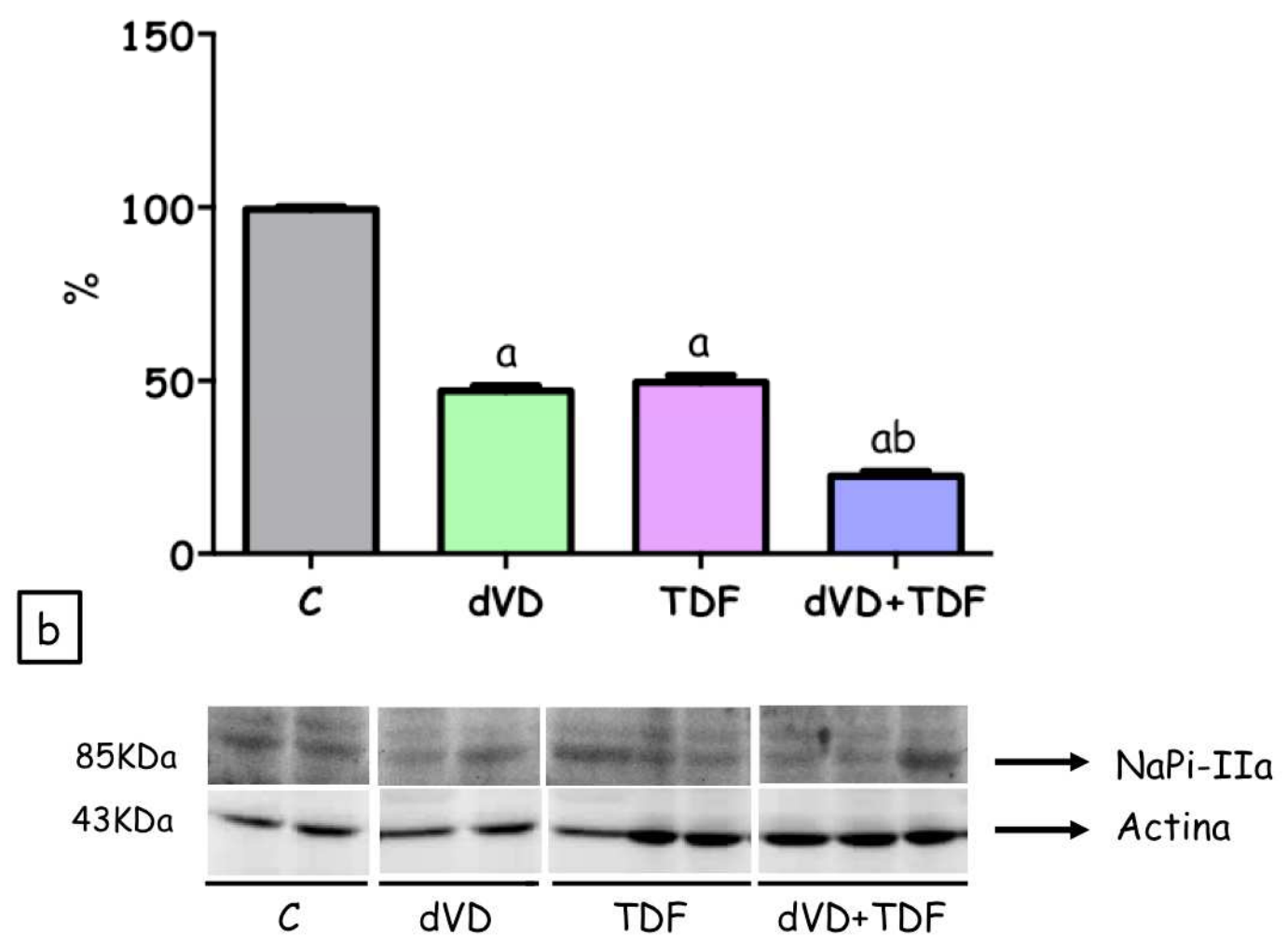

Figura 18 - Avaliação semiquantitativa da expressão proteica de NaPi-Ila no tecido renal. (a) Densitometria das amostras de ratos controles $(C, n=4)$, deficientes em vitamina $D(d V D, n=6)$, controles que receberam Tenofovir $(T D F, n=6)$ e deficientes em vitamina $D$ que receberam Tenofovir ( $d V D+T D F, n=6)$. (b) Foto ilustrativa da expressão de NaPi-lla e actina no tecido renal. Valores expressos em média \pm EPM. ${ }^{a} p<0,001$ vs. $C ;{ }^{b} p<0,001$ vs. TDF. 
Com relação à concentração de PTH plasmático, os animais do grupo dVD apresentaram

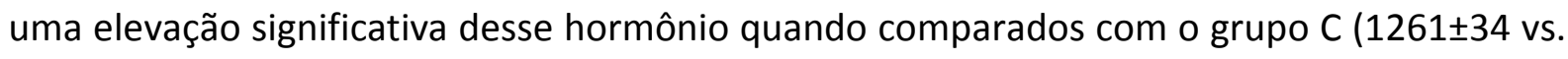
$120 \pm 11 \mathrm{pg} / \mathrm{mL}$ ). Não foi observado diferença entre os animais que receberam o TDF e os animais controle $(84 \pm 15$ vs. $120 \pm 11 \mathrm{pg} / \mathrm{mL})$. A associação da deficiência de vitamina $\mathrm{D}$ e a administração de TDF aumentou os níveis de PTH quando comparado com os grupos C e TDF ( $516 \pm 151$ vs. $120 \pm 11,83 \pm 15 \mathrm{pg} / \mathrm{mL}$ ), porém esse elevação não foi tão acentuada quando comparados com os animais do grupo dVD. Os níveis de PTH estão representados na tabela 2 e na figura 19.

\section{PTH}



Figura 19 - Níveis plasmáticos de PTH de ratos controles (C, $n=5)$, deficientes em vitamina $D(d V D, n=5)$, controles que receberam Tenofovir (TDF, $n=6)$ e deficientes em vitamina $D$ que receberam Tenofovir $(d V D+T D F, n=5)$. Valores expressos em média \pm EPM. ${ }^{a} p<0,01 ;{ }^{b} p<0,001$ vs. $C ;{ }^{c} p<0,01$ vs. TDF. 
Além do comprometimento da função renal e das alterações nos componentes do SRAA e no balanço de eletrólitos, foi observado o desenvolvimento de síndrome metabólica, evidenciada pelo aumento dos níveis de colesterol total e triglicérides. Os animais do grupo TDF apresentaram um aumento nos níveis de colesterol total $(54 \pm 3 \mathrm{mg} / \mathrm{dL})$ e triglicérides $(59 \pm 9 \mathrm{mg} / \mathrm{dL})$ quando comparado com o grupo C $(39 \pm 1 \mathrm{mg} / \mathrm{dL}$ para colesterol total e $17 \pm 4$ $\mathrm{mg} / \mathrm{dL}$ para triglicérides). A associação da deficiência em vitamina $D$ com o tratamento com TDF agravou os níveis de colesterol total quando comparado com os grupos C, dVD e TDF ( $80 \pm 7$ vs. $39 \pm 1,53 \pm 4,54 \pm 3 \mathrm{mg} / \mathrm{dL}$ ). Referente aos níveis de triglicérides, os animais do grupo dVD+TDF também apresentaram uma elevação mais acentuada quando comparado com os grupos C e dVD (74 \pm 13 vs. $17 \pm 4,34 \pm 5 \mathrm{mg} / \mathrm{dL})$. Além disso, os animais deficientes em vitamina $D$ apresentaram um aumento importante nos níveis de colesterol total $(53 \pm 4$ $\mathrm{mg} / \mathrm{dL}$ ) e uma elevação nos níveis de triglicérides $(34 \pm 5 \mathrm{mg} / \mathrm{dL}$ ) quando comparado com o grupo C $(39 \pm 1 \mathrm{mg} / \mathrm{dL}$ para colesterol total e $17 \pm 4 \mathrm{mg} / \mathrm{dL}$ para triglicérides). Os dados referentes ao perfil lipídico estão representados na tabela 2 e na figura 20 (a e b).
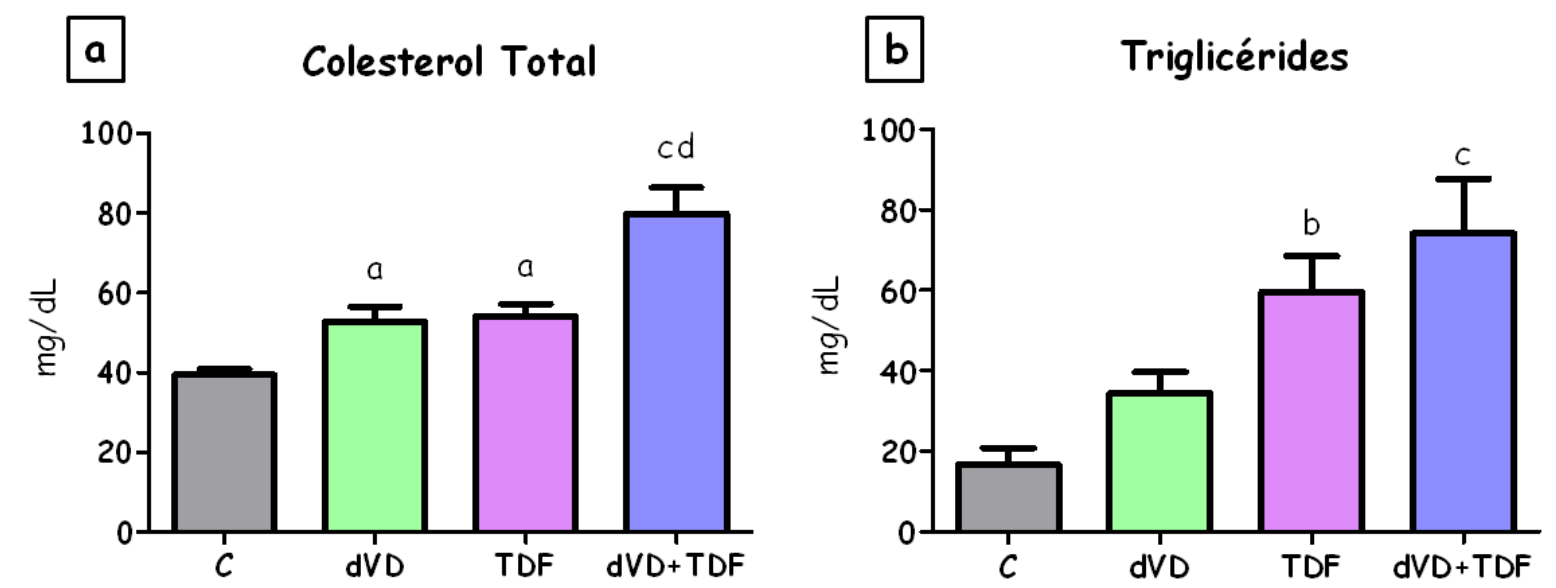

Figura 20 - Níveis plasmáticos de colesterol total (a) e de triglicérides (b) de ratos controles (C, $n=8$ ), deficientes em vitamina $D(d V D, n=7)$, controles que receberam Tenofovir (TDF, $n=11)$ e deficientes em vitamina $D$ que receberam Tenofovir (dVD+TDF. $\mathrm{N}=10$ ). Valores expressos em média $\pm \mathrm{EPM}$. ${ }^{a} p<0,05 ;{ }^{b} p<0,01 ;{ }^{c} p<0,001$ vs. $\mathrm{C}$; ${ }^{d} p<0,001$ vs. TDF. 
Os resultados dos estudos de estresse oxidativo estão representados na tabela 3 e nas figuras 21 ( $a$ e b) e 22. A concentração plasmática de TBARS estava aumentada no grupo TDF quando comparado com o grupo $\mathrm{C}(2,38 \pm 0,19$ vs. $1,60 \pm 0,07 \mathrm{nmol} / \mathrm{mL})$. Os animais do grupo dVD+TDF apresentaram uma elevação mais acentuada na concentração plasmática de TBARS quando comparado com o grupo TDF $(3,26 \pm 0,23$ vs. $2,38 \pm 0,19 \mathrm{nmol} / \mathrm{mL})$. Padrão semelhante foi observado na excreção urinária de TBARS, os animais TDF apresentaram

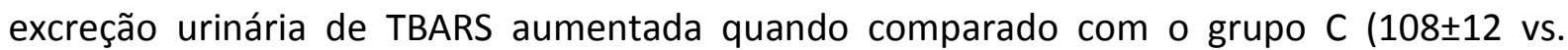
$70 \pm 11 \mathrm{nmol} / 24 \mathrm{~h})$ e esse aumento foi ainda maior nos animais do grupo dVD+TDF (164 \pm 9 $\mathrm{nmmol} / 24 \mathrm{~h}$ ). Os animais deficientes em vitamina $\mathrm{D}$ também apresentaram um aumento na

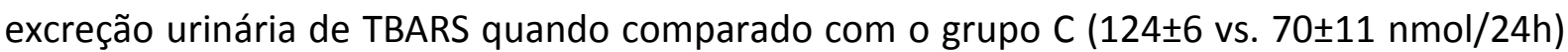
provavelmente devido ao papel da vitamina $D$ na modulação dos mecanismos de estresse oxidativo. Esses resultados sugerem que o tratamento com TDF aumentou a peroxidação lipídica e a deficiência em vitamina $D$ exacerbou os danos relacionados com o estresse oxidativo causados pelo TDF.
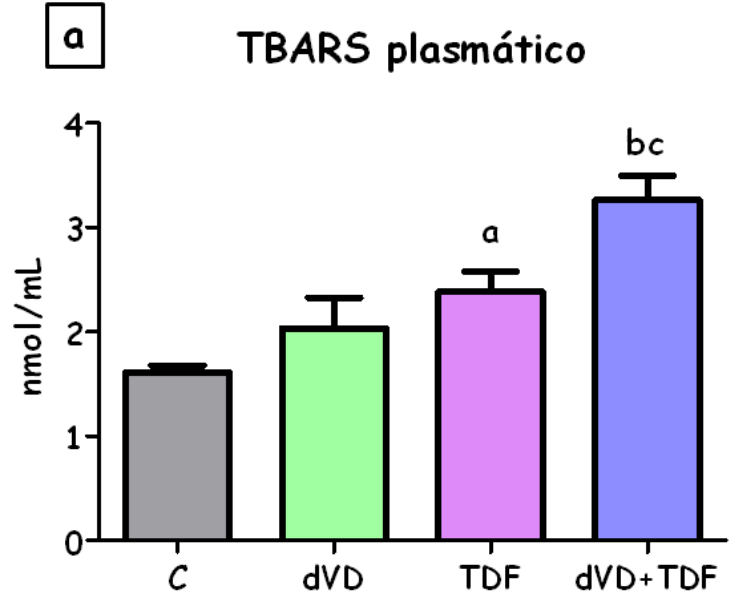

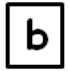

TBARS urinário

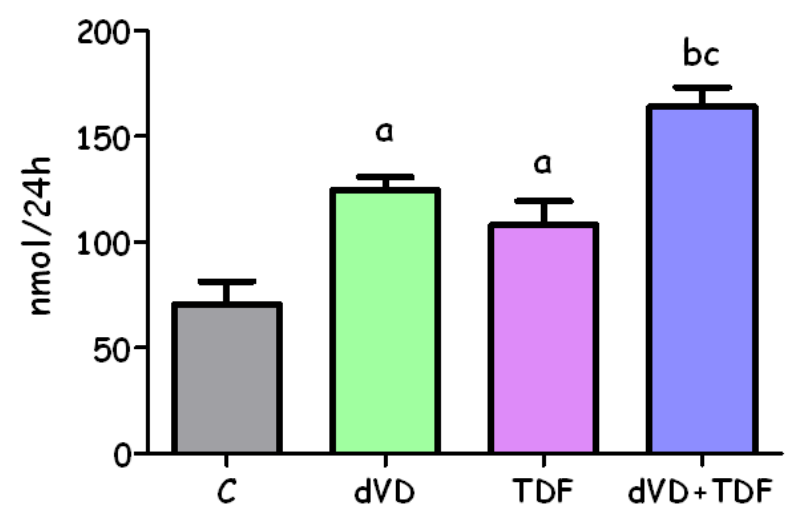

Figura 21 - Concentração plasmática de TBARS (a) e excreção urinária de TBARS (b) de ratos controles (C, $n=8)$, deficientes em vitamina $D(d V D, n=6)$, controles que receberam Tenofovir (TDF, $n=9$ ) e deficientes em vitamina $D$ que receberam Tenofovir ( $d V D+T D F, n=8$ ). Valores expressos em média $\pm E P M .{ }^{a} p<0,05 ;{ }^{b} p<0,001$ vs. $C ;{ }^{c} p<0,01$ vs. TDF. 


\section{TBARS no Tecido Renal}

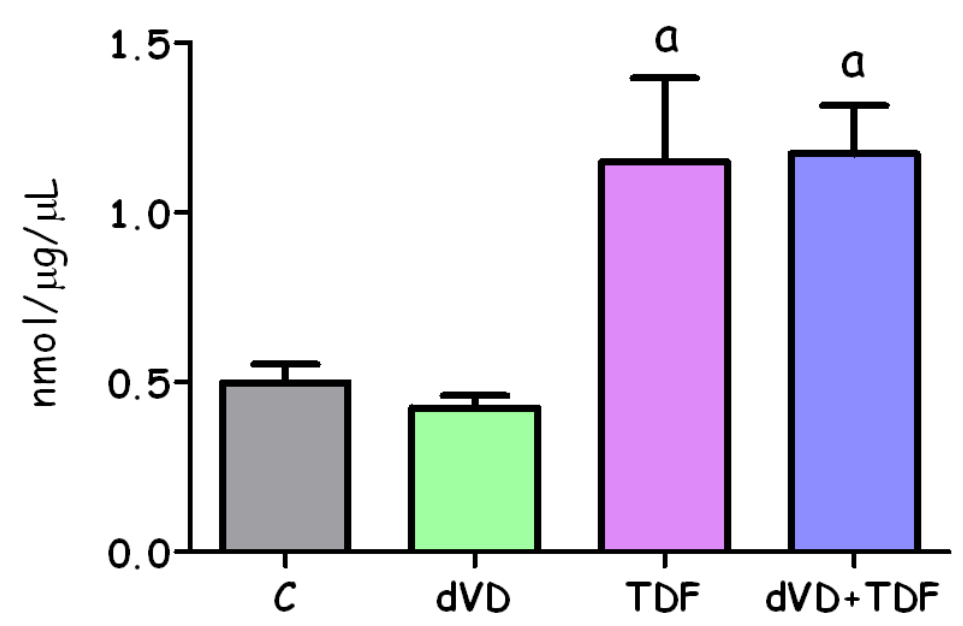

Figura 22 - Concentração de TBARS no tecido renal de ratos controles $(C, n=5)$, deficientes em vitamina $D$ (dVD, $n=6)$, controles que receberam Tenofovir (TDF, $n=6)$ e deficientes em vitamina $D$ que receberam Tenofovir ( $d V D+T D F, n=7)$. Valores expressos em média \pm EPM. ${ }^{a} p<0,05$ vs. $C$.

Outro marcador para avaliar o estado redox é a glutationa (GSH), um dos principais agentes antioxidantes intracelulares. Os animais dos grupos dVD $(2,05 \pm 0,04 \mu \mathrm{mol} / \mathrm{mL})$ e TDF $(2,26 \pm 0,22 \mu \mathrm{mol} / \mathrm{mL})$ apresentaram uma diminuição da concentração de glutationa quando comparados com o grupo $C(2,90 \pm 0,22 \mu \mathrm{mol} / \mathrm{mL})$. A associação da deficiência em vitamina $D$ com o tratamento com TDF $(1,45 \pm 0,12 \mu \mathrm{mol} / \mathrm{mL})$ reduziu mais acentuadamente a concentração de glutationa quando comparado com os grupos $C(2,90 \pm 0,22 \mu \mathrm{mol} / \mathrm{mL}), \mathrm{dVD}$ $(2,05 \pm 0,04 \mu \mathrm{mol} / \mathrm{mL})$ e $\operatorname{TDF}(2,26 \pm 0,22 \mu \mathrm{mol} / \mathrm{mL})$. Esses resultados corroboram os dados apresentados anteriormente referentes ao estresse oxidativo. A tabela 3 e a figura 23 mostram os dados da concentração de glutationa. 


\section{GSH}

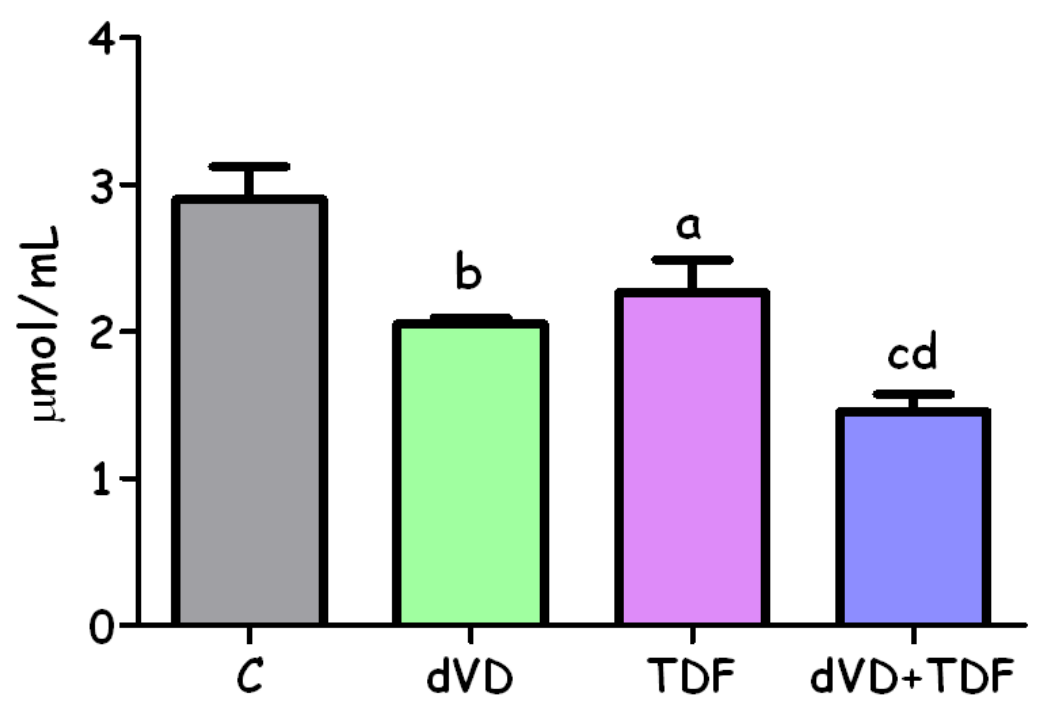

Figura 23 - Nível de glutationa de ratos controles $(C, n=5)$, deficientes em vitamina $D(d V D, n=5)$, controles que receberam Tenofovir (TDF, $n=5$ ) e deficientes em vitamina $D$ que receberam Tenofovir ( $d V D+T D F, n=5)$. Valores expressos em média \pm EPM. ${ }^{a} p<0,05 ;{ }^{b} p<0,01 ;{ }^{c} p<0,001$ vs. $C ;{ }^{d} p<0,01$ vs. TDF. 


\section{DISCUSSÃO}

A deficiência ou insuficiência de vitamina $D$ tem aumentado nos últimos anos alcançando 73\% do total de pacientes infectados pelo HIV e está associada com a progressão e as complicações da doença $[25,26,53]$. O tratamento com TDF levou a injúria renal, lesão tubular, hipertensão, estresse oxidativo e alteração do perfil lipídico. Nosso trabalho demonstrou que a deficiência de vitamina $\mathrm{D}$ agravou a nefrotoxicidade induzida pelo TDF.

\subsection{O agravamento da injúria renal induzida pelo TDF está associado com a deficiência de vitamina $D$}

Nosso estudo demonstrou que animais deficientes em vitamina $D$ tratados com TDF apresentaram comprometimento da função renal mais grave, evidenciado pela maior queda da taxa de filtração glomerular, hiperfosfatúria, proteinúria e o aparecimento de lesão tubular discreta. Scherzer et al [54] mostraram que o uso de TDF está associado ao aumento de proteinúria e da doença renal crônica e que a nefrotoxicidade induzida pelo TDF pode decorrer do acúmulo da droga nos túbulos proximais devido ao aumento da atividade do transportador aniônico orgânico 1 (OAT-1) ou diminuição da atividade de transporte da Multidrug Resistance-Associated Protein (MRP), acarretando lesão e depleção mitocondrial.

Por outro lado, a deficiência de vitamina D por si só está associada ao aumento da prevalência de proteinúria em adultos. Entretanto, os mecanismos pelos quais a proteinúria leva a redução dos níveis de vitamina $D$ ou vice-versa ainda não estão totalmente esclarecidos $[55,56]$. A vitamina $D$ tem um papel importante na imunomodulação e está envolvida tanto na imunidade inata quanto na adaptativa [57]. Zehnder et al [58] reportaram que a vitamina $D$ atenua a inflamação nas células epiteliais do túbulo proximal pela supressão da síntese da Monocyte Chemoattractant Protein-1 (MCP-1) em indivíduos com doença renal. Além disso, a vitamina $D$ também interfere na transição epitélio-mesenquimal, que é seguida de fibrose tubular intersticial contribuindo para a progressão da nefropatia associada ao HIV [59]. Outro possível mecanismo seria que essa vitamina é conhecida como um regulador endócrino negativo do SRAA, que possui um papel importante no 
desenvolvimento da doença renal. Li et al [60] demonstraram que camundongos knock-out para o receptor da vitamina $D(V D R)$ apresentam aumento nos níveis de renina e angiotensina II levando a hipertensão e aumento no consumo de água. Além disso, níveis baixos de vitamina $\mathrm{D}$ induzem a perda de podócitos e ao desenvolvimento de esclerose glomerular por meio de efeitos celulares diretos, comprometendo a integridade da barreira de filtração glomerular [39,61].

As lesões tubulares observadas em nosso estudo, embora discretas e com padrão focal possivelmente devido ao tempo curto de administração do TDF, corroboram muitos estudos clínicos [24,62] descritos na literatura. Rodriguez-Novoa et al [63] reportaram que, em modelos animais, o TDF pode induzir a uma diminuição da regulação de genes que codificam proteínas transportadoras envolvidas na excreção de muitos componentes, entre eles o sódio e o fosfato. A alteração na expressão desses transportadores de membrana provavelmente é responsável pela hiperfosfatúria/hipofosfatemia apresentada pelos animais que receberam o TDF e possivelmente contribuem para o agravamento da disfunção/lesão tubular.

\subsection{Hipertensão, participação do sistema renina-angiotensina-aldosterona e envolvimento da cascata do óxido nítrico na nefrotoxicidade induzida pelo TDF associada à deficiência em vitamina D}

Neste estudo, os animais deficientes em vitamina D que receberam TDF apresentaram um aumento importante na PAM. Essa alteração foi acompanhada de um aumento na expressão proteica de angiotensinogênio/angiotensina I e II e no seu receptor (AT1) e na expressão tecidual de angiotensina II. Corroborando esses achados, as expressões gênicas de parte dos componentes do SRAA também apresentaram uma tendência ao aumento. Além disso, foi demonstrada uma elevação na concentração de aldosterona plasmática.

O SRAA tem um papel importante na regulação da pressão sanguínea e na homeostase de sódio e água [64,65]. O néfron possui todos os componentes do SRAA: o angiotensinogênio ( $A G T$ ) sintetizado no túbulo proximal, a renina produzida pelo aparelho 
justaglomerular e túbulo distal, a enzima conversora de angiotensina (ECA) e os receptores de angiotensina II localizados ao longo do néfron [66]. A angiotensina II é o componente efetor chave do SRAA e é responsável pelas diversas respostas fisiológicas que influenciam no balanço de eletrólitos, no volume extracelular e na pressão sanguínea. Estudos indicam que a All estimula a reabsorção de sódio no túbulo proximal devido ao aumento da atividade do trocador $\mathrm{Na} / \mathrm{H}$ (NHE3) e a ativação do eixo renina-angiotensina leva ao aumento de aldosterona, que é a responsável pela estimulação dos canais epiteliais de sódio (ENaC) localizados no túbulo coletor [67-70].

Sendo assim, é possível especular que a hipertensão mais grave observada no grupo dVD+TDF possa estar relacionada com a elevação da expressão de angiotensina II e do seu receptor no tecido renal, estimulando a ação da aldosterona. É importante ressaltar que os animais deficientes em vitamina D que receberam o TDF apresentaram um aumento na relação das concentrações urinárias de potássio e sódio $\left(U_{K} / U_{\mathrm{Na}}\right)$ consequente ao maior nível plasmático de aldosterona observado neste grupo [71]. Esse hormônio estimula a atividade da $\mathrm{Na} / \mathrm{K}$ ATPase na membrana basolateral e a expressão do ENaC na membrana luminal. Isso facilita ainda mais a reabsorção de sódio, aumentando a eletronegatividade luminal, o que favorece a maior secreção de potássio, corroborando a elevação da relação $U_{K} / U_{N a}$.

Outro estudo relatou que o nível sérico de $1,25(\mathrm{OH})_{2} \mathrm{D}_{3}$ está inversamente associado com a pressão sanguínea em indivíduos normotensos e hipertensos e essa mesma relação também está presente entre o nível de $1,25(\mathrm{OH})_{2} \mathrm{D}_{3}$ circulante e a atividade de renina plasmática em pacientes com hipertensão essencial sugerindo que um distúrbio na via de sinalização da vitamina D pode levar a uma estimulação da síntese de renina e, consequentemente, a um aumento da angiotensina II [72]. Tomados em conjunto, essas linhas de evidências podem explicar o agravamento da hipertensão encontrada nos animais deficientes em vitamina $D$ que receberam TDF.

É conhecido que o estresse oxidativo também está envolvido no desenvolvimento da hipertensão. O estresse oxidativo pode ser resultado do excesso de radicais livres, da diminuição de antioxidantes ou da combinação de ambos. A angiotensina II induz o estresse oxidativo através da ativação da NADPH oxidase, responsável pela geração de superóxidos. 
Os superóxidos, espécies reativas de oxigênio (ROS), podem oxidar proteínas e DNA, promovendo a peroxidação lipídica na membrana vascular [73].

Nossos resultados demonstraram que animais deficientes em vitamina $D$ tratados com TDF apresentaram hipertensão acompanhada do aumento da RVR e da diminuição da expressão proteica renal de eNOS, sugerindo um possível envolvimento da cascata do óxido nítrico (NO). É importante mencionar que os animais tratados com uma dose alta de TDF (300 mg/kg de dieta) apresentaram uma redução de 60\% na expressão proteica de eNOS comparado com o grupo controle, demonstrando que altas doses de TDF por si só interfere na cascata do NO [13]. No rim, a eNOS é a principal isoforma da NOS responsável pela produção de NO nas células renais epiteliais e endoteliais [74].

O NO é um potente vasodilator que modula o tônus vascular e a função renal mantendo o balanço de sódio e o volume extracelular. A concentração elevada de angiotensina II ou o aumento progressivo da pressão arterial podem levar a um estresse no endotélio vascular e estimular a atividade da NOS por meio de mecanismos dependentes da concentração intracelular de cálcio. Consequentemente, o aumento da síntese de NO compensatório pode contrabalancear parcialmente as ações vasoconstritoras mediadas pela angiotensina II, preservando a hemodinâmica renal [75]. Andrukhova et al [76] reportaram que camundongos mutantes para o gene VDR apresentam menor biodisponibilidade de NO devido a redução da expressão de eNOS levando a disfunção endotelial e comprometimento da pressão arterial sistólica independentes de alterações no SRAA. Além disso, esses autores demonstraram que a 1,25(OH2)D3 é um regulador transcripcional direto da eNOS. Sendo assim, é possível que a diminuição da expressão proteica de eNOS observada nos animais deficientes em vitamina $D$ associado com o aumento da angiotensina II e a impossibilidade de balanço no eixo NO-SRA tenha agravado a hipertensão observada no grupo dVD+TDF. 


\subsection{O papel do paratormônio e da deficiência de vitamina D no metabolismo de cálcio e fósforo associado à administração de TDF}

Nosso estudo demonstrou que os animais do grupo dVD apresentaram hipofosfatemia, hipocalcemia e aumento nos níveis de PTH plasmático. Essas alterações já eram esperadas uma vez que a carência de vitamina $D$ diminui a absorção intestinal de cálcio levando a hipocalcemia e a estimulação da produção de PTH pelas paratireoides. O PTH, por sua vez, age no tecido ósseo a fim de atenuar a queda da calcemia e aumenta a excreção de fósforo. Como consequência desse evento, os níveis plasmáticos de fósforo diminuem. A associação da deficiência de vitamina $D$ e a administração de TDF não agravou os níveis plasmáticos de cálcio e fósforo.

\subsubsection{Fosfatúria e expressão do cotransportador sódio/fosfato}

O tratamento com TDF levou a lesão tubular proximal, evidenciado pelo aumento da excreção de fósforo e diminuição da expressão proteica renal do cotransportador NaPi-lla, demonstrando que o desenvolvimento da hiperfosfatúria, maior causa da hipofosfatemia, é devido a um comprometimento nesse cotransportador. O NaPi-lla está localizado no túbulo proximal e é responsável por aproximadamente $80 \%$ da reabsorção de fósforo ao longo do néfron. Esses achados corroboram os dados demonstrados previamente pelo nosso grupo [13]. A combinação da deficiência de vitamina D e o tratamento com TDF agravou essas alterações tubulares. Kurnik et al [77] mostraram que o tratamento com $1,25(\mathrm{OH})_{2} \mathrm{D}_{3}$ diminui a excreção e a fração de excreção de fósforo de ratos parcialmente depletados de vitamina D independentemente de mudanças no fosfato, cálcio e PTH plasmáticos, indicando que a $1,25(\mathrm{OH})_{2} \mathrm{D}_{3}$ possui um papel fisiológico estimulatório no transporte renal de fósforo. 


\subsubsection{Paratormônio na deficiência de vitamina $D$ e tratamento com TDF}

Referente aos níveis de PTH, os animais deficientes em vitamina D apresentaram um aumento deste hormônio corroborando estudos prévios que demonstram uma relação entre níveis elevados de PTH e concentrações baixas de vitamina D [78]. É conhecido que tanto a vitamina D quanto o cálcio são potentes reguladores do PTH, indicando que, possivelmente, a hipocalcemia e a hipovitaminose $D$ associadas à discreta queda de função renal observada nos animais do grupo dVD sejam as responsáveis pelo aumento do PTH a fim de restaurar esses parâmetros na doença renal [79]. A administração de TDF não alterou os níveis de PTH nos animais com níveis normais de vitamina $D$, porém um aumento deste hormônio foi observado nos animais deficientes em vitamina D. A hiperfosfatúria observada nos animais que receberam TDF pode ser um fator importante na regulação do complexo PTH/1,25(OH) 2 D/cálcio.

Conforme mencionado anteriormente, a resposta fisiológica à deficiência de vitamina $D$ é o aumento da estimulação de PTH com consequente redução na reabsorção de fósforo renal. Dessa forma, a perda urinária de fósforo induzida pelo TDF é mascarada pela deficiência de vitamina $D$ e apenas se torna aparente quando a vitamina $D$ retorna ao nível adequado, quando a excreção de fósforo é considerada fisiologicamente inapropriada diminuindo os níveis de PTH a fim de normalizar a fosfatúria [80]. Estudos clínicos mostram que concentrações elevadas de PTH são encontradas em indivíduos deficientes em vitamina D que usam TDF $[81,82]$ e que não há alteração do PTH em pacientes com níveis normais de vitamina D que desenvolveram síndrome de Fanconi [83].

\subsection{Síndrome metabólica associada ao tratamento com TDF e a deficiência em vitamina D}

Neste estudo, os animais que receberam TDF apresentaram um aumento nos parâmetros relacionados ao perfil lipídico que foi agravado com a deficiência de vitamina $D$, sugerindo que tanto o TDF quanto a vitamina $D$ têm um papel importante na homeostase metabólica e no desenvolvimento de dislipidemias. Gagnon et al [84] demonstraram que os 
níveis de vitamina D são inversamente proporcionais ao aparecimento de síndrome metabólica. Corroborando os dados apresentados, outro estudo realizado em camundongos com diabetes mellitus tipos 1 e 2 tratados com doxercalciferol demonstrou que esse análogo da vitamina D aumentou a expressão gênica renal de VDR e a ativação desse receptor levou a redução no acúmulo de triglicérides e colesterol. A análise das vias do metabolismo de lipídios no rim indica que a diminuição de triglicérides é mediada pela vitamina $D$ e acontece por meio de diferentes mecanismos: (a) a diminuição da síntese de ácidos graxos; (b) aumento da oxidação de ácidos e (c) a diminuição da captação de ácidos graxos. A redução nos níveis de colesterol pode ser atribuída à diminuição da síntese e captação de colesterol e a redução do receptor LDL [85]. Além disso, a dislipidemia é uma complicação muito prevalente em pacientes infectados com o HIV após a terapia antirretroviral $[86,87]$.

\subsection{Aumento do estresse oxidativo está associado à injúria renal e às alterações renovasculares}

A associação da deficiência de vitamina D e o tratamento com TDF levou a um aumento da peroxidação lipídica e a diminuição do principal antioxidante intracelular, observado pela elevação do TBARS e redução dos níveis de GSH respectivamente, mostrando a influência do estresse oxidativo no desenvolvimento da lesão renal e no aparecimento da hipertensão. Borges-Santos et al [88] demonstraram que indivíduos infectados com o HIV apresentam um déficit deste antioxidante, evidenciado pelo aumento nos níveis de glutationa oxidada (GSSG), contribuindo para a progressão da doença. Além disso, existem muitos estudos que mostram os efeitos indiretos da vitamina D na proteção contra o estresse oxidativo. Tarcin et al [89] mostraram uma correlação negativa entre os níveis de 25(OH)D e TBARS em pacientes deficientes em vitamina $D$ e o efeito protetor dessa vitamina na função endotelial. Outros estudos experimentais demonstraram que o tratamento com calcitriol aumentou a expressão de VDR e reduziu os níveis de malondialdeído, substância formada quando há lesão por estresse oxidativo [90].

Com relação à função endotelial, o tratamento com calcitriol protege a função renovascular na hipertensão. $O$ efeito protetor da vitamina $D$ provavelmente é mediado pela 
ativação do VDR levando a diminuição da expressão de AT1r e NAD(P)H e ao aumento na expressão de SOD-1 e SOD-2. A combinação desses fatores, por sua vez, previne a produção excessiva de espécies reativas de oxigênio (ROS), que são marcadores de lesão por estresse oxidativo [91].

Nossos resultados demonstram que a deficiência de vitamina D agrava a nefrotoxicidade induzida pelo TDF através do comprometimento do estado redox e da função renal, demonstrando que a vitamina $D$ tem um papel fundamental no desenvolvimento e progressão das doenças renais e cardiovasculares em indivíduos infectados com o HIV. Dessa forma, é importante o monitoramento dos níveis de vitamina $D$ em pacientes infectados com o HIV tratados com TDF. A análise dos mecanismos pelos quais a vitamina D agrava a nefrotoxicidade induzida pelo TDF ainda não foram completamente esclarecidos e deve ser estudado mais profundamente. 


\section{CONCLUSÃO}

A partir do estudo realizado podemos concluir que a deficiência de vitamina $D$ agrava os efeitos renovasculares e a nefrotoxicidade induzida por TDF, pelo menos em parte, devido à participação do sistema renina-angiotensina-aldosterona e ao aumento do estresse oxidativo. Portanto, é essencial monitorar os níveis de vitamina $D$ em pacientes infectados com o HIV tratados com TDF. 


\section{ANEXOS}

\subsection{Tabelas}

Tabela 1 - Peso corporal, parâmetros funcionais e hemodinâmicos

\begin{tabular}{|c|c|c|c|c|}
\hline & C & dVD & TDF & dVD+TDF \\
\hline PC & $498 \pm 12$ & $476 \pm 7$ & $461 \pm 5$ & $463 \pm 13$ \\
\hline$C_{\ln }$ & $0,88 \pm 0,04$ & $0,61 \pm 0,06^{b}$ & $0,63 \pm 0,04^{c}$ & $0,45 \pm 0,04^{c, d}$ \\
\hline PAM & $117 \pm 3$ & $127 \pm 4$ & $134 \pm 2^{b}$ & $148 \pm 5^{c, e}$ \\
\hline FSR & $5,58 \pm 0,03$ & $5,82 \pm 0,04$ & $5,59 \pm 0,05$ & $5,72 \pm 0,08$ \\
\hline RVR & $19,8 \pm 0,4$ & $21,1 \pm 0,8$ & $24,1 \pm 0,5^{c}$ & $26,9 \pm 1,0^{c, e}$ \\
\hline
\end{tabular}


Tabela 2 - Parâmetros bioquímicos

\begin{tabular}{|c|c|c|c|c|}
\hline & C & dVD & TDF & dVD+TDF \\
\hline $25(\mathrm{OH}) \mathrm{D}$ & $15,4 \pm 1,0$ & $<1,5$ (indetectável) $^{c}$ & $14,8 \pm 1,3$ & $<1,5$ (indetectável) $^{c, e}$ \\
\hline PTH & $120 \pm 11$ & $1261 \pm 33^{c}$ & $83 \pm 15$ & $516 \pm 151^{\mathrm{b}, \mathrm{e}}$ \\
\hline Aldosterona & $116 \pm 15$ & $234 \pm 46$ & $316 \pm 57^{\mathrm{a}}$ & $479 \pm 83^{c, d}$ \\
\hline $\mathrm{P}_{\mathrm{Na}}$ & $136 \pm 1$ & $139 \pm 3$ & $136 \pm 1$ & $138 \pm 1$ \\
\hline $\mathrm{P}_{\mathrm{K}}$ & $3,9 \pm 0,3$ & $4,3 \pm 0,2$ & $3,7 \pm 0,2$ & $4,1 \pm 0,2$ \\
\hline $\mathrm{P}_{\mathrm{P}}$ & $9,38 \pm 0,40$ & $5,03 \pm 0,11^{c}$ & $6,47 \pm 0,34^{c}$ & $6,29 \pm 0,39^{c}$ \\
\hline $\mathrm{P}_{\mathrm{Ca}}$ & $1,13 \pm 0,01$ & $0,94 \pm 0,05^{c}$ & $1,14 \pm 0,02$ & $0,94 \pm 0,03^{c, f}$ \\
\hline Colesterol & $39 \pm 1$ & $53 \pm 4^{a}$ & $54 \pm 3^{a}$ & $80 \pm 7^{c, f}$ \\
\hline Triglicérides & $17 \pm 4$ & $34 \pm 5$ & $59 \pm 9^{b}$ & $74 \pm 13^{c}$ \\
\hline $\mathrm{U}_{\mathrm{K}} / \mathrm{U}_{\mathrm{Na}}$ & $3,27 \pm 0,17$ & $3,39 \pm 0,16$ & $3,07 \pm 0,18$ & $4,46 \pm 0,49^{a, e}$ \\
\hline$U_{p} V$ & $14,9 \pm 1,1$ & $17,0 \pm 0,9$ & $18,7 \pm 0,8^{a}$ & $21,5 \pm 0,7^{c, d}$ \\
\hline $\mathrm{U}_{\mathrm{Ca}} \mathrm{V}$ & $0,08 \pm 0,01$ & $0,13 \pm 0,01$ & $0,11 \pm 0,02$ & $0,13 \pm 0,01$ \\
\hline $\mathrm{U}_{\text {Prot }} \mathrm{V}$ & $5,3 \pm 0,3$ & $11,3 \pm 0,8^{c}$ & $10,8 \pm 0,3^{c}$ & $11,8 \pm 0,5^{c}$ \\
\hline
\end{tabular}

25(OH)D, 25 hidroxivitamina D (ng/mL); PTH, paratormônio $(\mathrm{pg} / \mathrm{mL})$; aldosterona $(\mathrm{pg} / \mathrm{mL}) ; \mathrm{P}_{\mathrm{Na}}$, concentração sódio plasmática de $(\mathrm{mEq} / \mathrm{L}) ; \mathrm{P}_{\mathrm{K}}$, concentração plasmática de potássio $(\mathrm{mEq} / \mathrm{L}) ; \mathrm{P}_{\mathrm{p}}$, concentração plasmática de fósforo $(\mathrm{mg} / \mathrm{dL}) ; \mathrm{P}_{\mathrm{Ca}}$, concentração plasmática de cálcio $(\mathrm{mmol} / \mathrm{L}) ;$ Colesterol $(\mathrm{mg} / \mathrm{dL}) ;$ Triglicérides $(\mathrm{mg} / \mathrm{dL}) ; \mathrm{U}_{\mathrm{K}} / \mathrm{U}_{\mathrm{Na}}$, relação da excreção urinária de potássio e sódio; $U_{p} V$, excreção urinária de fósforo $(\mathrm{mg} / 24 \mathrm{~h}) ; U_{\mathrm{Ca}} \mathrm{V}$, excreção urinária de cálcio $(\mathrm{mg} / 24 \mathrm{~h}) ; \mathrm{U}_{\text {Prot }} \mathrm{V}$, excreção urinária de proteína $(\mathrm{mg} / \mathrm{dia})$. Valores expressos em média $\pm \mathrm{EPM} .{ }^{\mathrm{a}} \mathrm{p}<0,05 ;{ }^{\mathrm{b}} \mathrm{p}<$ 0,$01 ;{ }^{c} p<0,001$ vs. $C ;{ }^{d} p<0,05 ;{ }^{e} p<0,01 ;{ }^{f} p<0,001$ vs. TDF. 
Tabela 3 - Avaliação do estado redox

\begin{tabular}{|c|c|c|c|c|}
\hline & C & dVD & TDF & dVD+TDF \\
\hline TBARS $_{p}$ & $1,60 \pm 0,07$ & $2,03 \pm 0,29$ & $2,38 \pm 0,19^{a}$ & $3,26 \pm 0,23^{c, e}$ \\
\hline TBARS $_{\mathrm{u}}$ & $70 \pm 11$ & $124 \pm 6^{a}$ & $108 \pm 12^{\mathrm{a}}$ & $164 \pm 9^{c, e}$ \\
\hline TBARS $_{t}$ & $0,49 \pm 0,05$ & $0,42 \pm 0,04$ & $1,15 \pm 0,24^{a}$ & $1,17 \pm 0,14^{a}$ \\
\hline GSH & $2,90 \pm 0,22$ & $2,05 \pm 0,04^{b}$ & $2,26 \pm 0,22^{a}$ & $1,45 \pm 0,12^{\mathrm{c}, \mathrm{e}}$ \\
\hline \multirow{2}{*}{\multicolumn{5}{|c|}{$\begin{array}{l}\text { TBARS }_{p} \text {, concentração plasmática de TBARS }(\mathrm{nmol} / \mathrm{mL}) ; \text { TBARS }_{u} \text {, concentração urinária de TBARS (nmol/dia } \\
\text { concentração de TBARS no tecido renal }(\mathrm{nmol} / \mu \mathrm{g} / \mu \mathrm{L}) ; \mathrm{GSH} \text {, glutationa }(\mu \mathrm{mol} / \mathrm{mL}) \text {. Valores expressos en } \\
\text { EPM. }{ }^{a} \mathrm{p}<0,05 ;{ }^{b} p<0,01 ;{ }^{c} p<0,001 \text { vs. }{ }^{d}{ }^{d} p<0,05 ;{ }^{\mathrm{p}}<<0,01 \text { vs. TDF }\end{array}$}} \\
\hline & & & & \\
\hline & C & dVD & TDF & dVD+TDF \\
\hline eNOS & $99,0 \pm 1,0$ & $64,6 \pm 1,8^{c}$ & $95,0 \pm 5,0$ & $60,5 \pm 2,4^{c, e}$ \\
\hline $\mathrm{NaPi}$-Ila & $99,3 \pm 0,6$ & $47,0 \pm 1,5^{c}$ & $49,5 \pm 2,1^{\mathrm{c}}$ & $22,3 \pm 1,5^{c, e}$ \\
\hline Angiotensina II & $104 \pm 4$ & $201 \pm 32^{a}$ & $222 \pm 18^{a}$ & $244 \pm 26^{a}$ \\
\hline AT1r & $101 \pm 5$ & $173 \pm 26$ & $247 \pm 34^{a}$ & $359 \pm 56^{b, d}$ \\
\hline
\end{tabular}

eNOS, óxido nítrico sintase endotelial (\%); NaPi-lla, cotransportador sódio/fosfato subtipo Ila (\%); Angiotensina II (\%); AT1r, receptor AT1 da angiotensina II (\%). Valores expressos em média \pm EPM. ${ }^{a} p<0,05 ;{ }^{b} p<0,01 ;{ }^{c} p<0,001$ vs. C; ${ }^{d} p<0,05 ;{ }^{e} p<0,001$ vs. TDF.

Tabela 5 - Avaliação da expressão gênica dos componentes do SRAA no tecido renal

\begin{tabular}{lcccc}
\hline & C & dVD & TDF & dVD+TDF \\
\hline AGT & $0,88 \pm 0,18$ & $1,31 \pm 0,14$ & $1,13 \pm 0,12$ & $1,10 \pm 0,15$ \\
Renina & $0,93 \pm 0,22$ & $1,61 \pm 0,17$ & $1,16 \pm 0,22$ & $1,39 \pm 0,15$ \\
ECA & $0,94 \pm 0,14$ & $1,03 \pm 0,13$ & $1,68 \pm 0,48$ & $2,13 \pm 0,37$ \\
AT1a & $0,98 \pm 0,18$ & $1,00 \pm 0,06$ & $1,23 \pm 0,17$ & $1,49 \pm 0,25$ \\
\hline
\end{tabular}

AGT, angiotensinogênio $(\Delta \Delta \mathrm{Ct})$; Renina $(\Delta \Delta \mathrm{Ct})$; $\mathrm{ECA}$, enzima conversora de angiotensina $(\Delta \Delta \mathrm{Ct}) ; \mathrm{AT1}$ a, receptor $\mathrm{AT} 1$ da angiotensina II tipo a $(\Delta \Delta \mathrm{Ct})$. Valores expressos em média \pm EPM. 


\section{REFERÊNCIAS BIBLIOGRÁFICAS}

1. WHO (2009) Global Summary. WHO.

2. Triant VA, Lee H, Hadigan C, Grinspoon SK (2007) Increased acute myocardial infarction rates and cardiovascular risk factors among patients with human immunodeficiency virus disease. J Clin Endocrinol Metab 92: 2506-2512.

3. Brown TT, Qaqish RB (2006) Antiretroviral therapy and the prevalence of osteopenia and osteoporosis: a meta-analytic review. AIDS 20: 2165-2174.

4. Jao J, Wyatt CM (2010) Antiretroviral medications: adverse effects on the kidney. Adv Chronic Kidney Dis 17: 72-82.

5. Goulet JL, Fultz SL, Rimland D, Butt A, Gibert C, et al. (2007) Aging and infectious diseases: do patterns of comorbidity vary by HIV status, age, and HIV severity? Clin Infect Dis 45: 1593-1601.

6. Silva Junior GB, Liborio AB, Mota RM, Abreu KL, Silva AE, et al. (2010) Acute kidney injury in AIDS: frequency, RIFLE classification and outcome. Braz J Med Biol Res 43: 11021108.

7. Soler-Palacin P, Melendo S, Noguera-Julian A, Fortuny C, Navarro ML, et al. (2011) Prospective study of renal function in HIV-infected pediatric patients receiving tenofovir-containing HAART regimens. AIDS 25: 171-176.

8. Boyd SD (2011) Management of HIV infection in treatment-naive patients: a review of the most current recommendations. Am J Health Syst Pharm 68: 991-1001. 
9. Deeks ED, Perry CM (2010) Efavirenz/emtricitabine/tenofovir disoproxil fumarate singletablet regimen (Atripla(R)): a review of its use in the management of HIV infection. Drugs 70: 2315-2338.

10. Fernandez-Fernandez B, Montoya-Ferrer A, Sanz AB, Sanchez-Nino MD, Izquierdo MC, et al. (2011) Tenofovir nephrotoxicity: 2011 update. AIDS Res Treat 2011: 354908.

11. Gish R, Jia JD, Locarnini S, Zoulim F (2012) Selection of chronic hepatitis B therapy with high barrier to resistance. Lancet Infect Dis 12: 341-353.

12. Zhao SS, Tang LH, Dai XH, Wang W, Zhou RR, et al. (2011) Comparison of the efficacy of tenofovir and adefovir in the treatment of chronic hepatitis B: a systematic review. Virol J 8: 111.

13. Liborio AB, Andrade L, Pereira LV, Sanches TR, Shimizu MH, et al. (2008) Rosiglitazone reverses tenofovir-induced nephrotoxicity. Kidney Int 74: 910-918.

14. Fung HB, Stone EA, Piacenti FJ (2002) Tenofovir disoproxil fumarate: a nucleotide reverse transcriptase inhibitor for the treatment of HIV infection. Clin Ther 24: 1515-1548.

15. Kearney BP, Flaherty JF, Shah J (2004) Tenofovir disoproxil fumarate: clinical pharmacology and pharmacokinetics. Clin Pharmacokinet 43: 595-612.

16. Van Rompay KK, Brignolo LL, Meyer DJ, Jerome C, Tarara R, et al. (2004) Biological effects of short-term or prolonged administration of 9-[2(phosphonomethoxy)propyl]adenine (tenofovir) to newborn and infant rhesus macaques. Antimicrob Agents Chemother 48: 1469-1487.

17. FDA (2001) VIREAD (Tenofovir Disoproxil Fumarate). In: Report FaDA, editor. Background Package for NDA 
18. Woodward CL, Hall AM, Williams IG, Madge S, Copas A, et al. (2009) Tenofovir-associated renal and bone toxicity. HIV Med 10: 482-487.

19. Earle KE, Seneviratne T, Shaker J, Shoback D (2004) Fanconi's syndrome in HIV+ adults: report of three cases and literature review. J Bone Miner Res 19: 714-721.

20. Karras A, Lafaurie M, Furco A, Bourgarit A, Droz D, et al. (2003) Tenofovir-related nephrotoxicity in human immunodeficiency virus-infected patients: three cases of renal failure, Fanconi syndrome, and nephrogenic diabetes insipidus. Clin Infect Dis 36: 1070-1073.

21. Izzedine H, Launay-Vacher V, Deray G (2005) Antiviral drug-induced nephrotoxicity. Am J Kidney Dis 45: 804-817.

22. Lebrecht D, Venhoff AC, Kirschner J, Wiech T, Venhoff N, et al. (2009) Mitochondrial tubulopathy in tenofovir disoproxil fumarate-treated rats. J Acquir Immune Defic Syndr 51: 258-263.

23. Perazella MA (2010) Tenofovir-induced kidney disease: an acquired renal tubular mitochondriopathy. Kidney Int 78: 1060-1063.

24. Herlitz LC, Mohan S, Stokes MB, Radhakrishnan J, D'Agati VD, et al. (2010) Tenofovir nephrotoxicity: acute tubular necrosis with distinctive clinical, pathological, and mitochondrial abnormalities. Kidney Int 78: 1171-1177.

25. Mehta S, Giovannucci E, Mugusi FM, Spiegelman D, Aboud S, et al. (2010) Vitamin D status of HIV-infected women and its association with HIV disease progression, anemia, and mortality. PLoS One 5: e8770.

26. Sudfeld CR, Wang M, Aboud S, Giovannucci EL, Mugusi FM, et al. (2012) Vitamin D and HIV progression among Tanzanian adults initiating antiretroviral therapy. PLoS One 7: e40036. 
27. Baeke F, Gysemans C, Korf H, Mathieu C (2010) Vitamin D insufficiency: implications for the immune system. Pediatr Nephrol 25: 1597-1606.

28. Christakos S, Ajibade DV, Dhawan P, Fechner AJ, Mady LJ (2010) Vitamin D: metabolism. Endocrinol Metab Clin North Am 39: 243-253, table of contents.

29. Holick MF, Chen TC (2008) Vitamin D deficiency: a worldwide problem with health consequences. Am J Clin Nutr 87: 1080S-1086S.

30. Qazi RA, Martin KJ (2010) Vitamin D in kidney disease: pathophysiology and the utility of treatment. Endocrinol Metab Clin North Am 39: 355-363, table of contents.

31. Shroff R, Knott C, Rees $L$ (2010) The virtues of vitamin D--but how much is too much? Pediatr Nephrol 25: 1607-1620.

32. Willnow TE, Nykjaer A (2002) Pathways for kidney-specific uptake of the steroid hormone 25-hydroxyvitamin D3. Curr Opin Lipidol 13: 255-260.

33. Al-Badr W, Martin KJ (2008) Vitamin D and kidney disease. Clin J Am Soc Nephrol 3: 15551560.

34. Gutierrez O, Isakova T, Rhee E, Shah A, Holmes J, et al. (2005) Fibroblast growth factor-23 mitigates hyperphosphatemia but accentuates calcitriol deficiency in chronic kidney disease. J Am Soc Nephrol 16: 2205-2215.

35. Wong YF, Xu Q (2009) Ablation of klotho and premature aging: is 1,25-dihydroxyvitamin D the key middleman? Kidney Int 75: 1137-1139.

36. Dusso AS, Thadhani R, Slatopolsky E (2004) Vitamin D receptor and analogs. Semin Nephrol 24: 10-16. 
37. Cuppari L, Garcia Lopes MG, Kamimura MA (2011) Vitamin D biology: from the discovery to its significance in chronic kidney disease. J Ren Nutr 21: 113-116.

38. Gonzalez EA, Sachdeva A, Oliver DA, Martin KJ (2004) Vitamin D insufficiency and deficiency in chronic kidney disease. A single center observational study. Am J Nephrol 24: 503-510.

39. Li YC (2011) Podocytes as target of vitamin D. Curr Diabetes Rev 7: 35-40.

40. Ulerich L (2010) Vitamin D in chronic kidney disease--new insights. Nephrol Nurs J 37: 429-431.

41. Perwad F, Azam N, Zhang MY, Yamashita T, Tenenhouse HS, et al. (2005) Dietary and serum phosphorus regulate fibroblast growth factor 23 expression and 1,25dihydroxyvitamin D metabolism in mice. Endocrinology 146: 5358-5364.

42. Shimada T, Hasegawa H, Yamazaki Y, Muto T, Hino R, et al. (2004) FGF-23 is a potent regulator of vitamin D metabolism and phosphate homeostasis. J Bone Miner Res 19: 429-435.

43. Imanishi Y, Inaba M, Nakatsuka K, Nagasue K, Okuno S, et al. (2004) FGF-23 in patients with end-stage renal disease on hemodialysis. Kidney Int 65: 1943-1946.

44. Larsson T, Nisbeth U, Ljunggren O, Juppner H, Jonsson KB (2003) Circulating concentration of FGF-23 increases as renal function declines in patients with chronic kidney disease, but does not change in response to variation in phosphate intake in healthy volunteers. Kidney Int 64: 2272-2279.

45. Shigematsu T, Kazama JJ, Yamashita T, Fukumoto S, Hosoya T, et al. (2004) Possible involvement of circulating fibroblast growth factor 23 in the development of secondary hyperparathyroidism associated with renal insufficiency. Am J Kidney Dis 44: $250-256$. 
46. Unger MD, Cuppari L, Titan SM, Magalhaes MC, Sassaki AL, et al. (2010) Vitamin D status in a sunny country: where has the sun gone? Clin Nutr 29: 784-788.

47. Miyaji T, Kato A, Yasuda H, Fujigaki Y, Hishida A (2001) Role of the increase in p21 in cisplatin-induced acute renal failure in rats. J Am Soc Nephrol 12: 900-908.

48. Burnette WN (1981) "Western blotting": electrophoretic transfer of proteins from sodium dodecyl sulfate--polyacrylamide gels to unmodified nitrocellulose and radiographic detection with antibody and radioiodinated protein A. Anal Biochem 112: 195-203.

49. Livak KJ, Schmittgen TD (2001) Analysis of relative gene expression data using real-time quantitative PCR and the 2(-Delta Delta C(T)) Method. Methods 25: 402-408.

50. Ohkawa H, Ohishi N, Yagi K (1979) Assay for lipid peroxides in animal tissues by thiobarbituric acid reaction. Anal Biochem 95: 351-358.

51. Sedlak J, Lindsay RH (1968) Estimation of total, protein-bound, and nonprotein sulfhydryl groups in tissue with Ellman's reagent. Anal Biochem 25: 192-205.

52. Vogt BL, Richie JP, Jr. (2007) Glutathione depletion and recovery after acute ethanol administration in the aging mouse. Biochem Pharmacol 73: 1613-1621.

53. Childs K, Welz T, Samarawickrama A, Post FA (2012) Effects of vitamin D deficiency and combination antiretroviral therapy on bone in HIV-positive patients. AIDS 26: 253262.

54. Scherzer R, Estrella M, Li Y, Deeks SG, Grunfeld C, et al. (2012) Association of tenofovir exposure with kidney disease risk in HIV infection. AIDS 26: 867-875. 
55. de Boer IH, loannou GN, Kestenbaum B, Brunzell JD, Weiss NS (2007) 25-Hydroxyvitamin D levels and albuminuria in the Third National Health and Nutrition Examination Survey (NHANES III). Am J Kidney Dis 50: 69-77.

56. Lee DR, Kong JM, Cho KI, Chan L (2011) Impact of vitamin D on proteinuria, insulin resistance, and cardiovascular parameters in kidney transplant recipients. Transplant Proc 43: 3723-3729.

57. Mehta S, Mugusi FM, Spiegelman D, Villamor E, Finkelstein JL, et al. (2011) Vitamin D status and its association with morbidity including wasting and opportunistic illnesses in HIV-infected women in Tanzania. AIDS Patient Care STDS 25: 579-585.

58. Zehnder D, Quinkler M, Eardley KS, Bland R, Lepenies J, et al. (2008) Reduction of the vitamin $D$ hormonal system in kidney disease is associated with increased renal inflammation. Kidney Int 74: 1343-1353.

59. Estrella MM, Kirk GD, Mehta SH, Brown TT, Fine DM, et al. (2012) Vitamin D deficiency and persistent proteinuria among HIV-infected and uninfected injection drug users. AIDS 26: 295-302.

60. Li YC, Kong J, Wei M, Chen ZF, Liu SQ, et al. (2002) 1,25-Dihydroxyvitamin D(3) is a negative endocrine regulator of the renin-angiotensin system. J Clin Invest 110: 229238.

61. Kuhlmann A, Haas CS, Gross ML, Reulbach U, Holzinger M, et al. (2004) 1,25Dihydroxyvitamin D3 decreases podocyte loss and podocyte hypertrophy in the subtotally nephrectomized rat. Am J Physiol Renal Physiol 286: F526-533.

62. Kalyesubula R, Perazella MA (2011) Nephrotoxicity of HAART. AIDS Res Treat 2011: 562790. 
63. Rodriguez-Novoa S, Labarga P, Soriano V (2009) Pharmacogenetics of tenofovir treatment. Pharmacogenomics 10: 1675-1685.

64. Fyhrquist F, Saijonmaa O (2008) Renin-angiotensin system revisited. J Intern Med 264: 224-236.

65. Horiuchi M, Iwanami J, Mogi M (2012) Regulation of angiotensin II receptors beyond the classical pathway. Clin Sci (Lond) 123: 193-203.

66. Ramkumar N, Kohan DE (2013) Proximal tubule angiotensinogen modulation of arterial pressure. Curr Opin Nephrol Hypertens 22: 32-36.

67. McDonough AA (2010) Mechanisms of proximal tubule sodium transport regulation that link extracellular fluid volume and blood pressure. Am J Physiol Regul Integr Comp Physiol 298: R851-861.

68. Peti-Peterdi J, Warnock DG, Bell PD (2002) Angiotensin II directly stimulates ENaC activity in the cortical collecting duct via AT(1) receptors. J Am Soc Nephrol 13: 1131-1135.

69. Reilly AM, Harris PJ, Williams DA (1995) Biphasic effect of angiotensin II on intracellular sodium concentration in rat proximal tubules. Am J Physiol 269: F374-380.

70. Saccomani G, Mitchell KD, Navar LG (1990) Angiotensin II stimulation of $\mathrm{Na}(+)-\mathrm{H}+$ exchange in proximal tubule cells. Am J Physiol 258: F1188-1195.

71. Hene RJ, Koomans HA, Boer P, Roos JC, Dorhout Mees EJ (1984) Relation between plasma aldosterone concentration and renal handling of sodium and potassium, in particular in patients with chronic renal failure. Nephron 37: 94-99.

72. Li YC, Qiao G, Uskokovic M, Xiang W, Zheng W, et al. (2004) Vitamin D: a negative endocrine regulator of the renin-angiotensin system and blood pressure. J Steroid Biochem Mol Biol 89-90: 387-392. 
73. Finch JL, Suarez EB, Husain K, Ferder L, Cardema MC, et al. (2012) Effect of combining an ACE inhibitor and a VDR activator on glomerulosclerosis, proteinuria, and renal oxidative stress in uremic rats. Am J Physiol Renal Physiol 302: F141-149.

74. Herrera M, Coffman TM (2012) The kidney and hypertension: novel insights from transgenic models. Curr Opin Nephrol Hypertens 21: 171-178.

75. Navar LG, Ichihara A, Chin SY, Imig JD (2000) Nitric oxide-angiotensin II interactions in angiotensin II-dependent hypertension. Acta Physiol Scand 168: 139-147.

76. Andrukhova O, Slavic S, Zeitz U, Riesen SC, Heppelmann MS, et al. (2014) Vitamin d is a regulator of endothelial nitric oxide synthase and arterial stiffness in mice. Mol Endocrinol 28: 53-64.

77. Kurnik BR, Hruska KA (1984) Effects of 1,25-dihydroxycholecalciferol on phosphate transport in vitamin D-deprived rats. Am J Physiol 247: F177-184.

78. Masia M, Padilla S, Robledano C, Lopez N, Ramos JM, et al. (2012) Early changes in parathyroid hormone concentrations in HIV-infected patients initiating antiretroviral therapy with tenofovir. AIDS Res Hum Retroviruses 28: 242-246.

79. Garcia-Lopes MG, Pillar R, Kamimura MA, Rocha LA, Canziani ME, et al. (2012) Cholecalciferol supplementation in chronic kidney disease: restoration of vitamin D status and impact on parathyroid hormone. Ann Nutr Metab 61: 74-82.

80. Klassen K, Martineau AR, Wilkinson RJ, Cooke G, Courtney AP, et al. (2012) The effect of tenofovir on vitamin D metabolism in HIV-infected adults is dependent on sex and ethnicity. PLoS One 7: e44845.

81. Childs KE, Fishman SL, Constable C, Gutierrez JA, Wyatt CM, et al. (2010) Short communication: Inadequate vitamin D exacerbates parathyroid hormone elevations in tenofovir users. AIDS Res Hum Retroviruses 26: 855-859. 
82. Rosenvinge MM, Gedela K, Copas AJ, Wilkinson A, Sheehy CA, et al. (2010) Tenofovirlinked hyperparathyroidism is independently associated with the presence of vitamin D deficiency. J Acquir Immune Defic Syndr 54: 496-499.

83. Williams J, Chadwick DR (2006) Tenofovir-induced renal tubular dysfunction presenting with hypocalcaemia. J Infect 52: e107-108.

84. Gagnon C, Lu ZX, Magliano DJ, Dunstan DW, Shaw JE, et al. (2012) Low serum 25hydroxyvitamin $D$ is associated with increased risk of the development of the metabolic syndrome at five years: results from a national, population-based prospective study (The Australian Diabetes, Obesity and Lifestyle Study: AusDiab). J Clin Endocrinol Metab 97: 1953-1961.

85. Wang XX, Jiang T, Shen Y, Santamaria H, Solis N, et al. (2010) Vitamin D receptor agonist doxercalciferol modulates dietary fat-induced renal disease and renal lipid metabolism. Am J Physiol Renal Physiol 300: F801-810.

86. Kanjanavanit S, Puthanakit T, Vibol U, Kosalaraksa P, Hansudewechakul R, et al. (2011) High prevalence of lipid abnormalities among antiretroviral-naive HIV-infected Asian children with mild-to-moderate immunosuppression. Antivir Ther 16: 1351-1355.

87. McGee KC, Shahmanesh M, Boothby M, Nightingale P, Gathercole LL, et al. (2012) Evidence for a shift to anaerobic metabolism in adipose tissue in efavirenz-containing regimens for HIV with different nucleoside backbones. Antivir Ther 17: 495-507.

88. Borges-Santos MD, Moreto F, Pereira PC, Ming-Yu Y, Burini RC (2012) Plasma glutathione of $\mathrm{HIV}(+)$ patients responded positively and differently to dietary supplementation with cysteine or glutamine. Nutrition 28: 753-756.

89. Tarcin O, Yavuz DG, Ozben B, Telli A, Ogunc AV, et al. (2009) Effect of vitamin D deficiency and replacement on endothelial function in asymptomatic subjects. J Clin Endocrinol Metab 94: 4023-4030. 
90. Nair-Shalliker V, Armstrong BK, Fenech M (2012) Does vitamin D protect against DNA damage? Mutat Res 733: 50-57.

91. Dong J, Wong SL, Lau CW, Lee HK, Ng CF, et al. (2012) Calcitriol protects renovascular function in hypertension by down-regulating angiotensin II type 1 receptors and reducing oxidative stress. Eur Heart J 33: 2980-2990. 
MANUSCRITO SUBMETIDO - PLOS One 
Vitamin D Deficiency Aggravates Nephrotoxicity, Hypertension and Dyslipidemia Caused by Tenofovir: Role of Oxidative Stress and Renin-Angiotensin System

Daniele Canale ${ }^{1}$, Ana Carolina de Bragança ${ }^{1}$, Janaína Garcia Gonçalves ${ }^{1}$, Maria Heloísa Massola Shimizu ${ }^{1}$, Talita Rojas Sanches ${ }^{1}$, Lúcia Andrade ${ }^{1}$, Rildo Aparecido Volpini ${ }^{1}$ and Antonio Carlos Seguro ${ }^{1}$.

${ }^{1}$ Nephrology Department, University of São Paulo School of Medicine, São Paulo, Brazil.

Address for reprint requests and other correspondence: AC Seguro, Nephrology Dept., Univ. of São Paulo School of Medicine, Av. Dr. Arnaldo, 455, 3ํandar, sala 3310, CEP 01246903, São Paulo, Brazil (e-mail: trulu@usp.br). 


\section{Abstract}

Vitamin D deficiency (VDD) is prevalent among HIV-infected individuals. Vitamin D has been associated with renal and cardiovascular diseases because of its effects on oxidative stress, lipid metabolism and reninangiotensin-aldosterone system (RAAS). Tenofovir disoproxil fumarate (TDF), a widely used component of antiretroviral regimens for HIV treatment, can induce renal injury. The aim of this study was to investigate the effects of VDD on TDF-induced nephrotoxicity. Wistar rats were divided into four groups: control, receiving a standard diet for 60 days; VDD, receiving a vitamin D-free diet for 60 days; TDF, receiving a standard diet for 60 days with the addition of TDF (50 mg/kg food) for the last 30 days; and VDD+TDF receiving a vitamin D-free diet for 60 days with the addition of TDF for the last 30 days. TDF led to impaired renal function, hyperphosphaturia, hypophosphatemia, hypertension and increased renal vascular resistance due to downregulation of the sodium-phosphorus cotransporter and upregulation of angiotensin II and AT1 receptor. TDF also increased oxidative stress, as evidenced by higher TBARS and lower GSH levels, and induced dyslipidemia. Association of TDF and VDD aggravated renovascular effects and TDF-induced nephrotoxicity due to changes in the redox state and involvement of RAAS.

\section{Introduction}

Tenofovir disoproxil fumarate (TDF) is a nucleotide reverse transcriptase inhibitor commonly used for treatment of HIV infection and hepatitis B on the basis of its effectiveness in clinical trials $[1,2,3,4]$. However, the long-term use of TDF has been associated with hypophosphatemia, renal failure and tubular toxicity due to proximal renal tubular dysfunction [5] and enhancement of oxidative stress by disruption of mitochondrial DNA in proximal tubule cells [6]. In addition to the renal impairment caused by TDF-induced nephrotoxicity it has been recently shown that low vitamin D levels are associated with the progression of HIV-related diseases in patients receiving antiretroviral therapy $[7,8]$.

Vitamin $D$ is an essential nutrient for mineral homeostasis and bone metabolism [9]. The kidney plays a key role in vitamin D metabolism and, on the other hand, the kidney itself is a major target organ of vitamin D. Vitamin $D$ is also responsible for kidney protection and the regulation of several renal physiological activities [10]. Thus, vitamin D deficiency (VDD) $(<10 \mathrm{ng} / \mathrm{mL})$ or insufficiency $(10-30 \mathrm{ng} / \mathrm{mL})$ can accelerate the progression of kidney disease $[10,11,12,13]$.

Vitamin D has been associated with renal and cardiovascular diseases because of its effects on oxidative stress, lipid metabolism and renin-angiotensin-aldosterone system (RAAS). Tarcin et al demonstrated that vitamin D deficient individuals presented higher plasma levels of Thiobarbituric Acid Reactive Substances (TBARS) [14]. Besides the effects of VDD on oxidative stress, several studies have shown that HIV-infected patients present a deficiency of total glutathione (GSH) and its precursors [15] contributing to the aggravation of the redox state. Furthermore, several studies have shown that vitamin $D$ is a negative endocrine regulator of RAAS [16] and its concentration has been inversely associated with the prevalence of metabolic syndrome [17]. 
Given that VDD is highly prevalent among HIV-infected individuals, the aim of this study was to investigate the effects of VDD on TDF-induced nephrotoxicity, mainly focused on the role of oxidative stress and RAAS

\section{Materials and Methods}

All experimental procedures were approved by the local research ethics committee (CAPPesq, process no. 086/11) and developed in strict conformity with local institutional guidelines and with well-established international standards for manipulation and care of laboratory animals.

Animals and experimental protocol. Male Wistar rats, weighing 200-250 g, were obtained from the animal facilities of the University of São Paulo School of Medicine, housed in standard cages, and given ad libitum access to rodent chow, standard or vitamin D-free (MP Biomedicals, Irvine, CA, USA), and water. Rats were randomly allocated to the following groups: control ( $C, n=10)$, receiving a standard diet for 60 days; VDD $(n=7)$, receiving a vitamin D-free diet for 60 days; TDF $(n=10)$, receiving a standard diet for 60 days with the addition of TDF (50 mg/kg food) for the last 30 days; and VDD+TDF $(\mathrm{n}=8)$ receiving a vitamin D-free diet for 60 days with the addition of TDF (50 mg/kg food) for the last 30 days. The dose of TDF was based on a previous study from our laboratory [5] and is compatible with the dosage administered to humans.

Metabolic cage studies and analysis of urine samples. At the end of the protocol, rats were moved to metabolic cages (one rat per cage), maintained on a 12-h light/dark cycle and given free access to drinking water. The rats were acclimated to the housing conditions for 1 day before the experimental procedures, which began with the collection of 24-h urine samples. The volume of each 24-h urine sample was measured gravimetrically. Urine samples were centrifuged in aliquots to remove suspended material, and the supernatants were analyzed. Urine concentrations of sodium and potassium were determined with specific electrodes (ABL800Flex - Radiometer, Brønshøj, Denmark). Urinary potassium/sodium ratio was calculated $\left(U_{K} / U_{\mathrm{Na}}\right)$. Urine concentrations of phosphorus, calcium and protein were measured by a colorimetric system using a commercial kit (Labtest Diagnóstica - Minas Gerais, Brazil). Urinary excretions of phosphorus $\left(U_{P} V\right)$, calcium $\left(U_{\mathrm{Ca}} \mathrm{V}\right)$ and protein $\left(\mathrm{U}_{\text {Prot }} \mathrm{V}\right)$ were determined.

Hemodynamic studies. To determine glomerular filtration rate (GFR), inulin clearance studies were conducted at the end of the protocol. On the day of the experiment, the animals were anesthetized intraperitoneally with sodium pentobarbital $(50 \mathrm{mg} / \mathrm{kg}$ BW). The trachea was cannulated with a PE-240 catheter, and spontaneous breathing was maintained. To control mean arterial pressure (MAP) and allow blood sampling, a PE-60 catheter was inserted into the right carotid artery. MAP was assessed using Biopac Systems Inc MP100 (Santa Barbara, CA, USA). For the infusion of inulin and fluids, another PE-60 catheter was inserted into the left jugular vein. In order to collect urine samples, a suprapubic incision was made, and the urinary 
bladder was cannulated with a PE-240 catheter. After the surgical procedure has been completed, a loading dose of inulin (100 mg/kg BW diluted in $0.9 \%$ saline) was administered through the jugular vein. Subsequently, a constant infusion of inulin (10 mg/ $\mathrm{kg} \mathrm{BW}$ in $0.9 \%$ saline) was started and kept at $0.04 \mathrm{ml} / \mathrm{min}$ throughout the experiment. Three urine samples were collected at 30-min intervals. Blood samples were obtained at the beginning and at the end of the experiment. Blood and urine inulin were determined using the anthrone method. GFR data are expressed as $\mathrm{ml} / \mathrm{min} / 100 \mathrm{~g}$.

To measure renal blood flow (RBF), a midline incision was made. Then, we carefully dissected the left renal pedicle and isolated the renal artery, taking precautions to avoid disturbing the renal nerves. An ultrasonic flow probe was placed around the exposed renal artery. RBF was measured using an ultrasonic flowmeter (T402; Transonic Systems, Bethesda, MD, USA) and is expressed as $\mathrm{ml} / \mathrm{min}$. Renal vascular resistance (RVR) was calculated by dividing the blood pressure by RBF and is expressed as $\mathrm{mmHg} / \mathrm{ml} / \mathrm{min}$.

Evaluation of biochemical parameters. For assessment of plasma levels of 25-hydroxyvitamin D [25(OH)D], PTH, aldosterona, sodium $\left(\mathrm{P}_{\mathrm{Na}}\right)$, potassium $\left(\mathrm{P}_{\mathrm{K}}\right)$, phosphate $\left(\mathrm{P}_{\mathrm{P}}\right)$, calcium $\left(\mathrm{P}_{\mathrm{Ca}}\right)$, cholesterol and triglycerides blood samples were collected. 25(OH)D was measured by radioimmunoassay (RIA) using a commercial kit (DiaSorin , MN, USA), PTH was assessed by Enzyme-Linked Immunosorbent Assay (ELISA) using a commercial kit (Rat Bioactive Intact PTH (Immunotopics - California, USA), aldosterone was determined by radioimmunoassay (RIA) using a commercial kit (Immunotech, Marseille, FR), $P_{P}$ was evaluated by a colorimetric system using a commercial kit (Labtest Diagnóstica - Minas Gerais, Brazil) and $\mathrm{P}_{\mathrm{Na}}, \mathrm{P}_{\mathrm{K}}$ and $\mathrm{P}_{\mathrm{Ca}}$ were determined with specific electrodes (ABL800Flex - Radiometer, Brønshøj, Denmark). Cholesterol and triglycerides were evaluated by a colorimetric system using a commercial kit (Cobas C111 - Roche ${ }^{\circ}$, São Paulo, Brazil).

Tissue sample collection/preparation. At the end of the experiments, the organs were perfused with PBS solution (0.15 M NaCl and 0.01 $\mathrm{M}$ sodium phosphate buffer, $\mathrm{pH}$ 7.4). The left kidney were removed and weighed. For histological/immunohistochemical examination, a fragment of the right kidney was fixed in $10 \%$ neutral-buffered formalin solution. The kidney block was dehydrated in graded alcohol, embedded in paraffin and cut at 4- $\mu \mathrm{m}$ sections. Another fragment of the right kidney was frozen in liquid nitrogen and stored at $-80^{\circ} \mathrm{C}$ for assessment of endothelial nitric oxide syntase (eNOS), sodium-phosphate cotransporter subtype Ila (NaPi-Ila), AT1 receptor (AT1r) and angiotensinogen/angiotensin I and II (Ang) protein expression.

Light microscopy studies. Four- $\mu \mathrm{m}$ histological sections of renal tissue were stained with hematoxylineosin and examined under light microscope. For the evaluation of renal damage, 40-60 grid fields (x400 magnification) measuring $0.245 \mathrm{~mm}^{2}$ were evaluated by graded scores according to the following criteria: (0), less than $5 \%$ of the field showing tubular epithelial swelling, vacuolar degeneration, necrosis, and desquamation; (I), 5-25\% of the field presenting renal lesions; (II), involvement of $25-50 \%$ with renal damage; (III), $50-75 \%$ of damaged area; and (IV), more that $75 \%$ of the grid field presenting renal lesions. The morphometric examination was blinded to minimize observer bias, i.e. the observer was unaware of the 
treatment group from which the tissue originated. The mean score for each rat and the mean score for each group were calculated.

Immunohistochemistry studies. Four- $\mu \mathrm{m}$ sections of kidney were incubated $60 \mathrm{~min}$ at room temperature $(1 / 1,000)$ with a polyclonal primary antibody anti-angiotensin II (Santa Cruz Biotechnology). The reaction product was detected with an avidin-biotin-peroxidase complex (Vector Laboratories, Burlingame, CA). The color reaction was developed with 3,3-diaminobenzidine (Sigma), and the material was counterstained with Harris hematoxilin, dehydrated, and mounted.

Preparation of samples for the determination of eNOS, NaPi-Ila, AT1r and Ang protein expression. In order to quantify eNOS, NaPi-Ila, AT1r and Ang protein expression, kidney sections were prepared. The sections were homogenized using a Teflon pestle glass homogenizer (Schmidt and Co.) in an ice-cold isolation solution of $200 \mathrm{mM}$ mannitol, $80 \mathrm{mM}$ HEPES and $41 \mathrm{mM} \mathrm{KOH}, \mathrm{pH}$ 7.5, also containing a protease inhibitor cocktail (Sigma). The homogenates were centrifuged at a low speed $(3000 \times \mathrm{g})$ for $15 \mathrm{~min}$ at $4^{\circ} \mathrm{C}$ to remove nuclei and cell debris. The pellets were suspended in an isolation solution with protease inhibitors. Protein quantities were determined using the Bradford assay method (Bio-Rad Protein Assay kit, Bio-Rad Laboratories, Hercules, CA, USA).

Electrophoresis and immunoblotting. Kidney samples were run on $8 \%$ polyacrylamide minigels (for eNOS) or $10 \%$ polyacrylamide minigels (for NaPi-Ila, AT1r and Ang). After transfer by electroelution to nitrocellulose membranes (PolyScreen, PVDF Transfer, Life Science Products, Boston, MA, USA), blots were blocked with 5\% skin milk and 0.1\% Tween 20 in TBS for 1 hour. Blots were then incubated overnight with an anti-eNOS antibody (1:2,000), anti-NaPi-Ila antibody $(0.54 \mu \mathrm{g} / \mathrm{mL})$, anti-AT1r antibody (1:500) and anti-Ang antibody $(1: 1,000)$. The labeling was visualized with a horseradish peroxidase-conjugated secondary antibody (anti-mouse IgG diluted 1:2,000, anti-rabbit IgG, diluted 1:2,000 or anti-goat IgG diluted 1:10,000) using the enhanced chemiluminescence detection system ECL Western blotting detection reagents (GE Healthcare, Buckinghamshire, UK). The specific polyclonal antibody to NaPi-lla was kindly supplied by Dr Mark Knepper (NHLBI/NIH, Bethesda, MD, USA).The specific polyclonal antibody to eNOS was obtained from BD Transduction Laboratories (CA, USA) and specific polyclonal antibody to AT1 and angiotensin II were obtained from Santa Cruz Biotechnology (CA, USA). As a loading control, blots were incubated with an actin antibody (Santa Cruz, CA, USA; 1:2,000 with anti-goat 1:10,000)

Quantification of renal levels of eNOS, NaPi-Ila, AT1r and Ang. The images were obtained using chemiluminescence imaging system Alliance 4.2 (Uvitec, Cambridge, UK) and performed quantitative analysis of antibodies using densitometry, normalizing the bands to actin expression.

Gene expression of renin-angiotensin components. Quantitative real-time PCR (qPCR) was performed in frozen renal tissue to analyze the expression of genes deemed likely to be related to the development of 
hypertension in rats. The following genes were assessed: renin (Rn00561847_m1), angiotensinogen (AGT Rn00593114_m1), angiotensin converting enzyme (ECA - Rn00561094_m1) and angiotensin II receptor type a (AT1a - Rn02758772_s1). The extraction and preparation of total RNA were performed. For cDNA synthesis, total RNA and a Superscript ${ }^{\circledR}$ VILO $^{\text {TM }}$ MasterMix (Invitrogen Technologies, CA, USA) were employed. Real-time PCR was performed using TaqMan (Applied Biosystem, CA, USA) on Step One Plus (Applied Biosystem, CA, USA). All primers were purchased from Invitrogen Technologies. Relative gene expression values were evaluated with the $2^{-\Delta \Delta C t}$ method [19] using GAPDH as housekeeping gene.

Reactive oxygen metabolites. Urinary and plasma levels of thiobarbituric acid reactive substances (TBARS), which are markers of lipid peroxidation, were determined using the thiobarbituric acid assay. In brief, a $0.2-\mathrm{ml}$ sample was diluted in $0.8 \mathrm{ml}$ of distilled water. Immediately thereafter, $1 \mathrm{ml}$ of $17.5 \%$ trichloroacetic acid was added. Following the addition of $1 \mathrm{ml}$ of $0.6 \%$ thiobarbituric acid, $\mathrm{pH} \mathrm{2,} \mathrm{the} \mathrm{sample} \mathrm{was} \mathrm{placed} \mathrm{in} \mathrm{a}$ boiling water bath for $15 \mathrm{~min}$, after which it was allowed to cool. Subsequently, $1 \mathrm{ml}$ of $70 \%$ trichloroacetic acid was added, and the mixture was incubated for $20 \mathrm{~min}$. The sample was then centrifuged for $15 \mathrm{~min}$ at 2000 rpm. The optical density of the supernatant was read at $534 \mathrm{~nm}$ against a blank reagent using a spectrophotometer. The concentration of lipid peroxidation products was calculated as malondialdeide (MDA) equivalent using a molar extinction coefficient for the MDA-thiobarbituric acid complex of $1.56 \times 105$ $\mathrm{mol}^{-1} / \mathrm{cm}^{-1}$. Urinary and plasma levels of TBARS were expressed as $\mathrm{nM} / 24$ hours and $\mathrm{nM} / \mathrm{mL}$, respectively [20].

Renal reduced glutathione (GSH) was determined in total blood by the method of Sedlak and Lindsay [21]. Whole blood was processed by addition of four volumes of ice-cold 5\% (W/V) metaphosphoric acid (MPA) (Sigma) and centrifuged at 14,000 x $\mathrm{g}$ for $3 \mathrm{~min}$. This assay consists of reacting the supernatants of the total blood with Ellman's reagent to produce a yellow pigment measured spectrophotometrically at $412 \mathrm{~nm}$. The GSH was quantified by mean of standard curve and reported as $\mu \mathrm{mol}$ of $\mathrm{GSH} / \mathrm{mL}$ [22].

Statistical analysis. All quantitative data are expressed as mean \pm SEM. Differences among the means of multiple parameters were analyzed by one-way analysis of variance followed by the Student-Newman-Keuls test. Values of $\mathrm{P}<0.05$ were considered statistically significant.

\section{Results}

The animals were maintained on a standard or a free-vitamin D diet for 30 days. After this time, VDD animals had low levels of $25(\mathrm{OH}) \mathrm{D}(4.10 \pm 0.8 \mathrm{ng} / \mathrm{mL})$ compared to respective control animals $(14.79 \pm 0.9$ $\mathrm{ng} / \mathrm{mL}$ ), demonstrating that these animals were already deficient before treatment with TDF.

As described in Table 1, there were no significant changes in body weight among groups since all animals showed similar food ingestion during 60 days (approximately $25 \mathrm{~g} /$ day). Rats treated with TDF presented a higher blood pressure and significantly impaired renal function, evidenced by lower inulin clearance compared to control group. These alterations were accompanied by a renal vasoconstriction. VDD animals showed a decreased inulin clearance compared to control rats, without alterations in blood pressure 
and renal vascular resistance. Treatment of VDD with TDF resulted in an even greater elevation of blood pressure than in the TDF-group associated with a greater decrease in inulin clearance and an intense vasoconstriction, indicating that vitamin D deficiency is an aggravating factor in the progression of TDF-induced renal injury.

Another marker of renal impairment is proteinuria. As shown in Table 2, rats that received TDF, deficient or not in vitamin $\mathrm{D}$, showed a greater loss of urinary protein compared to the control group. Urinary protein excretion was also increased in the VDD group. It is worth considering that if we had evaluated urinary fraction excretion of proteins of VDD+TDF group, it would be higher due to decreased glomerular filtration rate with subsequent lower protein filtered load.

The histological study showed alterations characteristic of mild acute tubular necrosis in the renal cortex from the VDD $(0.21 \pm 0.02)$ and TDF $(0.24 \pm 0.02)$ groups compared to control $(0.07 \pm 0.01)$. Tubular cell necrosis, focal areas of denuded basement membrane, flattening of proximal tubular cells with brush border loss and tubular atrophy or dilatation were observed. Vitamin D deficient animals treated with TDF $(0.36 \pm 0.02)$ exhibited a higher tubular injury score compared to groups VDD and TDF (Figure 1).

Renal protein expression of angiotensinogen/angiotensin (Figure 2) was up-regulated in groups VDD $(201 \pm 32 \%)$, TDF $(222 \pm 18 \%)$ and VDD+TDF $(244 \pm 26 \%)$ compared to control (104 $\pm 45 \%)$. The immunohistochemical study showed an increased intensity of the immunoreaction of angiotensin II in the renal cortex of VDD, TDF and VDD+TDF (Figure 3). To support data previously shown, renal protein expression of AT1 receptor (Figure 4) was also up-regulated in TDF rats $(247 \pm 33 \%)$ compared to control and VDD (101 $\pm 5 \%$ and $173 \pm 27 \%)$. Treatment of VDD with TDF resulted in a more intense up-regulation of AT1 protein expression (359 $\pm 56 \%)$.

The renal expression of renin-angiotensin system components assessed by qPCR are given in Figure 5. $A G T$, renin, ECA and AT1a exhibited a tendency for upregulation in all experimental groups compared to control. As can be seen in Table 2, plasma aldosterone increased significantly and progressively in VDD, TDF and VDD+TDF groups compared to control animals. In addition, the $U_{K} / U_{N a}$ ratio was significantly higher in VDD+TDF in agreement with the more elevated aldosterona level in this group (Table 2). Altogether, this data confirms a possible involvement of the RAAS in the increase of MAP in vitamin D deficient rats treated with TDF.

The e-NOS expression (Figure 6) was downregulated in VDD groups (VDD=65 $\pm 2 \%$; VDD+TDF=60 $\pm 2 \%$ ) compared with control $(99 \pm 1 \%)$ and TDF rats $(95 \pm 5 \%)$. These findings may explain the more elevated blood pressure, the intense renal vasoconstriction, and the decrease in glomerular filtration rate in VDD+TDF, and it may be an additional mechanism responsible for the increased TDF toxicity induced by vitamin D deficiency.

Serum calcium and phosphate concentrations were lower in groups that were fed a vitamin D-free diet. Decreased serum calcium and phosphate levels were also expected since the diet composition has lower 
calcium and phosphorus concentration $(0.4 \% \mathrm{Ca}$ and $0.4 \% \mathrm{P})$ compared to the standard diet. However, group TDF showed diminished serum phosphate concentration, indicating that treatment with TDF alone leads to hypophosphatemia. Association of treatment with TDF and vitamin D deficiency did not aggravate serum phosphate concentration (Table 2).

Proximal tubule function was impaired in TDF rats, as was evidenced by increased urinary excretion of phosphorus (Table 2). Association of vitamin D deficiency and treatment with TDF showed a greater impairment of proximal tubule function. To support this data, renal protein expression of NaPi-lla was decreased by approximately 50\% in VDD and TDF rats and 78\% in VDD+TDF animals. Renal protein expression of NaPi-lla is shown in Figure 7.

VDD rats showed an increased plasma PTH concentration compared to control. TDF group did not exhibit alteration in PTH level. Combination of vitamin D deficiency and TDF increased PTH compared to groups C and TDF, but this elevation was moderate compared to VDD (Table 2).

As illustrated in Table 2, TDF animals showed higher levels of total cholesterol and triglycerides compared to control group. When compared with control group, VDD animals showed higher levels of total cholesterol and triglycerides, although the latter parameter was not statistically significant. Association of vitamin $D$ deficiency to treatment with TDF aggravated levels of both total cholesterol and triglycerides compared to groups C, VDD and TDF.

The oxidative stress was initially evaluated by TBARS plasma concentration and urinary excretion measurements. The results are presented in Figures $8 \mathrm{a}$ and b. Plasma TBARS concentration $(2.38 \pm 0.20$ $\mathrm{nmol} / \mathrm{mL}$ ) and urinary TBARS excretion $(107 \pm 11 \mathrm{nmol} / 24 \mathrm{~h})$ was higher in group TDF when compared with control rats (serum TBARS $=1.61 \pm 0.07$; urinary TBARS excretion $=70 \pm 11 \mathrm{nmol} / 24 \mathrm{~h}, \mathrm{p}<0.05$ ). VDD rats also exhibited a slight but not statistically significant increase in serum TBARS concentration $(2.04 \pm 0.29 \mathrm{nmol} / \mathrm{mL})$ and a higher urinary TBARS excretion $(125 \pm 6 \mathrm{nmol} / 24 \mathrm{~h}, \mathrm{p}<0.05)$ compared to control group probably due to the effects of vitamin $D$ in the modulation of the oxidative stress mechanism. VDD+TDF rats showed an even more pronounced increase of serum TBARS concentration $(3.26 \pm 0.23 \mathrm{nmol} / \mathrm{mL})$ and urinary TBARS excretion (164 $\pm 9 \mathrm{nmol} / 24 \mathrm{~h})$.

Glutathione is a major intracellular antioxidant agent. As shown in Figure 9, the total gluthatione concentration in control rats was $2.90 \pm 0.22 \mu \mathrm{ml} / \mathrm{mL}$, a value statistically higher than VDD group $(2.05 \pm 0.04$ $\mu \mathrm{ml} / \mathrm{mL}, \mathrm{p}<0.01)$ and TDF $(2.27 \pm 0.22 \mu \mathrm{mol} / \mathrm{mL}, \mathrm{p}<0.05)$. VDD+TDF presented markedly lower glutathione concentration compared to groups C, VDD and TDF $(1.46 \pm 0.12 \mu \mathrm{ml} / \mathrm{mL})$.

\section{Discussion}

Vitamin D deficiency or insufficiency has been increasing in recent years reaching $73 \%$ of total HIVinfected patients and has been associated with HIV disease progression and its related complications $[7,8,23]$. 
Treatment with TDF led to renal failure, proximal tubule injury, hypertension, abnormal lipid metabolism and oxidative stress. Our data demonstrated that vitamin D deficiency aggravates TDF-induced nephrotoxicity.

Scherzer et al [24] showed that TDF use was associated with proteinuria and chronic kidney disease. Furthermore, vitamin D deficiency itself has been associated with increased prevalence of proteinuria in adults. Vitamin $D$ is a known negative endocrine regulator of the RAAS, which plays a key role in the development of kidney disease. Li et al [25] demonstrated that VDR-null mice presented higher renin and angiotensin II levels leading to hypertension. Moreover, low levels of vitamin D also induce podocyte loss and the development of glomerulosclerosis through direct cellular effects, compromising the integrity of the glomerular filtration membrane $[10,26]$.

\subsection{Hypertension, renin-angiotensin-aldosterone system and nitric oxide in TDF-induced nephrotoxicity associated with vitamin D deficiency}

In this study, vitamin D deficient rats receiving TDF showed higher blood pressure. This alteration was accompanied by a marked increase in protein expression of angiotensin and AT1 receptor. mRNA expression of AGT, renin, ECA and AT1a were also augmented. Futhermore, we demonstrated a progressive elevation in plasma aldosterone. Vitamin D deficiency led to an upregulation of the renin-angiotensin system. Therefore it is possible to speculate that the more severe hypertension observed in VDD+TDF could be due to an elevation in angiotensin II and its receptor in the kidney, stimulating aldosterone. It is important to point out that vitamin D deficient rats treated with TDF exhibited a higher urinary concentration of potassium and sodium ratio suggesting an altered sensitivity of the distal tubule to aldosterone [27].

It is well known that oxidative stress is also implicated in the development of hypertension. Angiotensin II is known to induce oxidative stress by activating NADPH oxidase, which leads to the generation of superoxides [28,29]. Our data demonstrated that vitamin D deficient rats treated with TDF showed hypertension accompanied by elevated RVR and decreased renal eNOS expression, suggesting the possibility of the involvement of nitric oxide (NO) cascade. Within the kidney, e-NOS is the main NOS isoform responsible for NO production in both renal epithelial and endothelial cells. Nitric oxide is a potent vasodilator that modulates vascular tone and renal function maintaining sodium balance and extracellular fluid volume, thus regulating blood pressure. Kopkan el al [30] reported that mice lacking the gene for eNOS developed salt-sensitive hypertension due to oxidative imbalance to keep the optimal production of NO. The decrease in eNOS expression in vitamin D deficient rats treated with TDF may explain the more severe hypertension observed in this group.

\subsection{The role of PTH and vitamin D deficiency in calcium and phosphorus metabolism associated with TDF}

Our study showed that vitamin D deficient rats presented hypophosphatemia, hypocalcemia and higher levels of PTH. These alterations were expected since the lack of vitamin D reduces calcium intestinal absorption leading to a lower level of calcium and higher production of PTH by the parathyroid gland. PTH, in 
turn, acts on bone tissue in order to attenuate the decrease in serum calcium and the increase in phosphorus excretion.

Treatment with TDF led to proximal tubule injury, evidenced by higher excretion of phosphorus and decreased renal expression of the NaPi-lla cotransporter leading to hyperphosphaturia and hypophosphatemia. Combination of vitamin D deficiency and treatment with TDF aggravated these tubular alterations. Kurnik et al (1984) reported that treatment with $1,25(\mathrm{OH})_{2} \mathrm{D}_{3}$ decreased $\mathrm{U}_{\mathrm{P}} \mathrm{V}$ and $\mathrm{FE}_{\mathrm{p}}$ in partially vitamin $D$ depleted rats independent of changes in plasma phosphate, calcium and PTH, indicating a physiological stimulatory role of $1,25(\mathrm{OH})_{2} \mathrm{D}_{3}$ in renal phosphate transport.

Vitamin D deficient rats presented high levels of plasma PTH supporting previous studies that demonstrated a relationship between the highest PTH levels and the lowest vitamin D concentrations [31]. It is well known that vitamin $\mathrm{D}$ and calcium are potent regulators of PTH, suggesting that hypocalcemia and hypovitaminosis $D$ combined with a slight decrease in renal function, as observed in VDD animals, may be responsible for the increase in PTH. This may occur in order to restore these parameters in CKD. The hyperphosphaturic effect of TDF may explain the lower levels of PTH in VDD + TDF when compared with VDD group.

\subsection{TDF and vitamin D deficiency lead to metabolic syndrome}

TDF rats showed higher levels of triglycerides and total cholesterol. These parameters were aggravated when TDF was administered in association with vitamin D deficiency. Gagnon et al [17] demonstrated that vitamin $\mathrm{D}$ levels were associated inversely with the risk of developing metabolic syndrome. To support data previously shown, another study reported that mice with type 1 and 2 diabetes mellitus treated with doxercalciferol showed a higher renal VDR renal expression and the activation of this receptor led to a reduction in the accumulation of triglycerides and cholesterol. Moreover, dyslipidaemia is a common complication among HIV-infected individuals after antiretroviral therapy [32,33].

\subsection{Oxidative stress is associated with renal injury and renovascular alterations}

The association of vitamin D deficiency and treatment with TDF led to the increase of lipid peroxidation and the decrease in the major intracellular antioxidant agent, observed by higher TBARS and lower GSH levels respectively, showing the influence of oxidative stress in the development of renal injury and the onset of hypertension. Borges-Santos et al [15] reported that HIV-infected individuals presented an antioxidant deficit, evidenced by higher levels of oxidized glutathione (GSSG), contributing to disease progression. Furthermore, there are several studies regarding the indirect effects of vitamin $D$ on the protection against oxidative stress. Tarcin et al [14] showed a negative correlation between $25(\mathrm{OH}) \mathrm{D}_{3}$ levels and TBARS in vitamin $D$ deficient patients and the protective effect of vitamin $D$ on endothelial function. Experimental studies reported that treatment with calcitriol led to an increase of VDR expression and decrease in malondialdehyde levels, supporting the role of vitamin D in protecting DNA against oxidative damage [34]. 


\subsection{Final considerations}

In summary, our data confirms that vitamin D deficiency aggravates TDF nephrotoxicity at least in part by the increase of oxidative stress and the involvement of renin-angiotensin system and nitric oxide cascade, demonstrating that vitamin $\mathrm{D}$ has an essential role in the development and progression of kidney and cardiovascular diseases in HIV-infected subjects. Hence, it is important to monitor vitamin D levels in HIVinfected patients treated with TDF. Further studies are required for the clarification of specific mechanisms involved in the progression of HIV-related diseases in vitamin D deficient individuals.

\section{References}

1. Boyd SD (2011) Management of HIV infection in treatment-naive patients: a review of the most current recommendations. Am J Health Syst Pharm 68: 991-1001.

2. Deeks ED, Perry CM (2010) Efavirenz/emtricitabine/tenofovir disoproxil fumarate single-tablet regimen (Atripla(R)): a review of its use in the management of HIV infection. Drugs 70: 2315-2338.

3. Gish R, Jia JD, Locarnini S, Zoulim F (2012) Selection of chronic hepatitis B therapy with high barrier to resistance. Lancet Infect Dis 12: 341-353.

4. Zhao SS, Tang LH, Dai XH, Wang W, Zhou RR, et al. (2011) Comparison of the efficacy of tenofovir and adefovir in the treatment of chronic hepatitis $B$ : a systematic review. Virol J 8: 111.

5. Liborio AB, Andrade L, Pereira LV, Sanches TR, Shimizu MH, et al. (2008) Rosiglitazone reverses tenofovirinduced nephrotoxicity. Kidney Int 74: 910-918.

6. Izzedine H, Launay-Vacher V, Deray G (2005) Antiviral drug-induced nephrotoxicity. Am J Kidney Dis 45: 804817.

7. Mehta S, Giovannucci E, Mugusi FM, Spiegelman D, Aboud S, et al. (2010) Vitamin D status of HIV-infected women and its association with HIV disease progression, anemia, and mortality. PLoS One 5: e8770.

8. Sudfeld CR, Wang M, Aboud S, Giovannucci EL, Mugusi FM, et al. (2012) Vitamin D and HIV progression among Tanzanian adults initiating antiretroviral therapy. PLoS One 7: e40036.

9. Baeke F, Gysemans C, Korf H, Mathieu C (2010) Vitamin D insufficiency: implications for the immune system. Pediatr Nephrol 25: 1597-1606.

10. Li YC (2011) Podocytes as target of vitamin D. Curr Diabetes Rev 7: 35-40.

11. Cuppari L, Garcia Lopes MG, Kamimura MA (2011) Vitamin D biology: from the discovery to its significance in chronic kidney disease. J Ren Nutr 21: 113-116.

12. Gonzalez EA, Sachdeva A, Oliver DA, Martin KJ (2004) Vitamin D insufficiency and deficiency in chronic kidney disease. A single center observational study. Am J Nephrol 24: 503-510.

13. Ulerich L (2010) Vitamin D in chronic kidney disease--new insights. Nephrol Nurs J 37: 429-431.

14. Tarcin O, Yavuz DG, Ozben B, Telli A, Ogunc AV, et al. (2009) Effect of vitamin D deficiency and replacement on endothelial function in asymptomatic subjects. J Clin Endocrinol Metab 94: 4023-4030.

15. Borges-Santos MD, Moreto F, Pereira PC, Ming-Yu Y, Burini RC (2012) Plasma glutathione of HIV $(+)$ patients responded positively and differently to dietary supplementation with cysteine or glutamine. Nutrition 28: 753-756.

16. Petchey WG, Johnson DW, Isbel NM (2011) Shining D' light on chronic kidney disease: mechanisms that may underpin the cardiovascular benefit of vitamin D. Nephrology (Carlton) 16: 351-367.

17. Gagnon C, Lu ZX, Magliano DJ, Dunstan DW, Shaw JE, et al. (2012) Low serum 25-hydroxyvitamin D is associated with increased risk of the development of the metabolic syndrome at five years: results from a national, population-based prospective study (The Australian Diabetes, Obesity and Lifestyle Study: AusDiab). J Clin Endocrinol Metab 97: 1953-1961.

18. Miyaji T, Kato A, Yasuda H, Fujigaki Y, Hishida A (2001) Role of the increase in p21 in cisplatin-induced acute renal failure in rats. J Am Soc Nephrol 12: 900-908.

19. Livak KJ, Schmittgen TD (2001) Analysis of relative gene expression data using real-time quantitative PCR and the 2(-Delta Delta C(T)) Method. Methods 25: 402-408. 
20. Nath KA, Salahudeen AK (1990) Induction of renal growth and injury in the intact rat kidney by dietary deficiency of antioxidants. J Clin Invest 86: 1179-1192.

21. Sedlak J, Lindsay RH (1968) Estimation of total, protein-bound, and nonprotein sulfhydryl groups in tissue with Ellman's reagent. Anal Biochem 25: 192-205.

22. Vogt BL, Richie JP, Jr. (2007) Glutathione depletion and recovery after acute ethanol administration in the aging mouse. Biochem Pharmacol 73: 1613-1621.

23. Childs K, Welz T, Samarawickrama A, Post FA (2012) Effects of vitamin D deficiency and combination antiretroviral therapy on bone in HIV-positive patients. AIDS 26: 253-262.

24. Scherzer R, Estrella M, Li Y, Deeks SG, Grunfeld C, et al. (2012) Association of tenofovir exposure with kidney disease risk in HIV infection. AIDS 26: 867-875.

25. Li YC, Kong J, Wei M, Chen ZF, Liu SQ, et al. (2002) 1,25-Dihydroxyvitamin D(3) is a negative endocrine regulator of the renin-angiotensin system. J Clin Invest 110: 229-238.

26. Kuhlmann A, Haas CS, Gross ML, Reulbach U, Holzinger M, et al. (2004) 1,25-Dihydroxyvitamin D3 decreases podocyte loss and podocyte hypertrophy in the subtotally nephrectomized rat. Am J Physiol Renal Physiol 286: F526-533.

27. Hene RJ, Koomans HA, Boer P, Roos JC, Dorhout Mees EJ (1984) Relation between plasma aldosterone concentration and renal handling of sodium and potassium, in particular in patients with chronic renal failure. Nephron 37: 94-99.

28. Finch JL, Suarez EB, Husain K, Ferder L, Cardema MC, et al. (2012) Effect of combining an ACE inhibitor and a VDR activator on glomerulosclerosis, proteinuria, and renal oxidative stress in uremic rats. Am J Physiol Renal Physiol 302: F141-149.

29. Patzak A, Persson AE (2007) Angiotensin II-nitric oxide interaction in the kidney. Curr Opin Nephrol Hypertens 16: 46-51.

30. Kopkan L, Hess A, Huskova Z, Cervenka L, Navar LG, et al. (2010) High-salt intake enhances superoxide activity in eNOS knockout mice leading to the development of salt sensitivity. Am J Physiol Renal Physiol 299: F656-663.

31. Masia M, Padilla S, Robledano C, Lopez N, Ramos JM, et al. (2012) Early changes in parathyroid hormone concentrations in HIV-infected patients initiating antiretroviral therapy with tenofovir. AIDS Res Hum Retroviruses 28: 242-246.

32. Kanjanavanit S, Puthanakit T, Vibol U, Kosalaraksa P, Hansudewechakul R, et al. (2011) High prevalence of lipid abnormalities among antiretroviral-naive HIV-infected Asian children with mild-to-moderate immunosuppression. Antivir Ther 16: 1351-1355.

33. McGee KC, Shahmanesh M, Boothby M, Nightingale P, Gathercole LL, et al. (2012) Evidence for a shift to anaerobic metabolism in adipose tissue in efavirenz-containing regimens for HIV with different nucleoside backbones. Antivir Ther 17: 495-507.

34. Nair-Shalliker V, Armstrong BK, Fenech M (2012) Does vitamin D protect against DNA damage? Mutat Res 733: 50-57. 


\section{Tables and Figures}

Table 1 - Body weight, renal function and hemodynamic measurements in normal (control) rats, in rats maintained 60 days on vitamin $\mathrm{D}$ free diet (VDD), in rats on normal diet treated for additional 30 days with tenofovir (TDF) and in rats on vitamin D free diet for 60 days, to which tenofovir was added on day 30 and continued throughout (VDD + TDF)

\begin{tabular}{|c|c|c|c|c|}
\hline & C & VDD & TDF & VDD+TDF \\
\hline BW & $498 \pm 12$ & $476 \pm 7$ & $461 \pm 6$ & $463 \pm 14$ \\
\hline GFR & $0.88 \pm 0.04$ & $0.61 \pm 0.06^{b}$ & $0.63 \pm 0.04^{c}$ & $0.45 \pm 0.04^{c, d}$ \\
\hline MAP & $117 \pm 3$ & $127 \pm 4$ & $134 \pm 2^{b}$ & $148 \pm 5^{c, e}$ \\
\hline RBF & $5.58 \pm 0.03$ & $5.82 \pm 0.04$ & $5.59 \pm 0.05$ & $5.72 \pm 0.08$ \\
\hline RVR & $19.8 \pm 0.4$ & $21.1 \pm 0.8$ & $24.1 \pm 0.5^{c}$ & $26.9 \pm 1.0^{c, e}$ \\
\hline
\end{tabular}


Table 2 - Biochemical parameters measurements in normal (control) rats, in rats maintained 60 days on vitamin $\mathrm{D}$ free diet (VDD), in rats on normal diet treated for additional 30 days with tenofovir (TDF) and in rats on vitamin $D$ free diet for 60 days, to which tenofovir was added on day 30 and continued throughout (VDD + TDF)

\begin{tabular}{|c|c|c|c|c|}
\hline & C & VDD & TDF & VDD+TDF \\
\hline $25(\mathrm{OH}) \mathrm{D}$ & $15.4 \pm 1.0$ & $<1.5$ (undetectable) $^{\mathrm{c}}$ & $14.8 \pm 1.3$ & $<1.5$ (undetectable) ${ }^{\mathrm{c}, \mathrm{e}}$ \\
\hline PTH & $120 \pm 11$ & $1261 \pm 33^{c}$ & $83 \pm 15$ & $516 \pm 151^{\mathrm{b}, \mathrm{e}}$ \\
\hline Aldosterone & $116 \pm 15$ & $243 \pm 46$ & $316 \pm 57^{a}$ & $479 \pm 83^{c, d}$ \\
\hline$P_{p}$ & $9.38 \pm 0.40$ & $5.03 \pm 0.11^{c}$ & $6.47 \pm 0.34^{c}$ & $6.29 \pm 0.39^{c}$ \\
\hline $\mathrm{P}_{\mathrm{Ca}}$ & $1.13 \pm 0.01$ & $0.94 \pm 0.05^{c}$ & $1.14 \pm 0.02$ & $0.94 \pm 0.03^{c, f}$ \\
\hline $\mathrm{P}_{\mathrm{Na}}$ & $136 \pm 1$ & $139 \pm 3$ & $136 \pm 1$ & $138 \pm 1$ \\
\hline$P_{k}$ & $3.9 \pm 0.3$ & $4.3 \pm 0.2$ & $3.7 \pm 0.2$ & $4.1 \pm 0.2$ \\
\hline Cholesterol & $39 \pm 1$ & $53 \pm 4^{\mathrm{a}}$ & $54 \pm 3^{\mathrm{a}}$ & $80 \pm 7^{c, f}$ \\
\hline Triglycerides & $17 \pm 4$ & $34 \pm 5$ & $59 \pm 9^{b}$ & $74 \pm 13^{c}$ \\
\hline$U_{p} V$ & $14.9 \pm 1.1$ & $17.0 \pm 0.9$ & $18.7 \pm 0.8^{\mathrm{a}}$ & $21.5 \pm 0.7^{c, d}$ \\
\hline $\mathrm{U}_{\mathrm{Ca}} \mathrm{V}$ & $0.08 \pm 0.01$ & $0.13 \pm 0.01$ & $0.11 \pm 0.02$ & $0.13 \pm 0.01$ \\
\hline $\mathrm{U}_{\mathrm{K}} / \mathrm{U}_{\mathrm{Na}}$ & $3.27 \pm 0.17$ & $3.39 \pm 0.16$ & $3.07 \pm 0.18$ & $4.46 \pm 0.49^{\mathrm{a}, \mathrm{e}}$ \\
\hline $\mathrm{U}_{\text {Prot }} \mathrm{V}$ & $5.3 \pm 0.3$ & $11.3 \pm 0.8^{c}$ & $10.8 \pm 0.3^{c}$ & $11.8 \pm 0.5^{c}$ \\
\hline \multicolumn{5}{|c|}{ 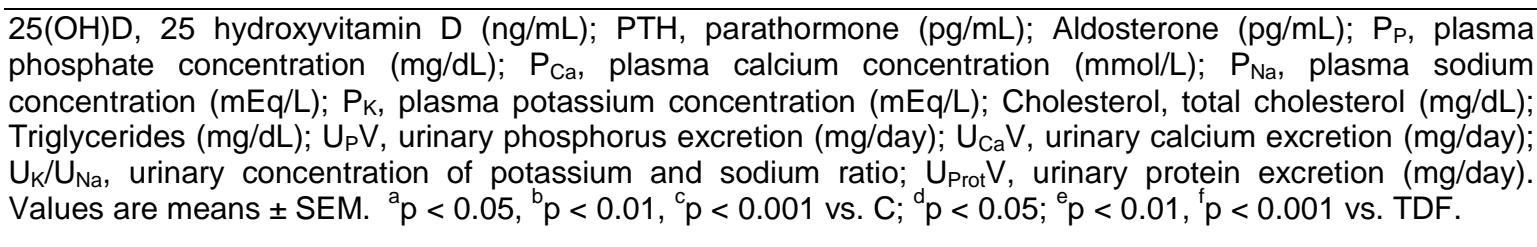 } \\
\hline
\end{tabular}



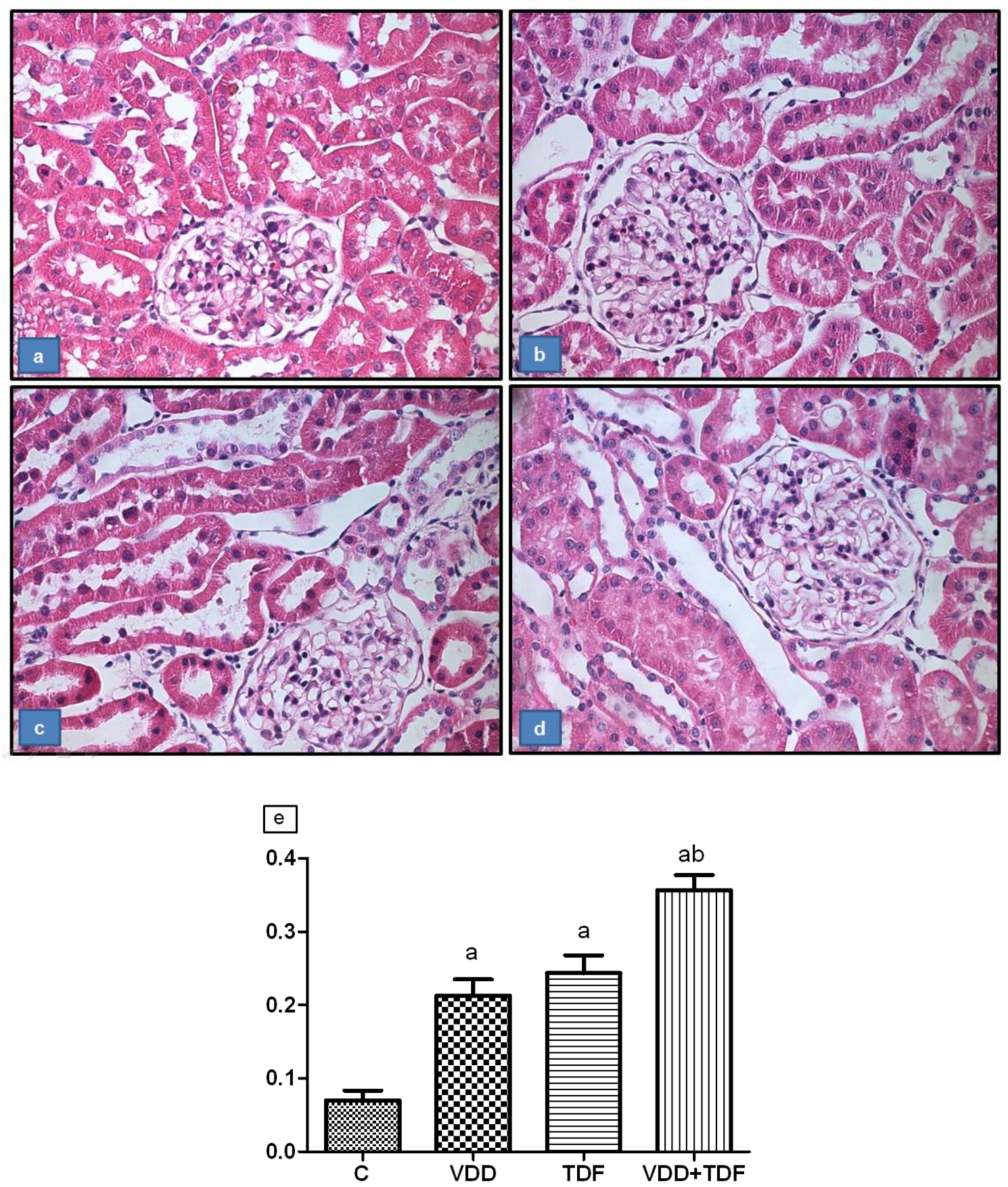

Figure 1 - Representative photomicrographs of the tubular injury. (a) control, (b) VDD, (c) TDF and (d) VDD+TDF. Magnification, 400x. (e) Score of tubular injury of C, VDD, TDF and VDD+TDF. Values are means \pm SEM. ${ }^{a} p<0.001$ vs. $C ;{ }^{b} p<0.001$ vs. TDF. 
a

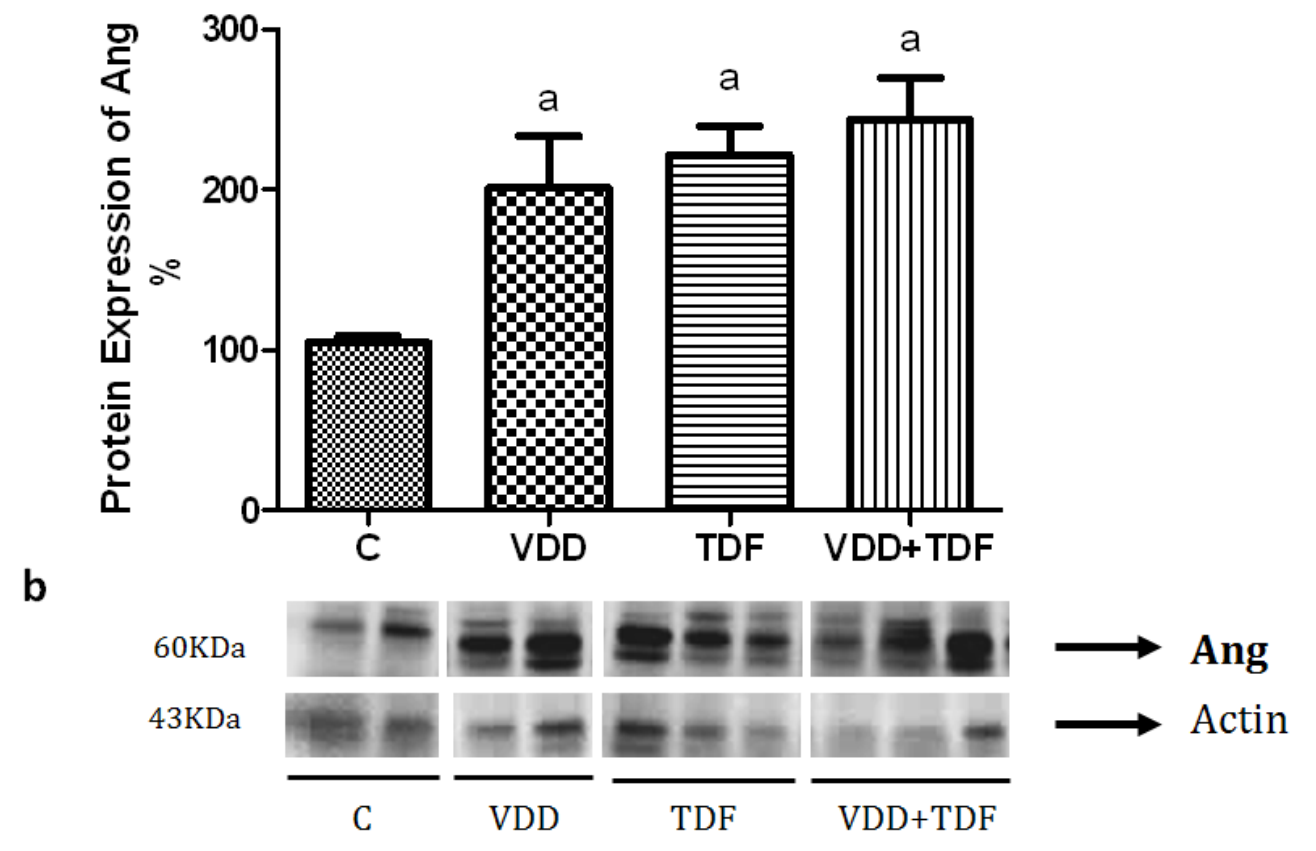

Figure 2 - Semiquantitative immunoblotting of kidney fractions. (a) A densitometric analysis of samples from control $(n=4), \operatorname{VDD}(n=6)$, TDF $(n=6)$ and VDD+TDF $(n=6)$ rats is shown. (b) Immunoblots reacted with anti-angiotensinogen/angiotensin I and II revealing a 60-kDa band. Values are means \pm SEM. ${ }^{a} p<0.05$ vs. $C$. 


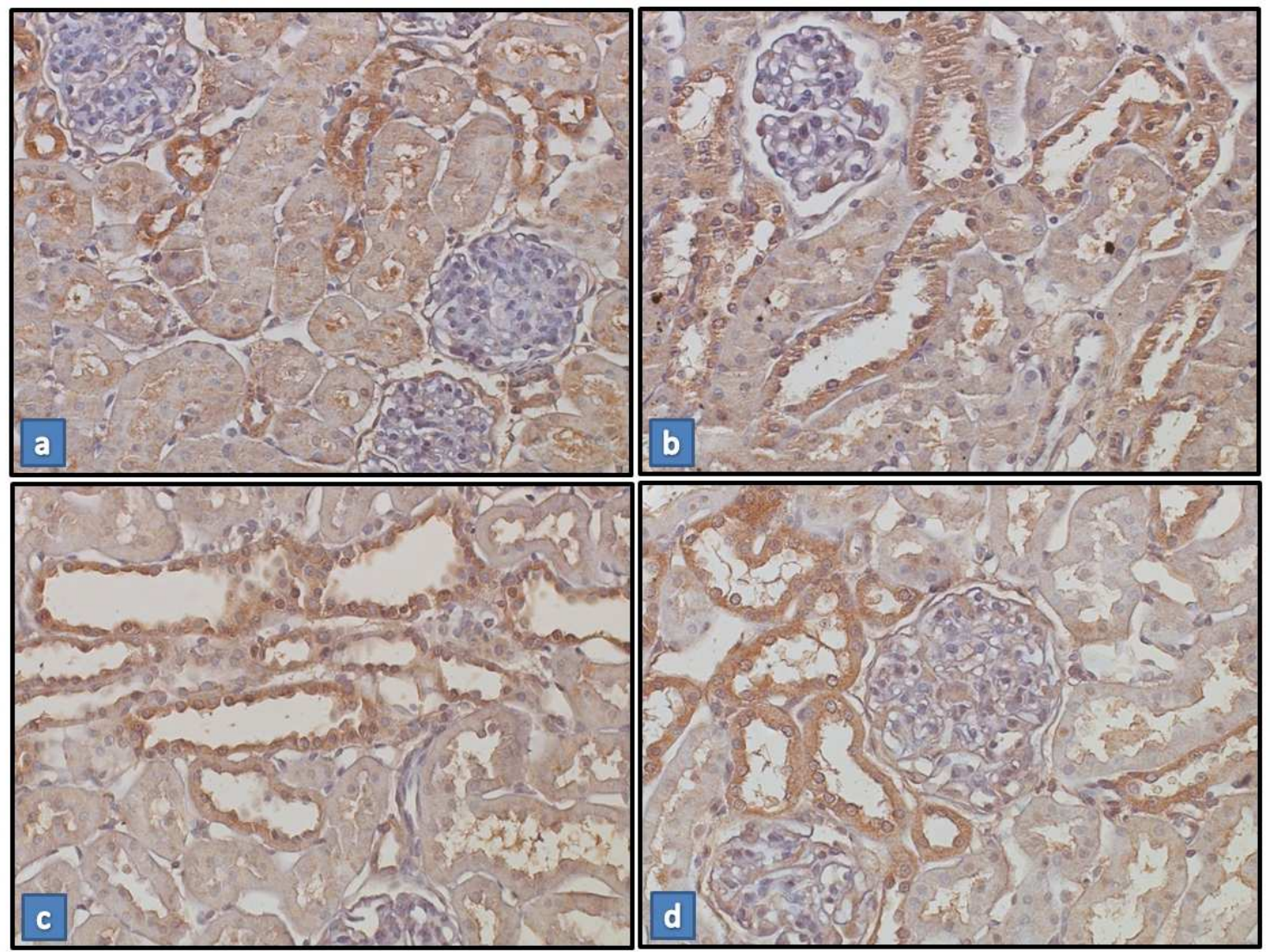

Figure 3 - Expression of Angiotensin II in renal tissue. Immunostaining for angiotensin II (brown) in kidney cortex samples from C (a), VDD (b), TDF (c) and VDD+TDF (d). Magnification, $x 400$. Note that the staining is more extensive and intense in the sample from the VDD, TDF and VDD+TDF. 


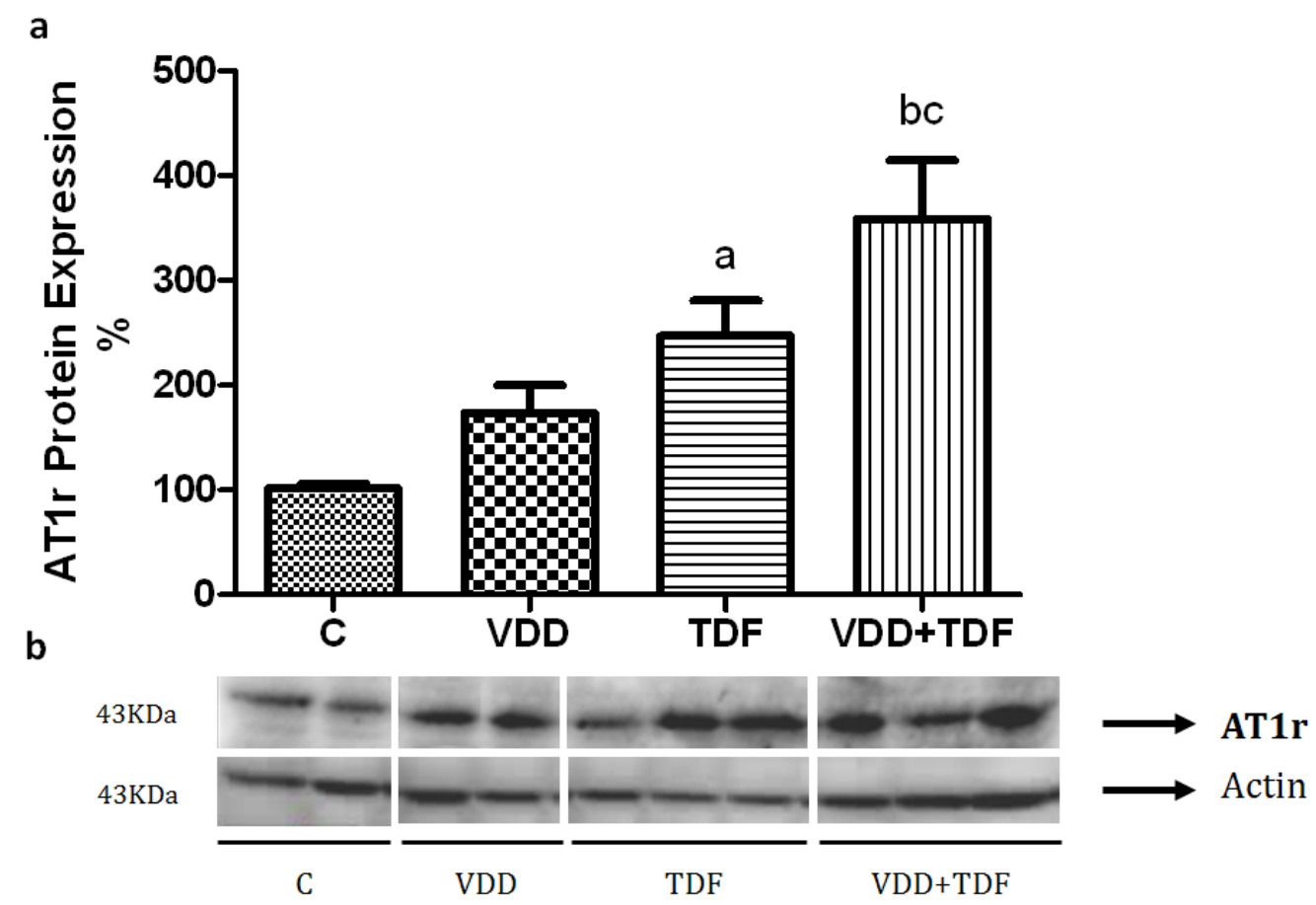

Figure 4 - Semiquantitative immunoblotting of kidney fractions. (a) A densitometric analysis of samples from control $(n=4)$, VDD $(n=6)$, TDF $(n=6)$ and VDD+TDF $(n=6)$ rats is shown. (b) Immunoblots reacted with anti-AT1 revealing a 43-kDa band. Values are means \pm SEM. ${ }^{a} p<$ 0.05 vs. $C ;{ }^{b} p<0.01$ vs. $C$ and ${ }^{c} p<0.05$ vs.TDF.

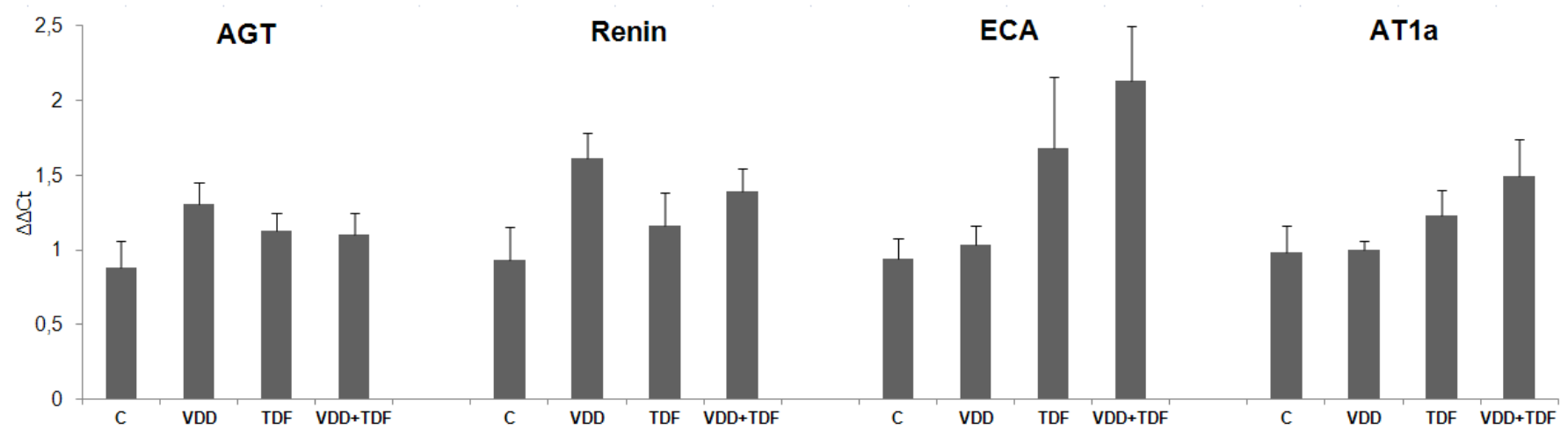

Figure 5 - Bar graph representation of the renal mRNA expression of components of renin-angiotensin system in $C(n=5)$, $\operatorname{VDD}(n=6), \operatorname{TDF}(n=5)$ and VDD+TDF $(n=6)$. 
a

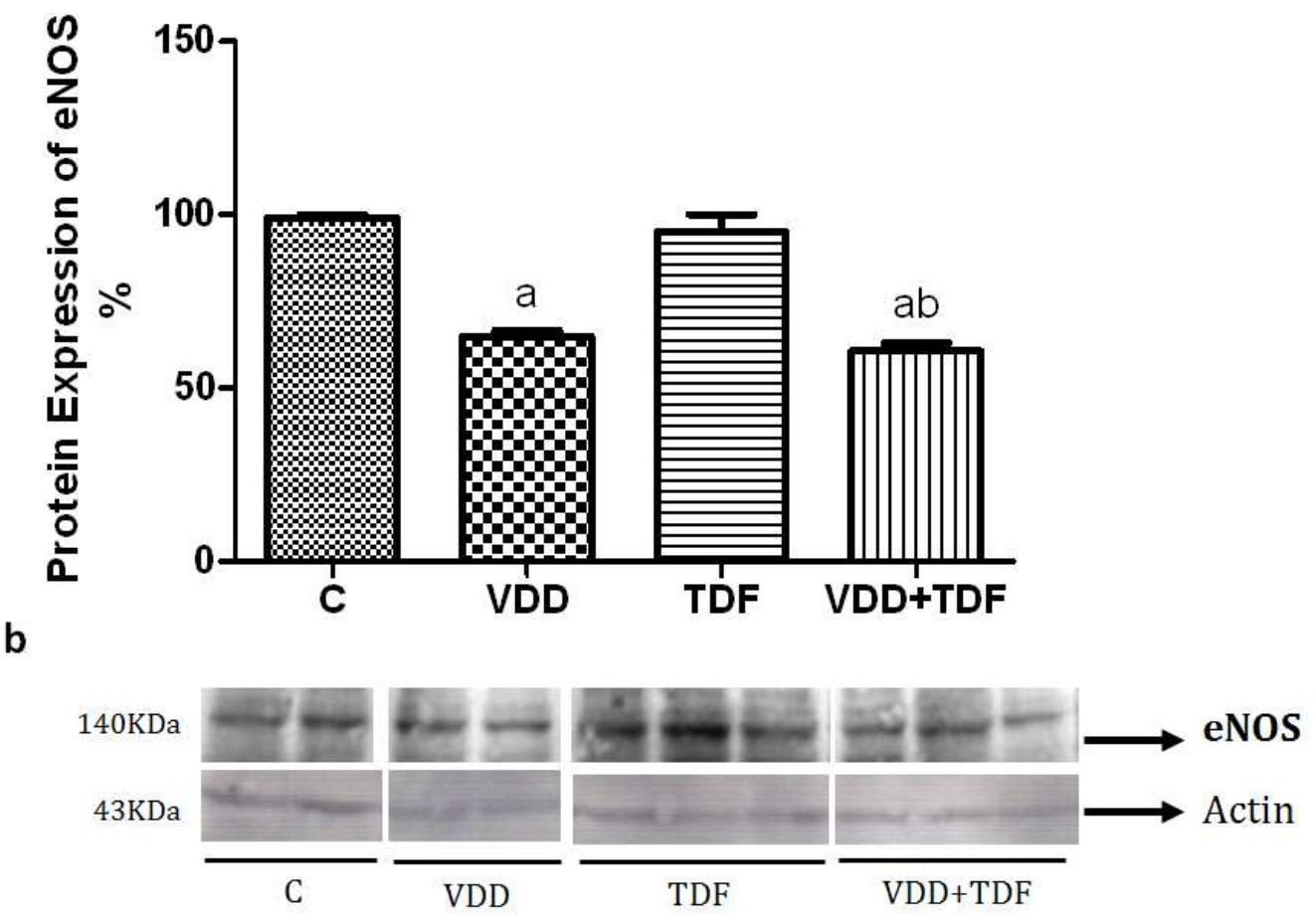

Figure 6 - Semiquantitative immunoblotting of kidney fractions. (a) A densitometric analysis of samples from control $(n=4)$, VDD $(n=6)$, TDF $(n=6)$ and VDD+TDF $(n=6)$ rats is shown. (b) Immunoblots reacted with anti-eNOS revealing a 140-kDa band. Values are means \pm SEM. ${ }^{a} p$ $<0.001$ vs. $C ;{ }^{b} p<0.001$ vs. TDF. 


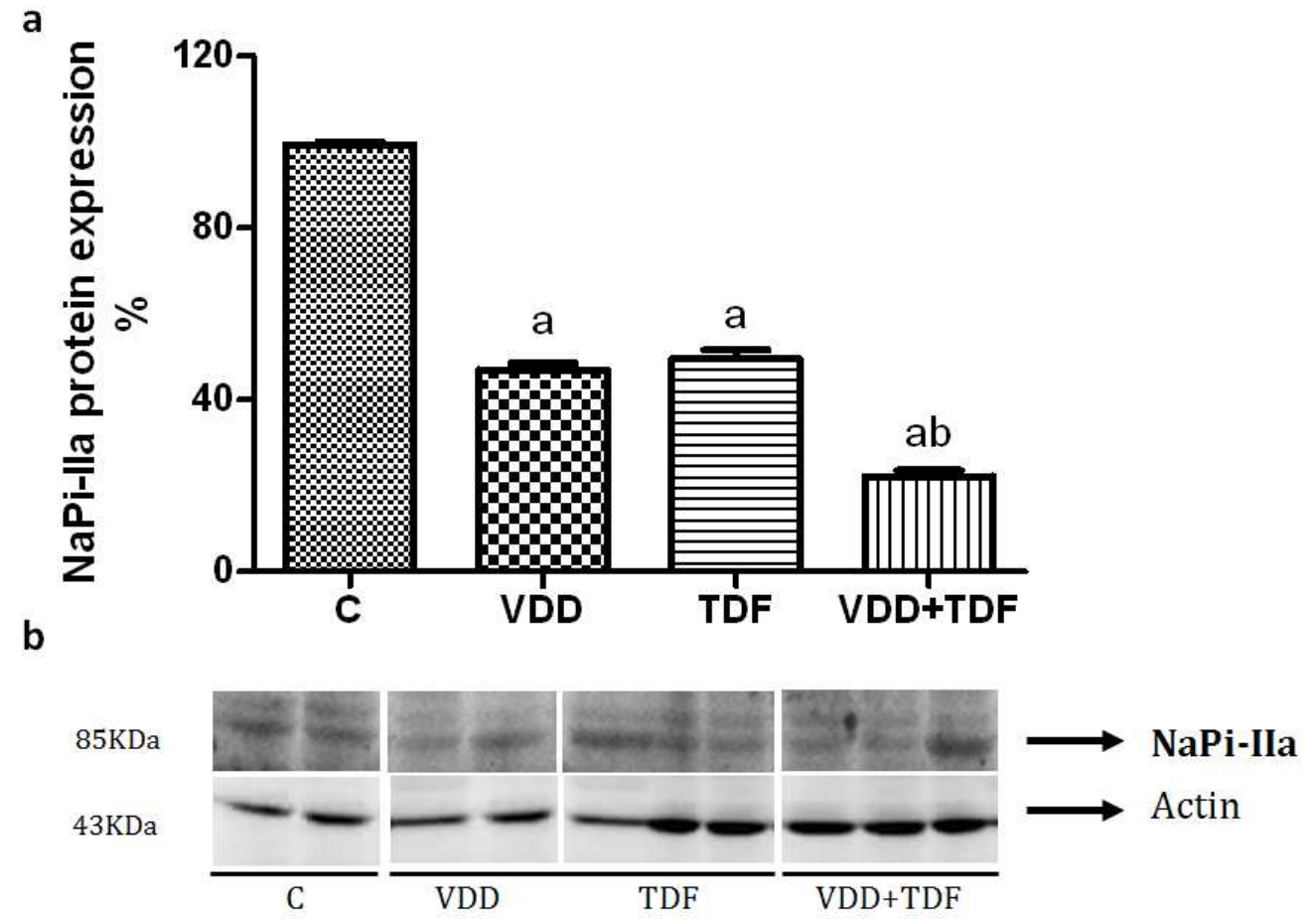

Figure 7 - Semiquantitative immunoblotting of kidney fractions. (a) A densitometric analysis of samples from control $(n=4), \operatorname{VDD}(n=6)$, TDF $(n=6)$ and VDD+TDF $(n=6)$ rats is shown. (b) Immunoblots reacted with anti-NaPi-lla revealing a $85-\mathrm{kDa}$ band. Values are means $\pm \mathrm{SEM}$. ${ }^{\mathrm{a} p}$ $<0.001$ vs. $C ;{ }^{b} p<0.001$ vs.TDF. 
a

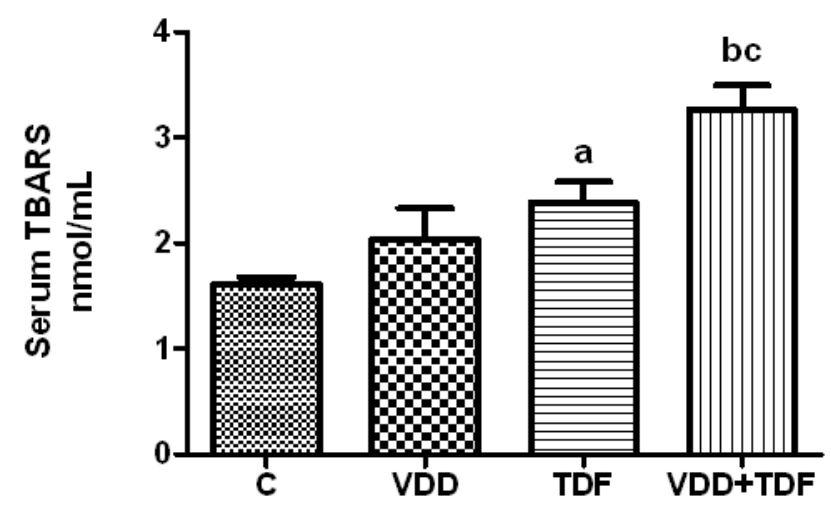

b

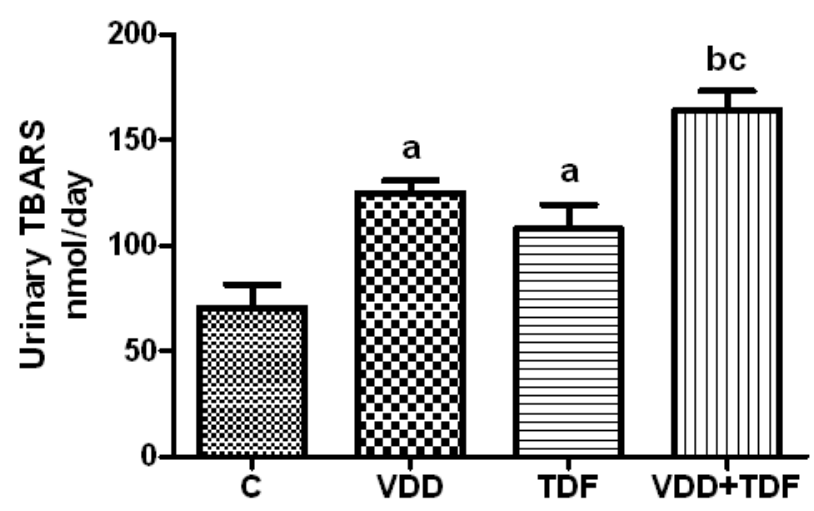

Figure 8 - Serum and urinary TBARS. (a) Serum TBARS concentration of $C, V D D, T D F$ and VDD+TDF groups and (b) urinary TBARS excretion of C, VDD, TDF and VDD+TDF groups. Values are means \pm SEM. ${ }^{a} p<0.05,{ }^{b} p<0.001$ vs. $C ;{ }^{c} p$ $<0.01$ vs. TDF.

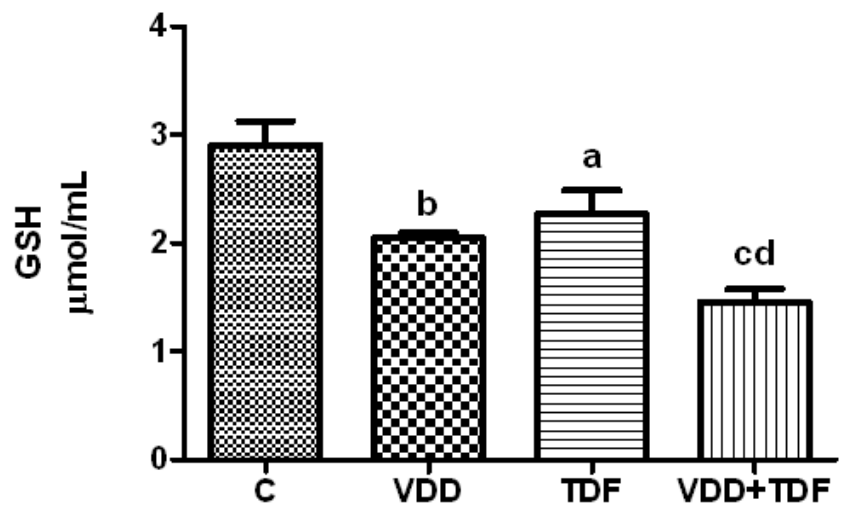

Figure 9 - Whole blood glutathione concentration of $C$, VDD, TDF and VDD+TDF groups. Values are means \pm SEM. ${ }^{a} p<$ $0.05,{ }^{b} p<0.01,{ }^{c} p<0.001$ vs. $C ;{ }^{d} p<0.01$ vs. TDF. 